Aus der Klinik für Kardiologie und Pneumologie

(Prof. Dr. med. G. Hasenfuß)

der Medizinischen Fakultät der Universität Göttingen

\title{
Funktionelle Charakterisierung neu entwickelter SERCA2a-Modulatoren an humanem Myokard und isolierten Herzmuskelzellen der Ratte
}

\section{INAUGURAL-DISSERTATION}

zur Erlangung des Doktorgrades

der Medizinischen Fakultät der

Georg-August-Universität zu Göttingen

vorgelegt von

Linn Karen Löns, geb. Lüllau

aus

Braunschweig

Göttingen 2016 
Dekan:

Referent:

Ko-Referentin:

Drittreferent:

Tag der mündlichen Prüfung: $\quad$ 24.04.2018
Prof. Dr. rer. nat. H. K. Kroemer

Prof. Dr. med. L. S. Maier

PD Dr. rer. nat. Laura Zelarayan-Behrend

Prof. Dr. med. Martin Oppermann 


\section{Inhaltsverzeichnis}

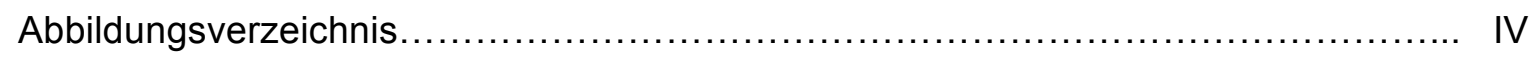

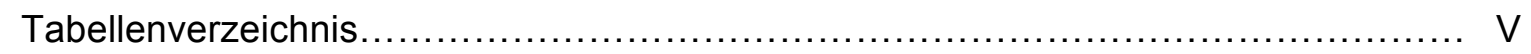

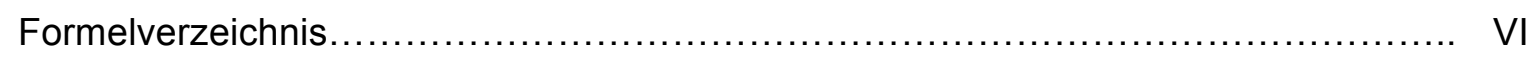

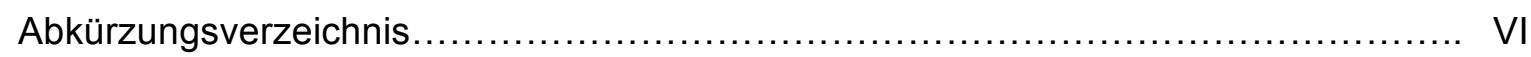

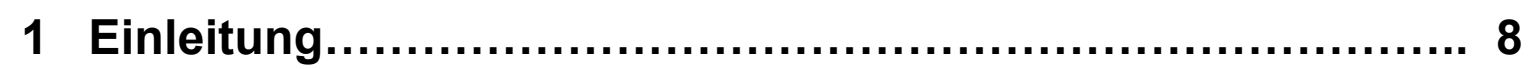

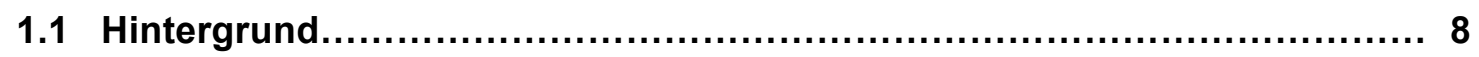

1.2 Ultrastruktureller Aufbau der Herzmuskelzelle............................. 9

1.3 Die elektromechanische Kopplung ........................................ 11

1.3.1 Die SR Ca ${ }^{2+}$-ATPase (SERCA): Funktion, Struktur und Regulation........... 15

1.4 Physiologische Regulationsmechanismen der Kontraktionskraft............ 17

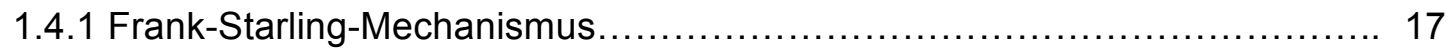

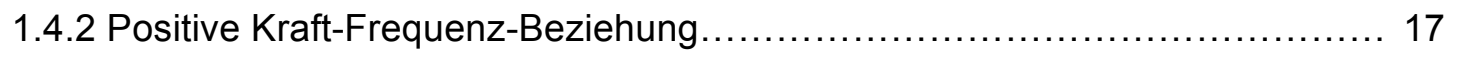

1.4.3 Neurohumorale Aktivierung............................................ 18

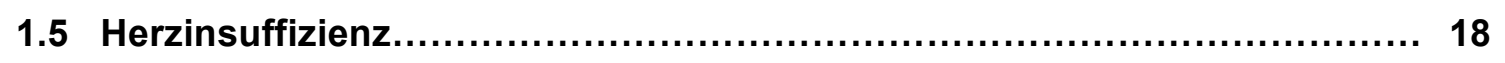

1.5.1 Definition, Ursachen, Klinik und Therapie............................................. 18

1.5.2 Pathophysiologie der Herzinsuffizienz................................. 19

1.5.2.1 Strukturelle und mechanische Veränderungen......................... 19

1.5.2.2 Neurohumorale Veränderungen.................................... 20

1.5.2.3 Molekulare und elektrophysiologische Veränderungen.................... 20

1.6 Bedeutung von Inotropika in der Herzinsuffizienztherapie.................. 21

1.7 Die SERCA2a-Modulatoren............................................... 23

1.7.1 SERCA2a-Stimulation in der Medizin.................................. 23

1.7.2 Entwicklung der SERCA2a-Modulatoren............................................ 24

1.8 Zielsetzung und Fragestellungen............................................ 25

2 Material und Methoden......................................... 26

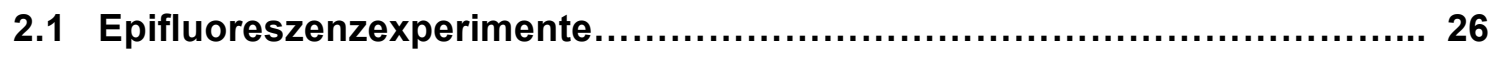

2.1.1 Isolation ventrikulärer Kardiomyozyten aus Rattenherzen................... 26

2.1.2 Messung von intrazellulären $\mathrm{Ca}^{2+}$-Transienten und der Myozytenverkürzung 27

2.1.2.1 Grundlagen des Epifluoreszenzverfahrens........................... 28

2.1.2.2 Eigenschaften des Kalzium-sensitiven Farbstoffs Fluo-3 AM.............. 28 
2.1.2.3 Das Epifluoreszenz-Setup .......................................... 29

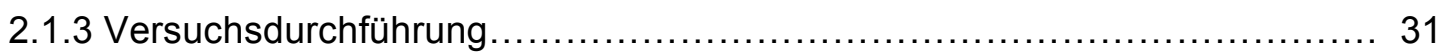

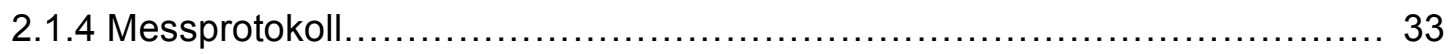

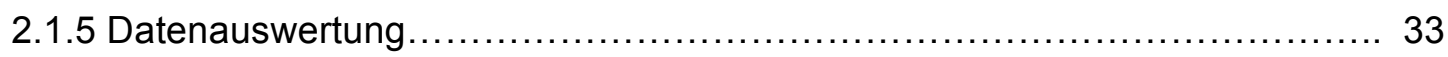

2.1.5.1 Fraktionelle Zellverkürzung und $\mathrm{Ca}^{2+}$ - Transienten $\mathrm{F} / \mathrm{F}_{0} \ldots \ldots \ldots \ldots \ldots \ldots \ldots \ldots \ldots$

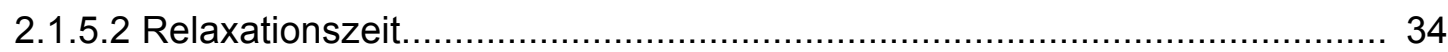

2.1.5.3 Bestimmung des SR $\mathrm{Ca}^{2+}$-Gehaltes und der fraktionellen SR $\mathrm{Ca}^{2+}$ -

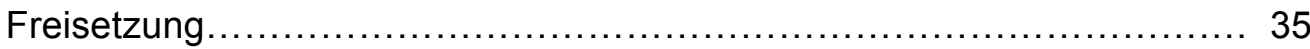

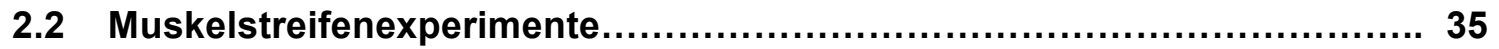

2.2.1 Gewinnung der humanen Muskelstreifen.............................. 35

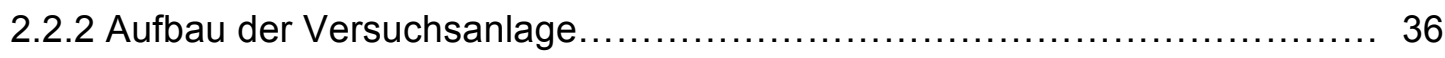

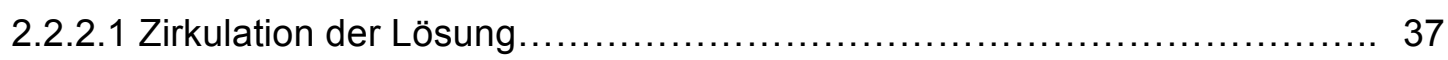

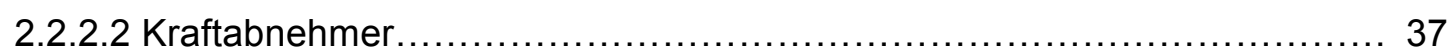

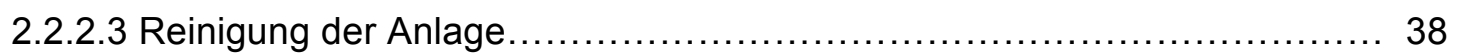

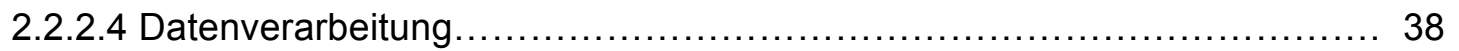

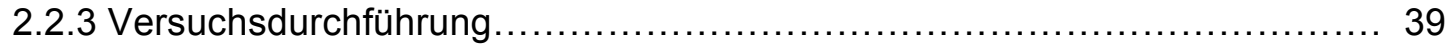

2.2.3.1 Einspannen der Muskelstreifen ........................................ 39

2.2.3.2 Ausspülen, Stimulation, Kalziumaufbau und Einschlagen................... 39

2.2.3.3 Dehnung des Muskelstreifens...................................... 40

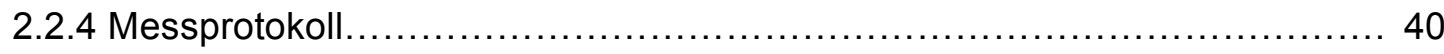

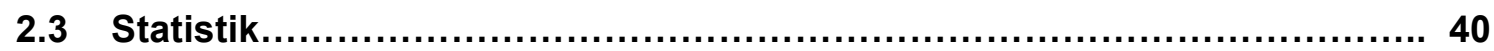

2.4 Lösungen und Chemikalien................................................. 41

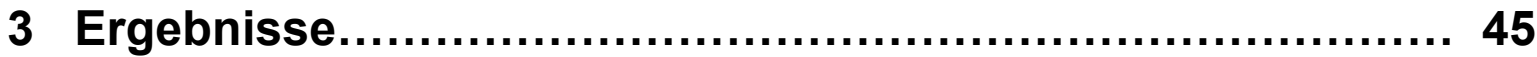

3.1 Screening der SERCA2a-Modulatoren an Einzelzellen ................... 45

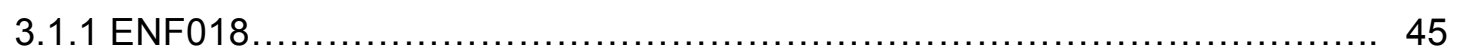

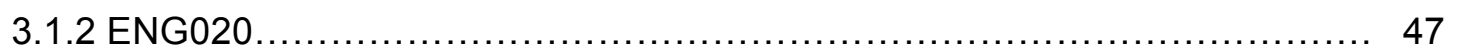

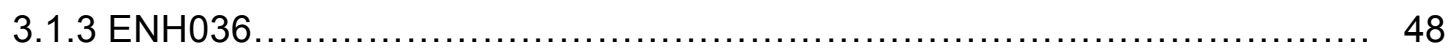

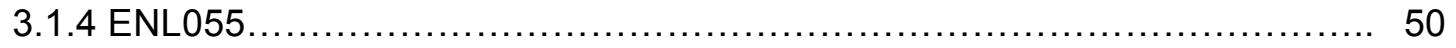

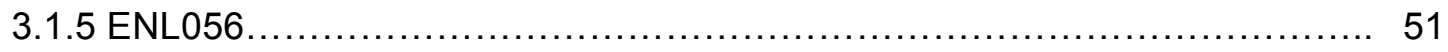

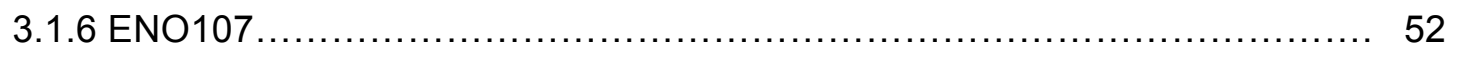

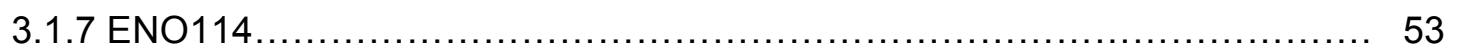

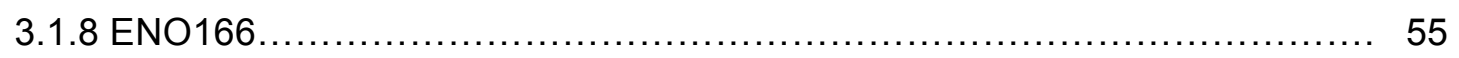

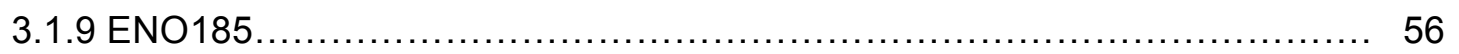

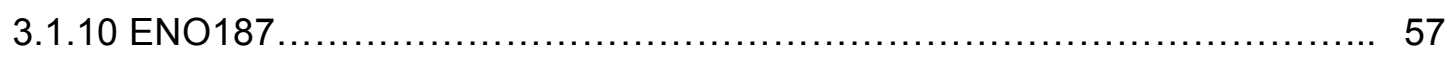

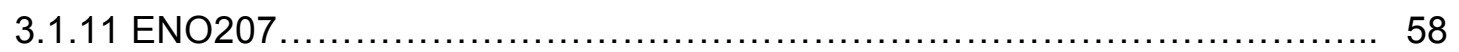

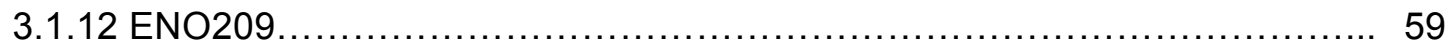




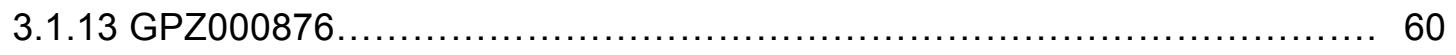

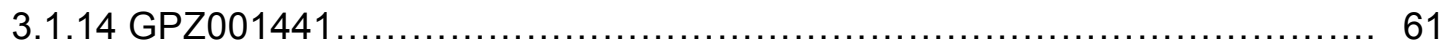

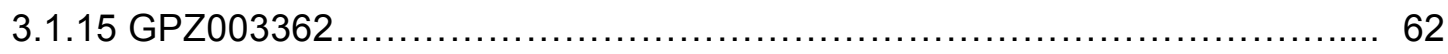

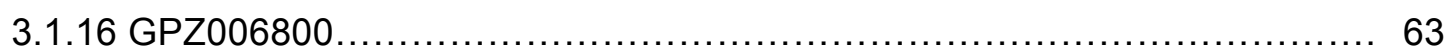

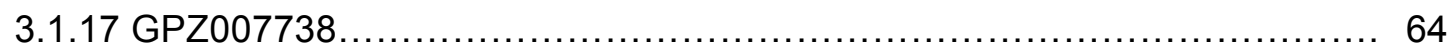

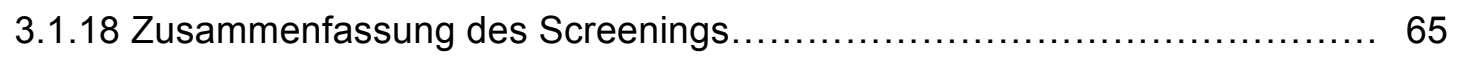

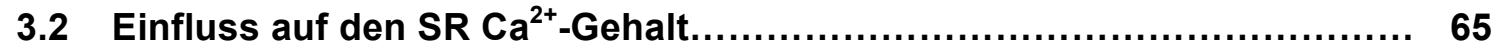

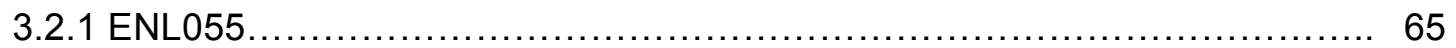

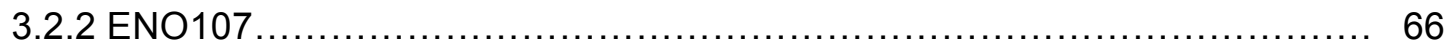

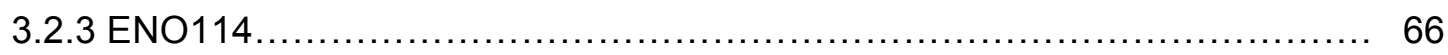

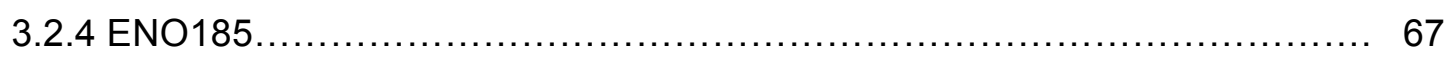

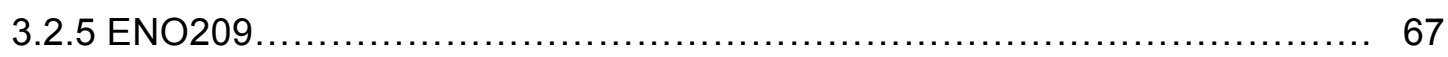

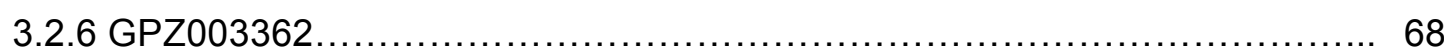

3.3 Einfluss auf humane Muskelzellverbände.................................. 68

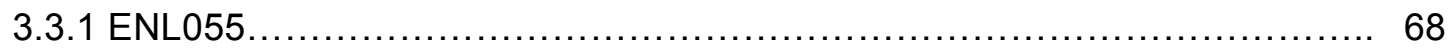

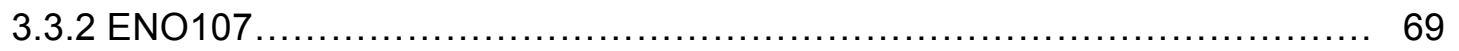

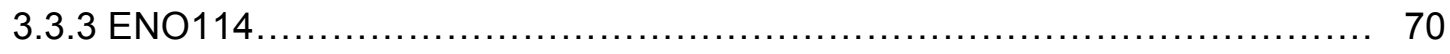

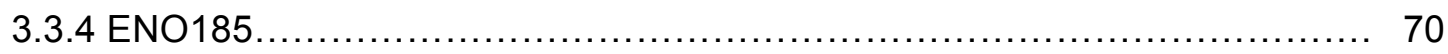

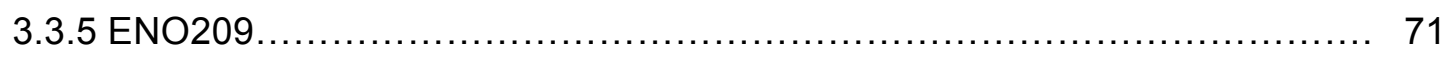

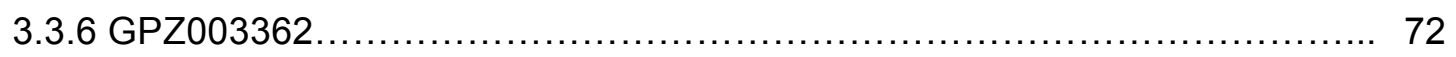

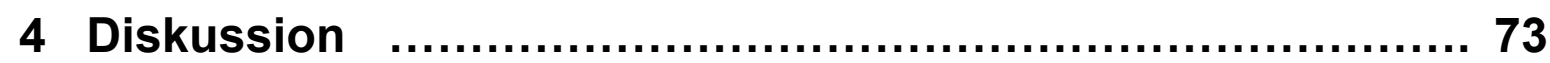

4.1 Positiv inotrope SERCA2a-Modulatoren................................... 74

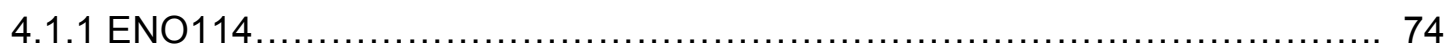

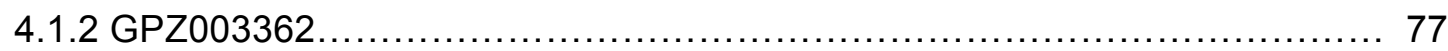

4.2 SERCA2a-Modulatoren ohne nachweisbaren Effekt auf die Kontraktilität 77

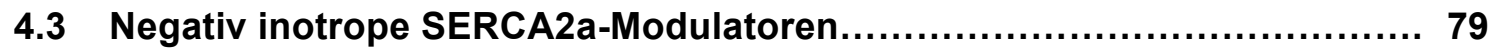

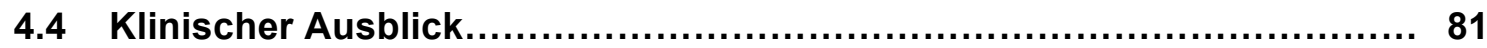

5 Zusammenfassung........................................... 83

6 Literaturverzeichnis......................................... 84 


\section{Abbildungsverzeichnis}

Abb. 1.1 Die Ultrastruktur der Herzmuskelzelle. 10

Abb. 1.2 Schematische Darstellung der elektromechanischen Kopplung............... 12

Abb. 1.3 Schematische Darstellung des Querbrückenzyklus........................... 13

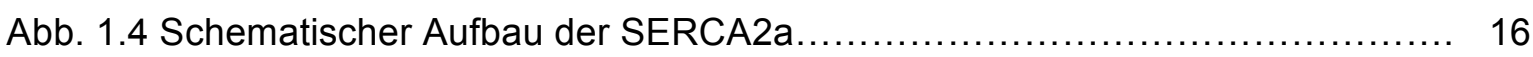

Abb. 2.1 Schematische Darstellung der Langendorff-Perfusionsanlage ................ 27

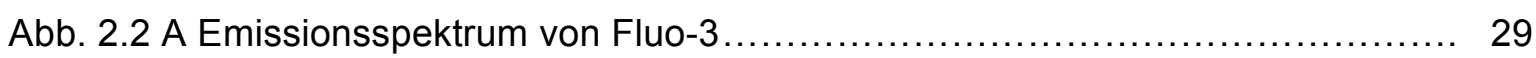

Abb. 2.2 B Strukturformel unterschiedlicher Fluo-Analoga........................... 29

Abb. 2.3 Schema des Epifluoreszenz-Setups und des Strahlenganges im Mikroskop... 30

Abb. 2.4 Schematische Darstellung einer Versuchskammer.......................... 31

Abb. 2.5 Originalregistrierung der Zellverkürzung einer Kardiomyozyte bei Stimulation

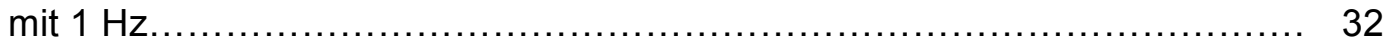

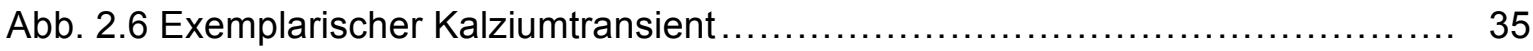

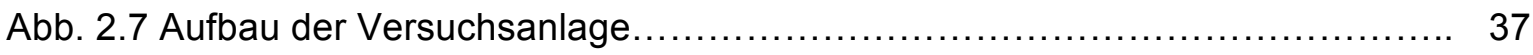

Abb. 3.1 Screeningergebnisse von ENF018 $(n=6)$ vs. Kontrolle $(n=6) \ldots \ldots \ldots \ldots \ldots \ldots . . \ldots 6$

Abb. 3.2 Exemplarische Originalregistrierung der normalisierten Zellverkürzung einer ENG020- Zelle (A) und einer Kontrollzelle (B) unter Stimulation von $2 \mathrm{~Hz} \ldots \ldots .47$

Abb. 3.3 Screeningergebnisse von ENG020 (n=6) vs. Kontrolle $(n=7) \ldots \ldots \ldots \ldots \ldots \ldots, 48$

Abb. 3.4 Screeningergebnisse von ENH036 (n=7) vs. Kontrolle $(n=6) \ldots \ldots \ldots \ldots \ldots \ldots . \ldots 49$

Abb. 3.5 Screeningergebnisse von ENL055 $(n=7)$ vs. Kontrolle $(n=6) \ldots \ldots \ldots \ldots \ldots \ldots . . . \ldots$

Abb. 3.6 Screeningergebnisse von ENL056 $(n=7)$ vs. Kontrolle $(n=7) \ldots \ldots \ldots \ldots \ldots \ldots \ldots \ldots \ldots \ldots$

Abb. 3.7 Screeningergebnisse von ENO107 $(n=7)$ vs. Kontrolle $(n=8) \ldots \ldots \ldots \ldots \ldots \ldots . \ldots 2$

Abb. 3.8 Exemplarische Originalregistrierung der normalisierten Zellverkürzung einer ENO114-Zelle (A) und einer Kontrollzelle (B) unter Stimulation von $2 \mathrm{~Hz} \ldots \ldots . .53$

Abb. 3.9 Exemplarische Originalregistrierung einer kurzzeitigen Arrhythmie unter $10 \mu \mathrm{M}$

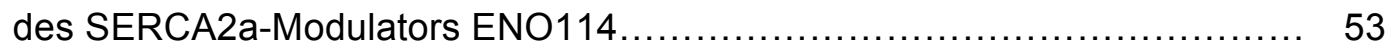

Abb. 3.10 Screeningergebnisse von ENO114 $(n=8)$ vs. Kontrolle $(n=8) \ldots \ldots \ldots \ldots \ldots \ldots . . \ldots 4$

Abb. 3.11 Screeningergebnisse von ENO166 $(n=7)$ vs. Kontrolle $(n=8) \ldots \ldots \ldots \ldots \ldots \ldots$

Abb. 3.12 Screeningergebnisse von ENO185 (n=7) vs. Kontrolle $(n=7) \ldots \ldots \ldots \ldots \ldots \ldots \ldots$

Abb. 3.13 Screeningergebnisse von ENO187 $(n=6)$ vs. Kontrolle $(n=7) \ldots \ldots \ldots \ldots \ldots \ldots \ldots \ldots$

Abb. 3.14 Screeningergebnisse von ENO207 $(n=7)$ vs. Kontrolle $(n=6) \ldots \ldots \ldots \ldots \ldots \ldots . \ldots$

Abb. 3.15 Screeningergebnisse von ENO209 $(n=7)$ vs. Kontrolle $(n=7) \ldots \ldots \ldots \ldots \ldots \ldots . . \ldots 9$

Abb. 3.16 Screeningergebnisse von GPZ000876 $(n=7)$ vs. Kontrolle $(n=7) \ldots \ldots \ldots \ldots .60$

Abb. 3.17 Screeningergebnisse von GPZ001441 (n=7) vs. Kontrolle $(n=7) \ldots \ldots \ldots \ldots \ldots .61$

Abb. 3.18 Screeningergebnisse von GPZ003362 $(n=7)$ vs. Kontrolle $(n=7) \ldots \ldots \ldots \ldots . \ldots 2$

Abb. 3.19 Screeningergebnisse von GPZ006800 $(n=6)$ vs. Kontrolle $(n=6) \ldots \ldots \ldots \ldots . . .63$

Abb. 3.20 Screeningergebnisse von GPZ007738 $(n=7)$ vs. Kontrolle $(n=8) \ldots \ldots \ldots \ldots . . .64$ 
Abb. 3.21 Auswirkungen von ENL055 auf den SR Ca ${ }^{2+}$-Gehalt von

Ratten-Kardiomyozyten .................................................. 65

Abb. 3.22 Auswirkungen von ENO107 auf den SR Ca ${ }^{2+}$-Gehalt von

Ratten-Kardiomyozyten.

Abb. 3.23 Auswirkungen von ENO114 auf den SR Ca ${ }^{2+}$-Gehalt von

Ratten-Kardiomyozyten. 66

Abb. 3.24 Auswirkungen von ENO185 auf den SR Ca ${ }^{2+}$-Gehalt von

Ratten-Kardiomyozyten

Abb. 3.25 Auswirkungen von ENO209 auf den SR Ca ${ }^{2+}$-Gehalt von

Ratten-Kardiomyozyten.

Abb. 3.26 Auswirkungen von GPZ003362 auf den SR Ca ${ }^{2+}$-Gehalt von

Ratten-Kardiomyozyten.

Abb. 3.27 Konzentrationsabhängige Änderung der relativen Kraft und der Relaxationszeit im Muskelstreifenexperiment durch ENL055 (n=3) vs. Kontrolle(n=3)...

Abb. 3.28 Konzentrationsabhängige Änderung der relativen Kraft und der Relaxationszeit im Muskelstreifenexperiment durch ENO107 ( $n=6)$ vs. Kontrolle $(n=6) \ldots 69$

Abb. 3.29 Konzentrationsabhängige Änderung der relativen Kraft und der Relaxationszeit im Muskelstreifenexperiment durch ENO114 (n=4) vs. Kontrolle(n=4)... 70

Abb. 3.30 Konzentrationsabhängige Änderung der relativen Kraft und der Relaxationszeit im Muskelstreifenexperiment durch ENO185 $(n=6)$ vs. Kontrolle(n=4)... 70

Abb. 3.31 Konzentrationsabhängige Änderung der relativen Kraft und der Relaxationszeit im Muskelstreifenexperiment durch ENO209 (n=4) vs. Kontrolle $(n=3) \ldots 71$

Abb. 3.32 Konzentrationsabhängige Änderung der relativen Kraft und der Relaxationszeit im Muskelstreifenexperiment durch GPZ003362 $(n=8)$ vs. Kontrolle $(n=8) 72$

\section{Tabellenverzeichnis}

Tab. 2.1 Lösungen zur Isolation ventrikulärer Kardiomyozyten aus Rattenherzen. 41

Tab. 2.2 Herstellung der Fluo 3 AM - Farbstofflösung. 41

Tab. 2.3 Zusammensetzung der Normaltyrode...... 42

Tab. 2.4 Herstellung der Messtyroden. 42

Tab. 2.5 Zusammensetzung von Krebs-Henseleit- und Präparierlösung für Muskel-

streifenexperimente. 43

Tab. 2.6 Herztransplantationspatienten. 44

Tab. 2.7 Medikation der Herztransplantationspatienten. 44 


\section{Formelverzeichnis}

Formel 2.1 Berechnung der fraktionellen Zellverkürzung. 34

Formel 2.2 Berechnung der Amplitude der $\mathrm{Ca}^{2+}$ - Transienten $\mathrm{F} / \mathrm{F}_{0}$ 34

Formel 2.3 Berechnung der Querschnittsfläche eines Muskelstreifens. 38

Formel 2.4 Berechnung des Standardfehlers des Mittelwertes (S.E.M.) 40

\section{Abkürzungsverzeichnis}

Abb.

ACE-Hemmer

ADP

A/D-Wandler

AM

AP

ATP

ATPasen

BDM

$\mathrm{Ca}^{2+},\left[\mathrm{Ca}^{2+}\right]_{\mathrm{i}}$

CaMKII

CAMP

CICR

DCM

DMSO

EF

engl.

$F_{\text {sys }}$

$\mathrm{F}_{\text {dia }}$

$\mathrm{F} / \mathrm{F}_{0}$

ICD

ICM

\section{Abbildung}

Hemmer des Angiotensin-konvertierenden Enzyms

Adenosindiphosphat

Analog-Digital-Wandler

Azetoxymethylester

Aktionspotential

Adenosintriphosphat

Adenosintriphosphatasen

2,3-Butandion-Monoxim

Kalzium, Kalziumkonzentration

$\mathrm{Ca}^{2+} /$ Calmodulin-abhängige Proteinkinase II

zyklisches 3',5'- Adeninmonophosphat

Ca-induced $\mathrm{Ca}$ release $\left(\mathrm{Ca}^{2+}\right.$-induzierte $\mathrm{Ca}^{2+}$-Freisetzung $)$

dilatative Kardiomyopathie

Dimethylsulfoxid

Ejektionsfraktion

englisch

systolische Kraft

diastolische Spannung

Quotient aus systolischer und diastolischer Fluoreszenz

implantierbarer Kardioverter-Defibrillator

ischämische Kardiomyopathie 


\begin{tabular}{|c|c|}
\hline $\mathrm{K}^{+},\left[\mathrm{K}^{+}\right]_{\mathrm{i}}$ & Kalium, Kaliumkonzentration \\
\hline KHK & koronare Herzkrankheit \\
\hline KH-Lösung & Krebs-Henseleit-Lösung \\
\hline lat. & lateinisch \\
\hline$L_{\max }$ & maximale Kraftentwicklung \\
\hline LVAD & linksventrikuläres Unterstützungssystem \\
\hline $\mathrm{Na}^{+},\left[\mathrm{Na}^{+}\right]_{\mathrm{i}}$ & Natrium, Natriumkonzentration \\
\hline $\mathrm{NCX}$ & Natrium/Kalzium-Austauscher \\
\hline NT & Normaltyrode \\
\hline NT-proBNP & N-terminales Pro-B-Typ Natriuretisches Peptid \\
\hline n. s. & nicht signifikant \\
\hline NYHA & New York Heart Association \\
\hline PKA & Proteinkinase $\mathrm{A}$ \\
\hline PKC & Proteinkinase C \\
\hline PLB & Phospholamban \\
\hline RAAS & Renin-Angiotensin-Aldosteron-System \\
\hline RyR & Ryanodin-Rezeptor des sarkoplasmatischen Retikulums \\
\hline $\mathrm{RT}_{50}$ & Zeit bis zur $50 \%$ igen Relaxation \\
\hline $\mathrm{RT}_{90}$ & Zeit bis zur 90\%igen Relaxation \\
\hline sATP & sarkolemmale ATPase \\
\hline S.E.M. & Standardfehler des Mittelwertes \\
\hline SERCA2a & $\mathrm{Ca}^{2+}$-ATPase des sarkoplasmatischen Retikulums \\
\hline SR & sarkoplasmatisches Retikulum \\
\hline$\tau_{\mathrm{Ca}}$ & monoexponentielle Zeitabfallskonstante des $\mathrm{Ca}^{2+}-$ Transienten \\
\hline Tab. & Tabelle \\
\hline TTP & Zeit bis zum Kraftmaximum \\
\hline vs. & versus \\
\hline
\end{tabular}




\section{Einleitung}

\subsection{Hintergrund}

Die Herzinsuffizienz ist mit einer Prävalenz von etwa 23 Millionen Betroffenen weltweit eine der häufigsten Erkrankungen der Inneren Medizin. Sowohl die derzeitige demografische Entwicklung als auch die erfreuliche Reduktion der Mortalität durch Myokardinfarkte führen dazu, dass diese Prävalenz weiter zunimmt (Bui et al. 2011; Go et al. 2013). Während sie in der Gesamtbevölkerung ungefähr $2 \%$ beträgt, liegt die Prävalenz bei der zunehmenden Altersgruppe der über 80 -Jährigen mit 10\% ausgesprochen hoch (McMurray und Stewart 2000).

Trotz der Etablierung lebensverlängernder Wirkstoffe wie z. B. ACE-Hemmer und $\beta$-Blocker sowie nicht-medikamentöser Therapien wie z. B. implantierbarer Kardioverter-Defibrillatoren (ICD) ist die Prognose der Herzinsuffizienz noch immer schlecht: Die 5-JahresÜberlebensrate bei chronischer Herzinsuffizienz beträgt durchschnittlich nur 45-60\% (Levy et al. 2002).

Ein wichtiger Mechanismus in der Pathophysiologie der Herzinsuffizienz liegt in einer gestörten Kalzium-Homöostase der Kardiomyozyten (Gwathmey et al. 1987; Morgan et al.1990; Hasenfuss und Pieske 2002). Maßgeblich beteiligt an der gestörten KalziumHomöostase bei Herzinsuffizienz ist eine verminderte Expression der Herz-spezifischen sarkoplasmatischen $\mathrm{Ca}^{2+}$-ATPase (SERCA2a), die zur reduzierten $\mathrm{Ca}^{2+}$-Beladung des sarkoplasmatischen Retikulums (SR) beiträgt (Hasenfuss et al.1994).

Im Rahmen des EUGeneHeart-Projektes wurden neue Wirkstoffe entwickelt, die spezifisch an die SERCA2a binden. Das Ziel der vorliegenden Arbeit bestand darin, den Einfluss dieser neuen SERCA2a-Modulatoren auf die Aktivität der SERCA2a, den Kalzium-Haushalt sowie die Kontraktilität von Kardiomyozyten zu untersuchen, mit der Absicht, eine neue Therapieoption für die Behandlung der Herzinsuffizienz zu finden. Hierbei wurde sowohl eine Einzelzellstudie mit isolierten Herzmuskelzellen aus Rattenmyokard verwandt als auch eine Versuchsreihe mit Muskelzellverbänden aus menschlichen, terminal insuffizienten Herzen gewählt.

Für ein weiteres Verständnis der möglichen Wirkungsweisen der SERCA2a-Modulatoren soll im Folgenden zunächst ein Überblick über die physiologischen Regulationsmechanismen der Herzmuskelzelle geschaffen werden. Neben einer Beschreibung des ultrastrukturellen Aufbaus des Herzens, der elektromechanischen Kopplung, der für den Kalziumstoffwechsel relevanten Proteine und Signalwege und der pathophysiologischen Vorgänge der Herzinsuffizienz soll abschließend auf die SERCA2a-Modulatoren im Zusammenhang aktueller Forschungsergebnisse eingegangen werden. 


\subsection{Ultrastruktureller Aufbau der Herzmuskelzelle}

Das Herzmuskelgewebe setzt sich aus einkernigen, teilweise auch zweikernigen, großen, parallel verlaufenden Herzmuskelzellen zusammen, die an ihren Enden über Glanzstreifen (lat. Disci intercalares) zahnartig untereinander in Verbindung stehen (Junqueira und Carneiro 2005). Die Glanzstreifen sorgen nicht nur für einen mechanischen Zusammenhalt, sondern auch für eine direkte Übertragung chemischer und elektrischer Reize zwischen den benachbarten Kardiomyozyten. Letzteres erfolgt über sog. gap junctions, kanalbildende Proteinkomplexe, die durchlässig für lonen, Botenstoffe und andere kleine Moleküle $(<1000$ Dalton) des Zellzytosols sein können und somit die Bezeichnung des Herzmuskelgewebes als funktionelles Synzytium begründen (Loewenstein 1981). Bei einem gestörten Elektrolytmilieu des Zytosols, wie z. B. bei einer Protonen- oder $\mathrm{Ca}^{2+}$-Überladung, können sich die gap junctions jedoch auch verschließen und somit gesunde Zellen vor dem Zelltod schützen (Vaughan-Jones et al. 2009).

Jeder Kardiomyozyt wird durch eine Lipid/Phospholipid-Doppelmembran, das sog. Sarkolemm, begrenzt, die das Zytosol vom Extrazellulärraum trennt. Sie enthält wichtige funktionelle Proteine wie lonenkanäle, lonenpumpen und Rezeptoren, die allesamt von Relevanz für die elektrische und chemische Signalübermittlung und letztlich für die Regulation der elektromechanischen Kopplung sind. $\mathrm{Zu}$ den wichtigsten sarkolemmalen Kanälen im ventrikulären Kardiomyozyten zählen der L-Typ-Ca ${ }^{2+}-\mathrm{Kanal}$, der $\mathrm{Na}^{+}-\mathrm{Kanal}$ und verschiedene $\mathrm{K}^{+}-$Kanäle. Wichtige sarkolemmale Austauscher und Pumpen sind der $\mathrm{Na}^{+} / \mathrm{Ca}^{2+}$-Austauscher (NCX), die $\mathrm{Na}^{+} / \mathrm{K}^{+}$-ATPase und die sarkolemmale $\mathrm{Ca}^{2+}$-ATPase. Die Funktion der einzelnen Kanäle soll im Abschnitt 1.3 näher erläutert werden.

Das Sarkolemm wirft quer zum Muskelfaserverlauf tiefe Falten in das Zellinnere auf. Diese als T-Tubuli bezeichneten sarkolemmalen Einstülpungen stehen in enger nachbarschaftlicher Beziehung zu den terminalen Zisternen des sarkoplasmatischen Retikulums und enthalten in ihrer Membran die oben genannten L-Typ-Ca ${ }^{2+}-K a n a ̈ l e$, die für die elektromechanische Kopplung eine besondere Rolle spielen (Ibrahim et al. 2011).

Eines der wichtigsten Zellkompartimente der Herzmuskelzelle für den kardialen Kalziumstoffwechsel stellt das sarkoplasmatische Retikulum (SR) dar. Da es sich schlauchförmig in Muskelfaserlängsrichtung ausdehnt, wird es auch als longitudinales Tubulus-System (L-Tubulus-System) bezeichnet. Es endet in den terminalen Zisternen, die zusammen mit den T-Tubuli des Sarkolemms durch ihre räumliche Nähe eine sogenannte Diadenstruktur bilden (Bers 2001). Das SR hat die Funktion der kontrollierten $\mathrm{Ca}^{2+}$. Speicherung und -Freisetzung inne, die es mithilfe zweier in seiner Membran integrierte Proteine erfüllt: der Herz-spezifischen SR Ca ${ }^{2+}$-ATPase (SERCA2a) und des $\mathrm{Ca}^{2+}$ Freisetzungskanals, auch Ryanodin-Rezeptor (RyR) genannt. Im Lumen des SR befindet 
sich neben einer großen Menge an Kalzium u. a. das Protein Calsequestrin, das durch seine hohe Kalziumbindungskapazität das Kalzium puffert (Campbell et al. 1983).

Als weitere Zellorganelle der Herzmuskelzelle sind die Myofibrillen zu nennen. Sie füllen allein etwa $50 \%$ des Zellvolumens aus und stellen den kontraktilen Apparat der Herzmuskelzelle dar (Bers 2001). Die etwa 1-2 $\mu \mathrm{m}$ dicken, zylindrisch aufgebauten Myofibrillen lassen sich aufgliedern in dünne Aktinfilamente und in dicke Myosinfilamente. Sie verlaufen parallel zueinander und bewirken durch ein gegenläufiges Ineinandergleiten eine Verkürzung der Zelle (Huxley 1969). Da sich die Myofilamente teilweise überlagern, entsteht die typische, im Mikroskop sichtbare Querstreifung der Herzmuskulatur. Wie aus Abb. 1.1 ersichtlich, lassen sich elektronenmikroskopisch Streifen unterschiedlicher Helligkeit voneinander abgrenzen (A-, H-, M-, I- und Z-Streifen). Die Z-Linien stellen den Ort dar, an dem die dünnen Aktinfilamente zusammen mit stützenden Titinsträngen verankert sind. Als Sarkomer bezeichnet man dabei den Abschnitt zwischen zwei aufeinanderfolgenden ZLinien, der die kleinste funktionelle Einheit der Myofibrille darstellt (Bers 2001).

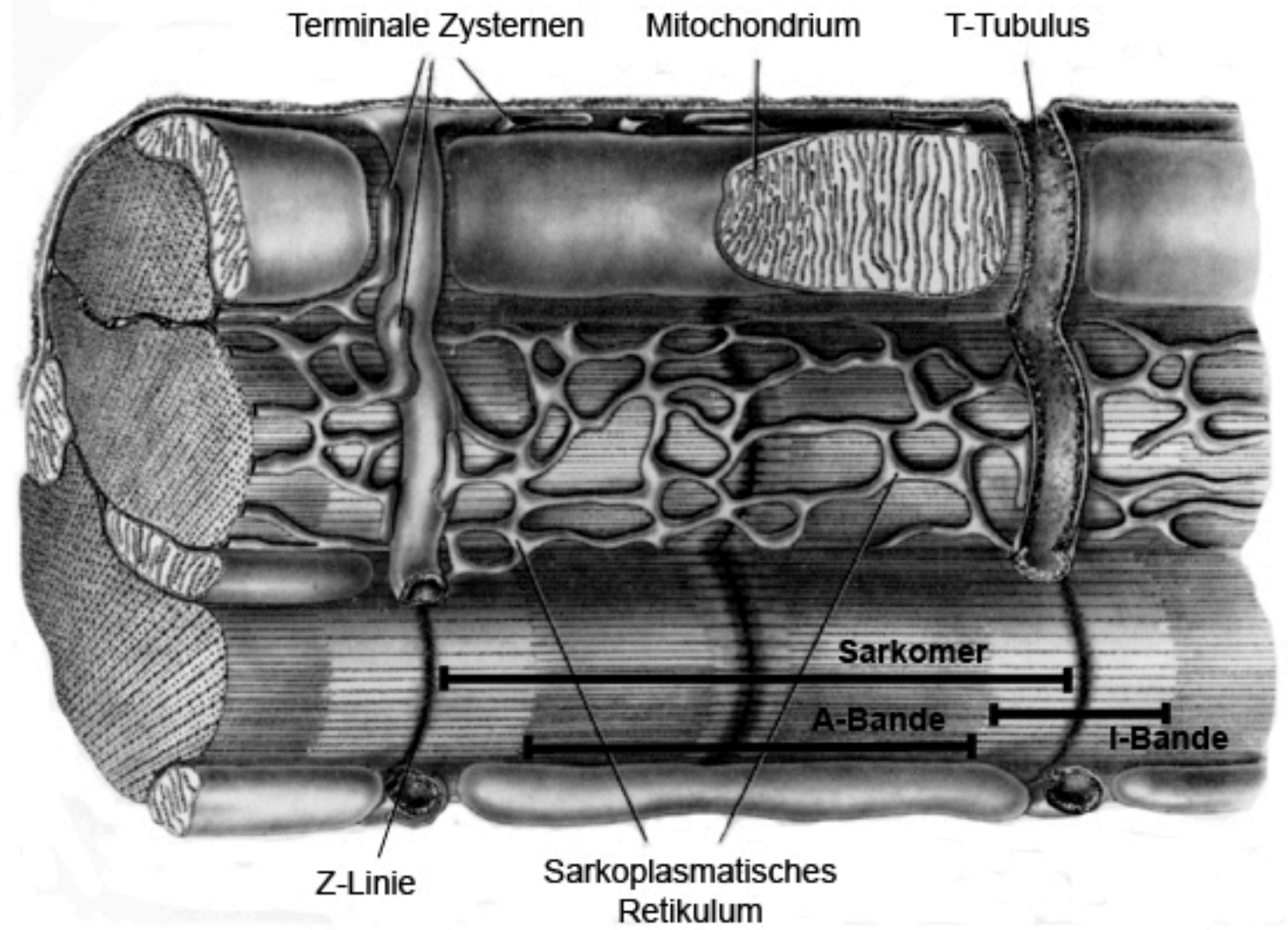

Abb. 1.1 Die Ultrastruktur der Herzmuskelzelle (modifiziert nach Bers 2001, Seite 2, mit freundlicher Genehmigung durch Springer Science and Bus Media BV) 
Den Myofibrillen angelagert sind mehrere verschiedene Proteine, wie z. B. der TroponinTropomyosin-Komplex, ein spezieller Proteinkomplex, der essentiell für die Regulation der Zellkontraktion ist.

Zwischen den Myofibrillen befinden sich die Mitochondrien, die mit einem Volumenanteil von $35 \%$ das zweitgrößte Kompartiment der Kardiomyozyte darstellen. Als Energielieferant versorgen die Mitochondrien die Zelle mit Adenosintriphosphat (ATP), das insbesondere für den energieaufwendigen Gleit-Filament-Mechansimus der Myofibrillen notwendig ist. Außerdem tragen sie mit ihren in der Membran eingelagerten $\mathrm{Ca}^{2+}$-Uniportern einen geringen Anteil zur Elimination des $\mathrm{Ca}^{2+}$ aus dem Zytosol (etwa 2 \%) und damit zur Relaxation der Zelle während der Diastole bei.

Weitere unerlässliche Zellorganellen der Kardiomyozyte sind sowohl der Golgi-Apparat, die Peroxysomen und Lysosomen als auch das Zytoskelett.

\subsection{Die elektromechanische Kopplung}

Vorraussetzung für die Initiierung der elektromechanischen Kopplung, d. h. der Umwandlung eines fortgeleiteten Aktionspotentials in eine Zellverkürzung, ist ein transienter Anstieg des intrazellulären Kalziums von ca. $100 \mathrm{nM}$ auf über $1 \mu \mathrm{M}$ (Drop 1985). Anschließend muss für die Relaxation der Zelle das intrazelluäre Kalzium wieder aus dem Zytosol eliminiert werden. Damit in der Zelle insgesamt kein Kalzium verloren geht oder angereichert wird, ist eine streng geregelte Balance zwischen Kalzium-Ein- und -Ausstrom notwendig (Bers 2002).

Die Erregungsbildung des Herzens beginnt in den spezialisierten Kardiomyozyten des Sinusknotens. Dort kommt es zu spontanen und rhythmischen Depolarisationen der Zellmembran und somit zu einem Aktionspotential, das über das Erregungsleitungssystem und schließlich über die oben genannten gap junctions direkt von Zelle zu Zelle weitergeleitet wird. Das Aktionspotential wird generiert durch das Öffnen sarkolemmaler spannungsabhängiger $\mathrm{Na}^{+}-$Kanäle. Durch den Einwärtsstrom von $\mathrm{Na}^{+}$-lonen kommt es zur Depolarisation der sarkolemmalen Membran, d. h. zu einem Anstieg des Membranpotentials von ca. $-80 \mathrm{mV}$, des Ruhemembranpotentials, auf positive Werte von ca. $+30 \mathrm{mV}$. Dies resultiert wiederum in einer Aktivierung auswärtsgerichteter $\mathrm{K}^{+}-\mathrm{Kanäle,} \mathrm{wodurch} \mathrm{ein}$ Auswärtsstrom von $\mathrm{K}^{+}$-lonen in den Extrazellulärraum entsteht. Fast gleichzeitig kommt es auch zu einem $\mathrm{Ca}^{2+}$-Einstrom über das Sarkolemm. Es entsteht die sogenannte PlateauPhase des Aktionspotentials, während der nun die Kontraktion der Zelle initiiert wird (Birkeland et al. 2005). Der zur Plateau-Phase führende Kalziumeinstrom erfolgt über die

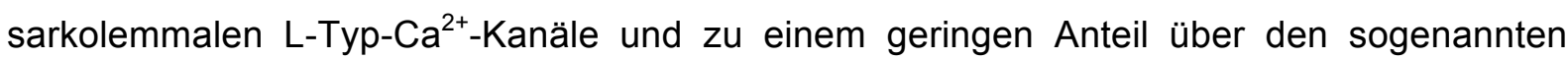
reverse mode des $\mathrm{Na}^{+} \mathrm{Ca}^{2+}$-Austauschers (NCX), angeregt durch die Depolarisation und den passager höheren $\mathrm{Na}^{+}$-Gehalt der Zelle infolge des Aktionspotentials (Leblanc und Hume 1990). Für die Generierung einer Kontraktion ist jedoch ein sehr viel höherer Kalziumanstieg 
im Zytosol notwendig. Dieser kommt durch die sogenannte Kalzium-induzierte-KalziumFreisetzung, engl. calcium induced calcium release (CICR), zustande (Fabiato und Fabiato 1973): Die lokal erhöhte Menge an $\mathrm{Ca}^{2+}$-Ionen zwischen den L-Typ-Ca ${ }^{2+}-$ Känalen in den TTubuli und den eng benachbarten Ryanodin-Rezeptoren des sarkoplasmatischen Retikulums führt zur Freisetzung von Kalzium aus dem SR. Das Kalzium stellt hierbei den adäquaten Trigger für den RyR dar sich zu öffnen und eine große Menge des im SR gespeicherten Kalziums freizusetzen.

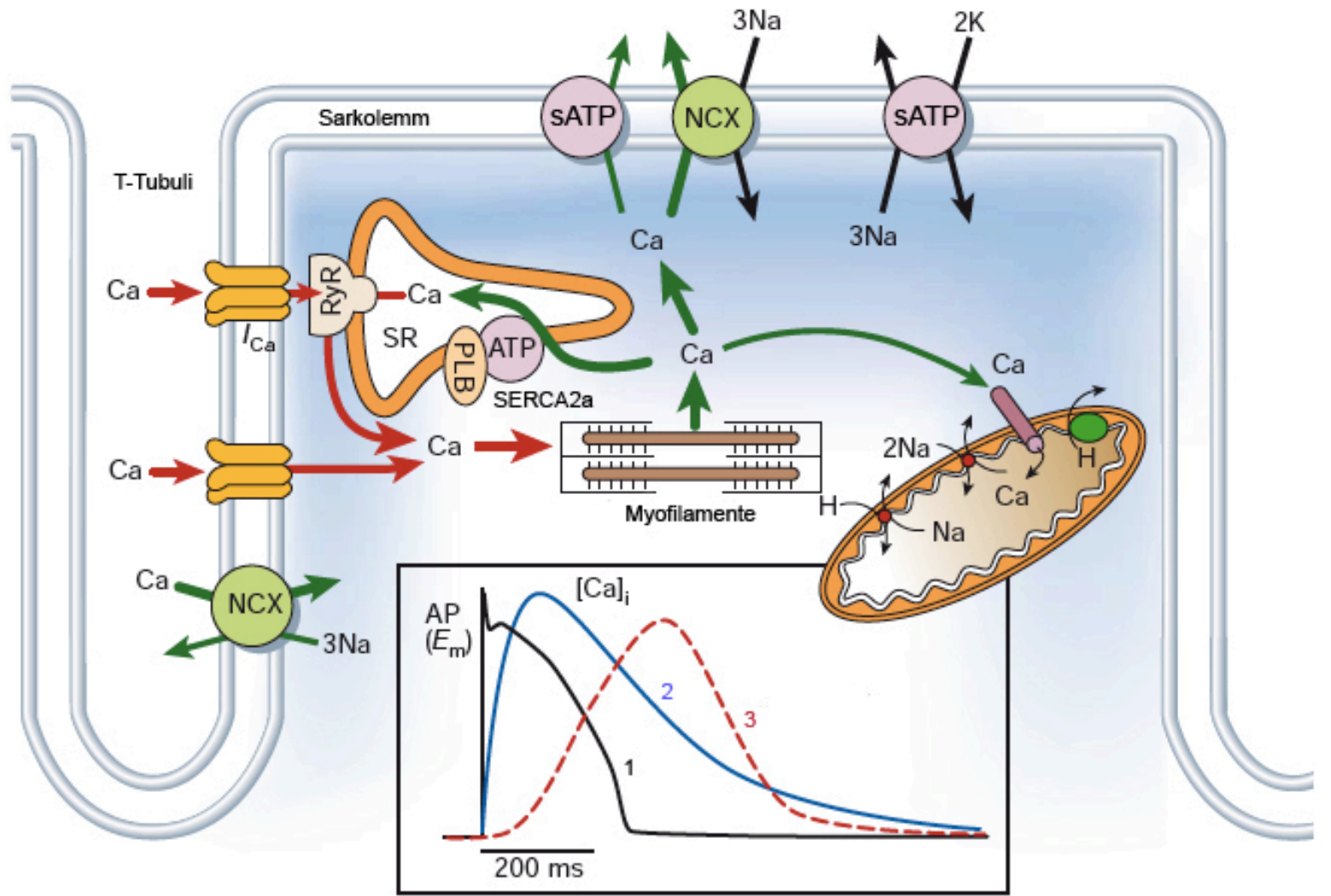

Abb. 1.2 Schematische Darstellung der elektromechanischen Kopplung

Die roten Pfeile demonstrieren den Kalziumeinstrom während der Systole, die grünen Pfeile den Kalziumausstrom während der Diastole. Das Diagramm unten zeigt die Beziehung zwischen Aktionspotential (1), intrazellulärer $\mathrm{Ca}^{2+}-$ Konzentration (2) und Myozytenverkürzung (3). (Modifiziert nach Bers 2002, Seite 198, mit freundlicher Genehmigung durch Macmillan Publishers Ltd) 
Im Weiteren erfolgt dann die Kontraktion der Myozyte über mehrere nacheinander folgende Schritte, die in Abb. 1.3 veranschaulicht werden:

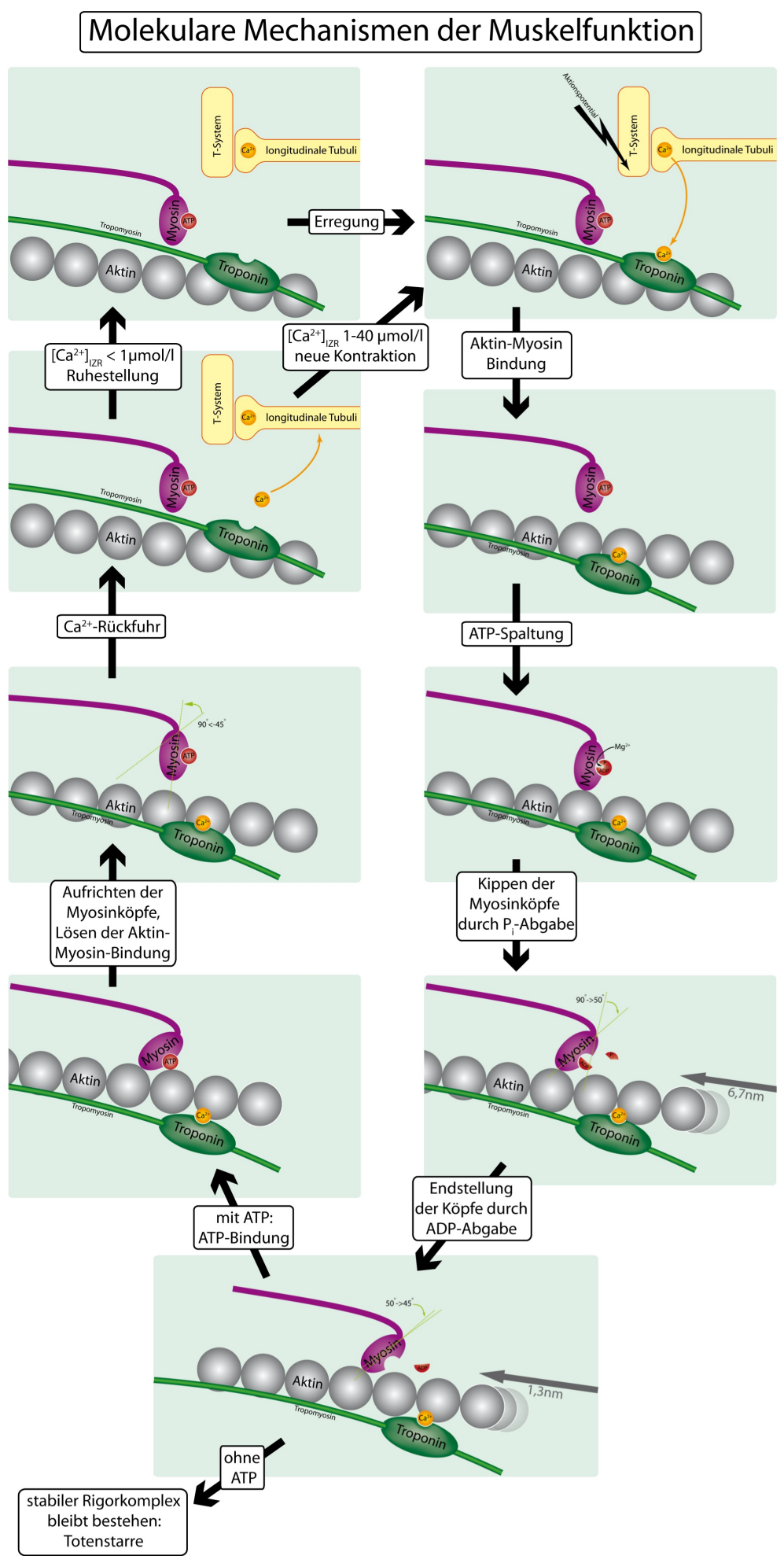

Abb. 1.3 Schematische Darstellung des Querbrückenzyklus. Initial wird Kalzium an Troponin C gebunden. Dies bedingt die Freigabe der Bindungsstelle des Aktinstranges für das Myosinköpfchen. Unter Spaltung von ATP kommt es zur Anlagerung des ausgerichteten Hebelarms am Aktinstrang. Nach Abspaltung des Phosphats erfolgt die Rotationsbewegung des Kopfes und somit das gegenläufige Ineinandergleiten der Filamente. (Mit freundlicher Genehmigung durch CC BY-SA 2.5, https://commons. wikimedia.org/w/index.php?curid=558850) 
Für das Zustandekommen einer Kontraktion muss der Kopf des Myosinfilaments an das Aktinfilament binden. In der Ausgangssituation wird diese Bindungsstelle jedoch durch den am Aktinfilament befindlichen Troponin-Tropomyosin-Komplex verdeckt. Durch Bindung von Kalzium an Troponin C dieses Komplexes kommt es zur Konformationsänderung des Tropomyosins, wodurch die Bindungsstelle für das Myosinköpfchen frei wird. Der folgende Prozess geschieht nun unter Energieaufwand, d. h. ATP-abhängig: Das Myosinköpfchen katalysiert als ATPase die Spaltung von einem Molekül ATP in ADP und Phosphat. Hierdurch kommt es zur Ausrichtung eines Hebelarms zwischen Myosinstrang und Myosinkopf und zu einer zunächst schwachen Bindung des Myosinköpfchens an der Aktinbindungsstelle. Anschließend erhöht sich die Bindungsaffinität der beiden Myofilamente. Erst durch die endgültige Abspaltung des Phosphats kommt es im folgenden Schritt zum Abkippen des Hebelarms und somit zu einem Gleiten des Aktinfilaments in Richtung der MLinie des Sarkomers. Das Sarkomer ist nun um ca. 5-10 nm verkürzt. Im letzten Schritt dissoziiert das noch gebundene ADP-Molekül vom Myosinkopf ab und wird durch ein neues ATP-Molekül ersetzt. Das Myosinköpfchen löst sich vom Aktinstrang, und es kann ein weiterer Durchlauf dieses sog. Querbrückenzyklus erfolgen. Um eine adäquate Kontraktion der Zelle zu bewirken, muss der Querbrückenzyklus mehrere Male und von den in Reihe liegenden Myofilamenten synchron durchlaufen werden (Huxley 1969; Ebashi et al. 1974; Potter und Gergely 1974; Rayment et al. 1993).

Erst wenn die Kalziumkonzentration im Zytosol sinkt, kommt es zur Relaxation der Zelle. Da nun der auswärtsgerichtete $\mathrm{K}^{+}$-Ausstrom gegenüber dem $\mathrm{Ca}^{2+}$-Einstrom dominiert, kommt es zur Repolarisation der Membran auf ca. - $80 \mathrm{mV}$. Um ein Abdiffundieren des Kalziums von den Myofilamenten zu gewährleisten, muss die zytosolische Kalziumkonzentration auf den Ausgangswert von ca. 100 nM gesenkt werden. Dies erfolgt über vier verschiedene Mechanismen: Der größte Anteil des während der Systole im Zytosol befindlichen Kalziums wird über die SERCA2a wieder zurück ins SR gepumpt. Ein nicht unerheblicher Anteil wird über den NCX aus der Zelle in den Extrazellulärraum geschleust. Mit einem deutlich geringeren Anteil von 1-2\% der zytosolischen Kalziumelimination trägt die sarkolemmale $\mathrm{Ca}^{2+}$-ATPase zur Kalziumausschleusung in den Extrazellulärraum bei. Insgesamt entspricht die über den NCX und die $\mathrm{Ca}^{2+}$-ATPase beförderte Kalziummenge ungefähr derjenigen, die zu Beginn der Systole über den L-Typ-Ca ${ }^{2+}-K a n a l$ in die Zelle gelangt ist. Ein weiterer geringer Anteil an Kalzium (ca. 2\%) wird ferner über einen mitochondrialen Uniporter ins Lumen der Mitochondrien eliminiert (Bers 2001).

Der Abtransport des Kalziums über die SERCA2a und den NCX variiert innerhalb verschiedener Spezies: Während bei der Maus und der Ratte ca. 92 \% des zytosolischen Kalziums über die SERCA2a und nur knapp $7 \%$ über den NCX eliminiert wird, liegt das Verhältnis SERCA2a zu NCX der zytosolischen Kalziumelimination im menschlichen 
Myokard bei ca. 70\% zu 30 \% (Bers 2002; Maier und Bers 2002). Allerdings unterliegen die Verhältnisse einer Frequenzabhängigkeit. Im gesunden menschlichen Myokard führt eine gesteigerte stimulierende Frequenz zu einer Erhöhung der Kalziumelimination über die SERCA2a bei gleichzeitig reduzierter Kalziumelimination über den NCX. Am herzinsuffizienten Myokard dagegen bleibt der Beitrag der SERCA2a zur Kalziumelimination bei gesteigeter Frequenz unverändert (Pieske et al. 1999). Bei der Ratte wiederum fällt die Steigerung der Kalziumelimination über die SERCA2a bei Frequenzerhöhung gering aus (Maier et al. 2000).

\subsubsection{Die SR $\mathrm{Ca}^{2+}$-ATPase (SERCA): Funktion, Struktur und Regulation}

Die Funktion der sarkoendoplasmatischen $\mathrm{Ca}^{2+}$-ATPase (SERCA) besteht darin, während der Diastole unter Energieaufwand, d. h. unter Spaltung eines ATP-Moleküls, zwei $\mathrm{Ca}^{2+}$ Ionen in das sarkoplasmatische Retikulum zu befördern (Tada et al. 1978). Einerseits trägt sie hiermit entscheidend zur diastolischen Kalziumelimination und somit zur Relaxation der Kardiomyozyte bei (Inesi 1985; Schatzmann 1989). Andererseits wird unter normalen Bedingungen über ihre Aktivität indirekt die Kontraktilität reguliert: Je mehr Kalzium während der Relaxation in das SR befördert wird, desto mehr Kalzium kann innerhalb der nächsten Systole freigesetzt werden, desto stärker fällt also die folgende Kontraktion aus. Außerdem bestimmt ihre Aktivität die Relaxationsgeschwindigkeit (Shull et al. 2000).

In Säugetieren existieren mehrere Isoformen der SERCA, die sich in Lokalisation, Aktivität und Regulation voneinander unterscheiden und von insgesamt drei verschiedenen Genen (ATP2A1, ATP2A2 und ATP2A3) kodiert werden. Die Isoformen entstehen durch alternatives Spleißen während der Transkription dieser Gene. Das ATP2A1-Gen wird in schnell kontrahierenden Skelettmuskelzellen transkribiert. Hier entsteht über alternatives Spleißen einerseits die neonatale SERCA-Isoform SERCA1b und andererseits die adulte Isoform SERCA1a. Das ATP2A2-Gen kodiert für weitere drei bekannte Isoformen: Während die Isoformen SERCA2a und SERCA2c vorwiegend in Herzmuskelzellen und in langsam kontrahierenden Skelettmuskelzellen vorkommen, wird die Isoform SERCA2b in allen Gewebezellen des Körpers, d. h. auch in nicht-muskulären Geweben, auf niedrigem Niveau exprimiert. Die Isoformen des ATP2A3-Gens kommen allgemein verteilt in nicht-muskulären Zellen vor und dominieren in hämatopoetischen Zellen, Thrombozyten, Epithelzellen, Fibroblasten und Endothelzellen (Periasamy und Kalyanasundaram 2007).

Da die SERCA-Isoform SERCA2a die dominierende Isoform der Herzmuskelzelle ist, wird im Folgenden nur diese genauer beschrieben.

Die SERCA2a ist ein ca. 110 kDa schweres Transmembranprotein, das den größten Anteil des Proteingehaltes des SR ausmacht und, wie bereits beschrieben, vorwiegend in den geraden Regionen der L-Tubuli lokalisiert ist (Tada et al. 1978). Wie in Abb. 1.4 zu sehen, 
besteht die SERCA2a aus zehn transmembranären, a-helikalen Domänen (M1 - M10) und zwei zytoplasmatischen Anteilen. Die zytoplasmatischen Anteile wiederum setzen sich zusammen aus einer kleinen Schlaufe, der sog. $\beta$-Domäne, und einer großen Schlaufe, bestehend aus einer Phosphorylierungsstelle an Asp351, einer ATP-Bindungsstelle und einer Scharnierregion. Als Vorraussetzung für den Beginn eines Kalziumtransport-Prozesses müssen ein ATP-Molekül an die ATP-Bindungsstelle und zwei $\mathrm{Ca}^{2+}$-Ionen an die Transmembrandomäne binden. Anschließend wird unter ATP-Hydrolyse die freiwerdende Phosphatgruppe auf die Aminosäure Asp351 übertragen, was zur Konformationsänderung der SERCA2a führt. Diese bewirkt, dass die Kalziumaffinität der SERCA2a sinkt, so dass das gebundene Kalzium in das Lumen des SR entlassen werden kann. Nach Abspaltung des Phosphats kann ein neuer Zyklus beginnen (MacLennan 1990; Lompré et al. 1994; Wankerl und Schwartz 1995).

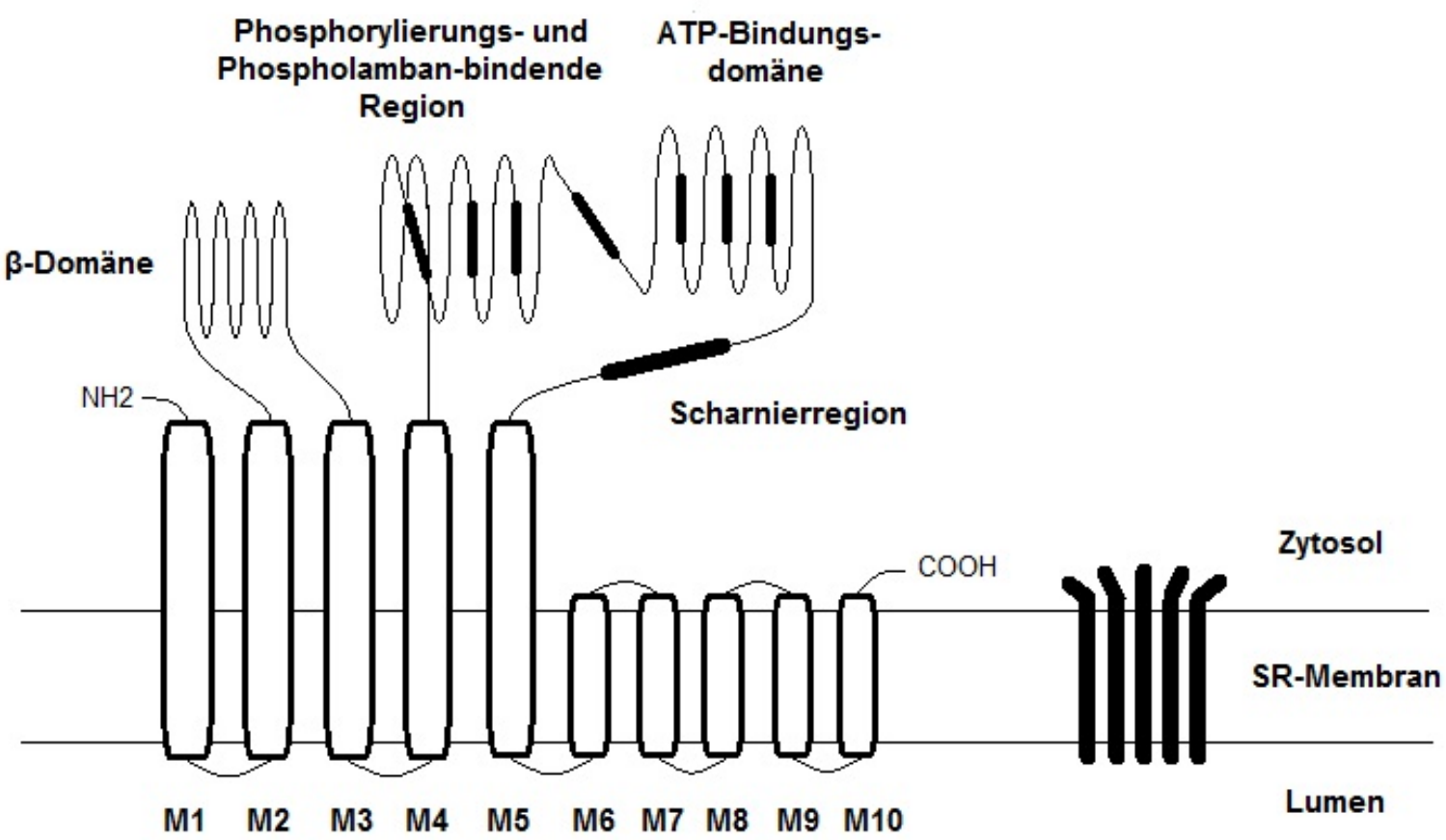

Transmembranäre Domäne

Phospholamban

Abb. 1.4 Schematischer Aufbau der SERCA2a (Angelehnt an Lompré et al. 1994, Vol. 26, Seite 1111, Abbildung 1, mit freundlicher Genehmigung durch Elsevier)

Reguliert wird die SERCA2a-Aktivität durch das Phosphoprotein Phospholamban (PLB). In dephosphorylierter Form inhibiert Phospholamban die Funktion der SERCA2a, indem es die Kalziumaffinität der $\mathrm{Ca}^{2+}$-ATPase mindert. Die Bindungsstelle für dephosphoryliertes Phospholamban befindet sich neben der Phosphorylierungsstelle der SERCA2a (James et al. 1989; Toyofuku et al. 1993). Durch Phosphorylierung dissoziiert Phospholamban von der SERCA2a ab, so dass die Kalziumaffinität der $\mathrm{Ca}^{2+}$-ATPase und somit die Aufnahme von Kalzium in das SR wieder steigt (Tada und Katz 1982; James et al. 1989; Kim et al. 1990). 
An der Phosphorylierung von Phospholamban sind vornehmlich drei verschiedene Proteinkinasen beteiligt: zum einen die Proteinkinase A (PKA), die durch $\beta$-adrenerge Stimulation cAMP-abhängig aktiviert wird und Phospholamban an der Aminosäure Serin-16 phosphoryliert, zum anderen die $\mathrm{Ca}^{2+}$-/Calmodulin-abhängige Proteinkinase II (CaMKII), die PLB an Threonin-17 phosphoryliert, und schließlich die $\mathrm{Ca}^{2+} /$ Phospholipid-abhängige Proteinkinase C (PKC), die an Serin-10 des PLB phosphoryliert (Wegener et al. 1989; Colyer 1998). Die Phosphatbindung wird anschließend wieder durch SR-assoziierte Phosphatasen gespalten (Kranias und DiSalvo 1986).

Ferner wird die Aktivität der SERCA2a durch den physiologischen pH-Wert der Zelle beeinflusst. Bei Azidose wird die Funktion der SERCA2a herabgesetzt (Hulme und Orchard 1998). Dies kommt zum Beispiel im Rahmen eines Myokardinfarktes vor, wobei die reduzierte SR $\mathrm{Ca}^{2+}$-Aufnahme letztlich zu einer gestörten Relaxation und verminderten Kontraktilität führt.

\subsection{Physiologische Regulationsmechanismen der Kontraktionskraft}

In Belastungssituationen kann die Kontraktionskraft des Herzens durch unterschiedliche Anpassungsmechanismen gesteigert werden. Zu diesen gehören der Frank-StarlingMechanismus, die positive Kraft-Frequenz-Beziehung (Bowditch-Effekt) sowie die Aktivierung neurohumoraler Systeme.

\subsubsection{Frank-Starling-Mechanismus}

Erhöhte enddiastolische Füllungsdrücke führen zu einer Steigerung der Kontraktionskraft (Frank 1895; Starling 1918). Dieser als Frank-Starling-Mechanismus bezeichnete Effekt beruht nach heutiger Ansicht überwiegend auf einer Erhöhung der $\mathrm{Ca}^{2+}$-Sensitivität der Myofilamente bei Dehnung (Allen und Kurihara 1982; Allen und Kentish 1985; Shiels und White 2008). Zum kleineren Teil wird er durch eine verbesserte Überlappung der Myofilamente hervorgerufen (Gordon et al. 1966).

\subsubsection{Positive Kraft-Frequenz-Beziehung}

Bei dem erstmals 1871 von Bowditch beschriebenen Anpassungsmechanismus wird die erhöhte Kontraktionskraft durch eine Steigerung der Herzfrequenz bewirkt. Der positiv inotrope Effekt beruht auf einem gesteigerten Einstrom von Kalzium aus dem Extrazellulärraum aufgrund schnell aufeinander folgender Depolarisationen. Sowohl eine erhöhte Kalzium-Beladung des SR (Pieske et al. 1999 b), ein vermehrter Kalzium-Einstrom über den L-Typ-Kalzium-Kanal (Piot et al. 1996) als auch eine Erhöhung des intrazellulären Natriums mit konsekutiv erhöhtem Kalzium-Einstrom über den NCX (Cohen et al. 1982; Pieske et al. 2002) sind an der Steigerung der intrazellulären Kalziumkonzentration beteiligt. 


\subsubsection{Neurohumorale Aktivierung}

In Belastungssituationen kommt es zur Ausschüttung diverser neurohumoraler Stoffe, die über verschiedene Mechanismen die Kontraktilität des Herzens beeinflussen können. Zu den wichtigsten zählen Katecholamine, das Renin-Angiotensin-Aldosteron-System (RAAS) sowie Endothelin-1.

Die Katecholamine Adrenalin und Noradrenalin wirken am Herzen über $\alpha$ - und $\beta_{1-}$ Rezeptoren stark positiv inotrop, wobei der Effekt über die $\beta_{1}$-Rezeptoren stärker ausgeprägt ist (Brodde 1991). Die Stimulation der $\beta_{1}$-Rezeptoren löst eine Signalkaskade aus, die zur Bildung von cyclischem $3^{\prime}, 5^{\prime}$ - Adeninmonophosphat (cAMP) führt. Das cAMP aktiviert die Proteinkinase A (PKA), die bestimmte Zielproteine im Zytosol phosphoryliert wie z. B. den LTyp-Ca ${ }^{2+}-$ Kanal, Phospholamban, Troponin I und den RyR. Insgesamt resultieren hieraus zum einen eine Erhöhung der intrazellulären Kalziumkonzentration und somit ein positiv inotroper Effekt und zum anderen auch eine positiv chronotrope, dromotrope und lusitrope Wirkung (Nawrath 1989; Brodde et al. 1992). Die Stimulation der a-Rezeptoren führt dagegen u. a. zur Aktivierung der Proteinkinase C. Der positiv inotrope Effekt wird hier hauptsächlich durch eine Erhöhung der $\mathrm{Ca}^{2+}$-Sensitivität der Myofilamente hervorgerufen (Endoh 1991). Peripher führt die Stimulation der a-Rezeptoren zu einer Vasokonstriktion (Ahlquist 1976; Kohl et al. 1989).

Bei Blutdruckabfällen und Reduktion des zirkulierenden Blutvolumens kommt es zur Aktivierung des RAAS, das den Kreislauf durch Gefäßkonstriktion und $\mathrm{Na}^{+}-$und WasserRetention stabil hält. Ferner ist für das körpereigene Polypeptid Angiotensin II auch eine positiv inotrope Wirkung auf den Herzvorhof nachgewiesen (Holubarsch et al. 1993; Möllmann et al. 2007).

Der neurohumorale Stoff Endothelin-1 führt über eine Steigerung der $\mathrm{Ca}^{2+}$-Sensitivität der Myofilamente ebenfalls zu einer erhöhten Kontraktionskraft (Pieske et al. 1999 a). Außerdem wirkt er als potenter Vasokonstriktor und erhöht somit den peripheren Widerstand.

\subsection{Herzinsuffizienz}

\subsubsection{Definition, Ursachen, Klinik und Therapie}

Bei der Herzinsuffizienz handelt es sich definitionsgemäß um die Unfähigkeit des Herzens, die peripheren Organe trotz ausreichender linksventrikulärer Füllung mit genügend Sauerstoff zu versorgen (McMurray 1996).

Die Ursachen der Herzinsuffizienz sind vielfältig. Man unterscheidet zwischen der systolischen Herzinsuffizienz mit eingeschränkter Pumpfunktion und der diastolischen Herzinsuffizienz mit gestörter Relaxation des Herzens bei erhaltener Pumpfunktion. Die häufigste Ursache der systolischen Herzinsuffizienz ist die Koronare Herzkrankheit (KHK), die entweder akut im Rahmen eines Myokardinfarktes oder chronisch über einen langen 
Zeitraum zum Untergang des Herzmuskels und damit zur Einschränkung der Auswurfleistung führt. Neben der KHK sind die arterielle Hypertonie, die dilatative Kardiomyopathie (DCM), Herzvitien sowie die Myokarditis als weitere Ursachen der systolischen Herzinsuffizienz zu nennen (McMurray und Stewart 2000). Der diastolischen Herzinsuffizienz liegt häufig eine Herzhypertrophie zugrunde, die beispielsweise durch einen arteriellen Hypertonus bedingt sein kann. Häufig sind die ursächlichen Mechanismen der diastolischen Herzinsuffizienz jedoch unbekannt.

Klinisch können sich die systolische und die diastolische Herzinsuffizienz sehr ähneln. Unterschieden werden Symptome des Vorwärtsversagens wie z. B. Zyanose, Leistungsminderung und Synkopen von Symptomen des Rückwärtsversagens wie z. B. Dyspnoe bei Lungenödem, periphere Ödeme und Aszites.

Die Therapie der Herzinsuffizienz erfolgt abgestuft nach der Schweregrad-Klassifikation der New York Heart Association (NYHA-Klassen I-IV) mit ACE-Hemmern, $\beta$-Blockern, Diuretika, Aldosteronantagonisten und Digitalis. Bei fortgeschrittener Herzinsuffizienz wird zudem nichtmedikamentös mittels implantierbarer Kardioverter-Defibrillatoren und/oder kardialer Resynchronisationstherapie behandelt (Weinbrenner et al. 2012).

\subsubsection{Pathophysiologie der Herzinsuffizienz}

Allen Entitäten, die zur Entstehung der Herzinsuffizienz führen, ist der Verlust funktionellen Herzmuskels gemeinsam, der über einen begrenzten Zeitraum durch eine Hypertrophie der verbliebenen Herzmuskelanteile sowie sympathoadrenerge und neurohumorale Mechanismen kompensiert wird (siehe Abschnitt 1.4). Im Verlauf werden diese Kompensationsmechanismen jedoch ineffektiv, zum größten Teil schädigen sie sogar im Sinne eines circulus vitiosus die Funktion des Herzens und führen zur weiteren klinischen Manifestation der Herzinsuffizienz.

\subsubsection{Strukturelle und mechanische Veränderungen}

Als Antwort auf eine dauerhafte Belastung entsteht eine Hypertrophie des Herzens, die bei Druckbelastung konzentrisch und bei Volumenbelastung exzentrisch angeordnet ist (Grossman et al. 1975). Durch Zunahme der Zellgröße und gesteigerter Synthese von kontraktilen Proteinen wird die Auswurfleistung des Herzens zunächst aufrechterhalten (Ferrans et al. 1976; Takahashi et al. 1980; Olivetti 1994). Ab einem kritischen Herzgewicht von ca. $500 \mathrm{~g} \mathrm{kommt} \mathrm{es} \mathrm{jedoch} \mathrm{zu} \mathrm{einem} \mathrm{Missverhältnis} \mathrm{zwischen} \mathrm{Sauerstoffzufuhr} \mathrm{und} \mathrm{-}$ Bedarf des Herzens. Es folgen subendokardiale Ischämien, die einen weiteren Verlust an Herzmuskelanteilen und somit eine zunehmende myokardiale Kraftminderung bewirken. Zusätzlich wird aufgrund einer gesteigerten Kollagensynthese die ventrikuläre Dehnbarkeit eingeschränkt, woraus eine diastolische Dysfunktion resultiert. 
Des Weiteren werden bei Herzinssuffizienz Veränderungen der intrinsischen Kraftregulation gefunden: Sowohl in tierexperimentellen Herzinsuffizienzmodellen als auch in Versuchen mit humanen insuffizienten Kardiomyozyten wurde ein abgeschwächter oder fehlender FrankStarling-Mechanismus beschrieben (Komamura et al. 1993; Schwinger et al. 1994). Im Gegensatz hierzu war dieser in vergleichbaren Versuchen anderer Arbeitsgruppen jedoch weiterhin vorhanden (Holubarsch et al. 1996; Vahl et al. 1997). Ferner ist auch der BowditchEffekt bei Herzinsuffizienz verändert: Unter Frequenzzunahme kommt es hier im Gegensatz zum gesunden Myokard zu einer Verminderung der Kontraktilität, d. h. einer negativen KraftFrequenz-Beziehung (Ezzaher et al. 1992; Mulieri et al 1992).

\subsubsection{Neurohumorale Veränderungen}

Erhöhte Katecholamin-Spiegel führen langfristig zu einer Herunterregulation und Desensibilisierung der $\beta_{1}$-Rezeptoren (Bristow et al. 1982; Brodde 1991). Die positiv inotrope Wirkung der Katecholamine als wichtiger Anpassungsmechanismus ist folglich bei Herzinsuffizienz vermindert. Durch die chronische Stimulation der verbliebenen $\beta_{1}$ Rezeptoren wird über eine Hypertrophie der Herzmuskulatur eine weitere Progredienz der Herzinsuffizienz bewirkt. Ferner wurde nachgewiesen, dass die Dauerstimulation der $\beta_{1^{-}}$ Rezeptoren zu einer Induktion von Apoptosevorgängen und somit zum Entstehen von Myokardnekrosen führt (Communal 1999).

Auch eine Dauerstimulation des RAAS führt durch die vasokonstriktorische Wirkung von Angiotensin II und die Wasser-retendierende Wirkung von Aldosteron zu einer weiteren Arbeitsbelastung des Herzens (Chatterjee 2005). Für Angiotensin II ist zudem ebenfalls eine proapoptotische Wirkung nachgewiesen (Packer 1992).

\subsubsection{Molekulare und elektrophysiologische Veränderungen}

Obwohl ätiologisch verschiedene Erkrankungen zu einer Herzinsuffizienz führen können, lassen sich auf molekularer Ebene am terminal insuffizienten Herzen stets gleiche Veränderungen finden. $\mathrm{Zu}$ diesen molekularen Veränderungen gehört vor allem eine gestörte Kalziumhomöostase, die die Hauptursache für die beeinträchtigte Kontraktion und Relaxation des Herzens darstellt (Gwathmey et al. 1987, Morgan et al. 1990, Hasenfuß et al. 1992).

So lässt sich bei Herzinsuffizienz eine verminderte Kalziumtransienten-Amplitude, eine Verlangsamung des Abfalls der Kalziumtransienten und ein erhöhter diastolischer Kalziumgehalt nachweisen (Beuckelmann und Erdmann 1992, Pieske et al. 1995).

Außerdem ist bei Herzinsuffizienz ein verminderter SR $\mathrm{Ca}^{2+}$-Gehalt zu verzeichnen (Lindner et al. 1998; Hobai und O'Rourke 2001; Baartscheer et al. 2003). Ursache hierfür ist hauptsächlich ein veränderter Expressionsgrad der SERCA2a und des NCX. Es ist vielfach 
gezeigt worden, dass die SERCA2a bei Herzinsuffizienz vermindert exprimiert wird, sowohl auf mRNA- als auch auf Proteinebene (Mercadier et al. 1990; Hasenfuss et al. 1994; Studer et al. 1994; Meyer et al. 1995). Konsekutiv wird angenommen, dass die hierdurch bedingte reduzierte SR $\mathrm{Ca}^{2+}$-Aufnahme einerseits zur diastolischen Dysfunktion mit enddiastolisch erhöhten Kalziumkonzentrationen und verlangsamtem $\mathrm{Ca}^{2+}$-Transienten-Abfall führt (Beuckelmann et al. 1995; Stüdeli et al 2006). Im Weiteren wird durch die verringerte Verfügbarkeit des systolisch freisetzbaren Kalziums eine verminderte Kontraktilität hervorgerufen.

Neben einer reduzierten SERCA2a-Expression können auch eine verminderte Phosphorylierung von Phospholamban (Schmidt et al. 1999; Schwinger et al. 1999; Dash 2001; Sande et al. 2002) sowie ein vermindertes SERCA2a/Phosphlamban-Verhältnis (Koss et al. 1997) zu der reduzierten Aktivität der SERCA2a beitragen.

Ferner konnte belegt werden, dass der NCX bei Herzinsuffizienz verstärkt exprimiert wird (Studer et al. 1994, Flesch et al. 1996, Bers et al. 2002) oder zumindest ein erhöhtes NCX/SERCA2a-Verhältnis vorliegt (Hasenfuss et al. 1999). Da folglich während der Diastole vermehrt Kalzium über den NCX verloren geht, trägt die NCX-Überexpression zum verminderten SR $\mathrm{Ca}^{2+}$-Gehalt bei.

Eine womöglich zusätzliche Ursache für den verminderten $\mathrm{SR} \mathrm{Ca}^{2+}$-Gehalt bei Herzinsuffizienz ist ein erhöhtes sog. diastolisches SR Ca ${ }^{2+}$-Leck über den RyR (Shannon et al. 2003), das vermutlich als Resultat einer gesteigerten Hyperphosphorylierung auftritt. Diese entsteht einerseits durch die bei Herzinsuffizienz gesteigerte $\beta$-adrenerge Stimulation und andererseits durch eine erhöhte Expression und Aktivität der $\mathrm{Ca}^{2+}-$ /Calmodulinabhängigen Proteinkinase II (CaMKII), eines Enzyms, das neben anderen Zielproteinen auch den RyR phosphoryliert und somit dessen Öffnungswahrscheinlichkeit erhöht (Maier et al. 2003; Ai et al. 2005; Curran et a. 2007; Sossalla et al. 2010).

Weitere pathophysiologische Mechanismen der Herzinsuffizienz sind eine verminderte ATPase-Aktivität der Myofibrillen (Alpert und Gordon 1962), die eine Störung des Querbrückenzyklus zur Folge hat, sowie eine verlängerte Aktionspotentialdauer, die auf eine Herunterregulation der Kalium-Ströme zurückzuführen zu sein scheint (Beuckelmann et al. 1993; Li et al. 2002).

\subsection{Bedeutung von Inotropika in der Herzinsuffizienztherapie}

Die systolische Herzinsuffizienz ist gekennzeichnet durch eine reduzierte Kontraktionskraft des Myokards. Seit Jahrzehnten wird daher intensiv an der Entwicklung und Etablierung postitiv inotroper Medikamente geforscht, die nicht nur kurzfristig die Kontraktionskraft des Herzens verbessern, sondern auch zur Langzeittherapie der chronischen Herzinsuffizienz eingesetzt werden können. Die einzigen positiv inotropen Generika, die derzeit von der 
Deutschen Gesellschaft für Kardiologie zur Langzeittherapie der chronischen Herzinsuffizienz empfohlen werden, sind Herzglykoside (Hoppe et al. 2005). Herzglykoside wie Digoxin und Digitoxin entfalten ihre Wirkung über eine Hemmung der membranständigen $\mathrm{Na}^{+} / \mathrm{K}^{+}$-ATPase. Dies führt zu einem Anstieg der intrazellulären $\mathrm{Na}^{+}-$Konzentration. Durch den fallenden $\mathrm{Na}^{+}$-Gradienten kommt es zu einer Hemmung des $\mathrm{NCX}$, so dass weniger Kalzium in den Extrazellulärraum eliminiert wird. Letztlich resultiert aus der so erhöhten intrazellulären $\mathrm{Ca}^{2+}-$ Konzentration eine Steigerung der Kontraktionskraft (Hauptman und Kelly 1999). Nachteile der Digitalis-Therapie sind jedoch eine enge therapeutische Breite und eine proarrhythmogene Wirkung (Fisch und Knoebel 1985), weshalb Digitalis-Präparate nur eingeschränkt angewendet werden können. Zudem wird die Prognose der Herzinsuffizienz durch Herzglykoside nicht verbessert (Ahmed et al. 2006).

Andere Inotropika wie z. B. Katecholamine werden vor allem zur vorübergehenden Therapie der akuten Herzinssuffizienz herangezogen. Kurzfristig verbessern diese via cAMPErhöhung sowohl die hämodynamische Situation als auch die Symptome der Patienten. Aufgrund diverser nachteiliger Effekte können sie jedoch nicht zur Langzeittherapie der chronischen Herzinssuffizienz eingesetzt werden. $\mathrm{Zu}$ diesen zählen $u$. a. eine negative Energiebilanz, d. h. ein hoher ATP- bzw. Sauerstoffverbrauch (Bendersky et al. 1981; Nikolaidis et al.2004), der die Kardiomyozyten auf Dauer schwächt und sogar schädigt, ein auf lange Sicht entstehender Wirkverlust der Katecholamine aufgrund einer Herunterregulation der adrenergen Rezeptoren (Chang et al. 1982; Colucci et al. 1987; Soltysinska et al. 2011) sowie eine zusätzliche chronotrope Wirkung (Burger et al. 2002), die die Herzarbeit und somit den Energieverbrauch weiter erhöht.

Zu den neuen Inotropika, die in den letzten Jahren etabliert wurden, zählen Phosphodiesterasehemmer und $\mathrm{Ca}^{2+}$-Sensitizer. Phosphodiesterasehemmer wie Milrinon, Amrinon und Enoximon führen wie Katecholamine zu einer Erhöhung des cAMP-Spiegels. Als Vorteil gegenüber den Katecholaminen bewirken sie jedoch keine Herunterregulation der adrenergen Rezeptoren, so dass langfristig kein Wirkverlust entsteht (Mager et al. 1991). Aufgrund beträchtlicher Nebenwirkungen wie z. B. Arrhythmien (Cuffe et al. 2002) werden Phosphodiesterasehemmer jedoch nur bei therapieresistenter schwerer Herzinsuffizienz eingesetzt.

$\mathrm{Ca}^{2+}$-Sensitizer wie Levosimendan sind Inotropika, die die $\mathrm{Ca}^{2+}$-Sensitivität der Myofilamente erhöhen (Haikala et al. 1995) und somit vorübergehend, d. h. erfahrungsgemäß für ca. zwei bis drei Wochen nach einmaliger Infusion, die Kontraktilität des Herzens verbessern (Nieminen et al. 2014). Nachteilig ist jedoch, dass $\mathrm{Ca}^{2+}$-Sensitzer nur intravenös appliziert werden können. Zudem können sie extreme Blutdrucksenkungen verursachen (Slawsky et al. 2000; Moiseyev et al. 2002), so dass sie nur auf Intensivstationen Anwendung finden. 


\subsection{Die SERCA2a-Modulatoren}

\subsubsection{SERCA2a-Stimulation in der Medizin}

Aufgrund der verminderten SERCA2a-Expression bei Herzinsuffizienz erscheint eine Stimulation der SERCA2a als neuer therapeutischer Ansatz vielversprechend. Tatsächlich ist es in Tiermodellen gelungen, mittels Gen-therapeutischer Überexpression der SERCA2a eine Erhöhung der Kontraktilität und der $\mathrm{Ca}^{2+}$-Transienten sowie eine Steigerung der Relaxationsgeschwindigkeit und der $\mathrm{Ca}^{2+}$-Extrusion zu erzielen (Hajjar et al. 1997; Baker et al. 1998; Meyer und Dillmann 1998; Yao et al. 1998; Müller et al. 2003; Maier et al. 2005). Des Weiteren konnte auch in Herzinsuffizienzmodellen durch eine adenoviral vermittelte SERCA2a-Überexpression eine Verbesserung der diastolischen und systolischen Funktionsparameter erreicht werden (Miyamoto et al. 2000; Müller et al. 2003; Byrne et al. 2008; Mi et al. 2009; Mariani et al. 2011; Xin et al. 2011). Ferner zeigten del Monte et al. 2004 und Prunier et al. 2008, dass eine Überexpression der SERCA2a in einem Ischämie/Reperfusionsmodell der Ratte bzw. von Schweinen zu einem verminderten Auftreten von Arrhythmien führt. Derartige Ergebnisse konnten auch Lyon et al. 2011 und Cutler et al. 2012 an Herzinsuffizienzmodellen bestätigen. Neben einer verbesserten linksventrikulären Funktion konnten $\mathrm{Fu}$ et al. 2012 in einem Herzinsuffizienz-Modell mit Hunden auch reduzierte inflammatorische und Stress- assoziierte Proteine im Serum nachweisen.

Die adenoviral vermittelte SERCA2a-Überexpression wurde darüber hinaus auch in präklinischen Untersuchungen mit großen Säugetieren getestet, die hier ebenfalls zu einer Verbesserung der kontraktilen Funktion führte (Fu et al.2008; Kawase et al. 2008). Momentan sind bereits klinische Untersuchungen dabei, die Sicherheit und positiven Effekte des SERCA2a-Gentransfers am Menschen zu prüfen. In der CUPID-Studie der Arbeitsgruppe Jessup et al. 2011 wurden 39 Patienten nach einem Zeitraum von 6 und 12 Monaten nach einer Adenovirus Typ 1 - vermittelten SERCA2a-Überexpression untersucht. Die Applikation des viralen Vektors erfolgte intrakoronar. Es zeigte sich eine Verbesserung oder zumindest Stabilisierung der Symptome gemäß NYHA-Klassifikation, der Leistung in einem 6-minütigen Geh-Test, des Biomarkers NT-pro-BNP und der linksventrikulären Funktion. Nach drei Jahren konnte bei der gleichen Patientengruppe eine Reduktion des Wiederauftretens kardiovaskulärer Ereignisse verzeichnet werden (Zsebo et al. 2014). Jedoch scheinen sich präexistente Antikörper gegen den Adenovirus Typ 1 limitierend auf die Gentherapie auszuwirken (Greenberg et al. 2016). 


\subsubsection{Entwicklung der SERCA2a-Modulatoren}

Da neben einer Gen-vermittelten Steigerung der SERCA2a-Aktivität auch eine medikamentöse Beeinflussung der SERCA2a sinnvoll erscheint, wurde im Rahmen des EUGeneHeart-Projektes nach Stoffen gesucht, die sich durch eine strukturbedingte Affinität zur SERCA2a auszeichnen. Die Entwicklung dieser neuen SERCA2a-Modulatoren erfolgte durch die Pharmaunternehmen GreenPharma (Orléans, Frankreich) und Endotherm (Saarbrücken, Deutschland).

Vorraussetzung hierfür war zunächst die Ermittlung der exakten dreidimensionalen Molekülstruktur der SERCA2a. Diese erfolgte computergestützt, d. h. in silico, durch eine sog. Kristallstrukturanalyse. Prinzip dieses Verfahrens ist, mithilfe geeigneter Strahlung wie z. B. Röntgenstrahlung ein für die Kristallstruktur des Zielproteins charakteristisches Beugungsmuster zu bestimmen, aus dem sich die Elektronendichte und somit die Lage der Atome des Proteins ablesen lässt.

Im nächsten Schritt wurden die Datenbänke der Pharmaunternehmen virtuell nach Molekülen durchsucht, deren Struktur zu derjenigen der SERCA2a passen. Mithilfe einer erneuten Strukturanalyse der SERCA2a zusammen mit dem gebundenen Wirkstoff ließ sich anschließend ermitteln, wie die Wechselwirkung zwischen den beiden Molekülen aussieht. Auf diese Weise konnten insgesamt 17 Stoffe gefunden werden, die anschließend synthetisiert und im Rahmen dieser Arbeit bezüglich ihrer Eigenschaften in vitro untersucht wurden. 


\subsection{Zielsetzung und Fragestellungen}

Das Ziel der vorliegenden Arbeit bestand darin, den Einfluss der insgesamt 17 verschiedenen SERCA2a-Modulatoren auf die Kontraktilität und den $\mathrm{Ca}^{2+}$-Haushalt von Herzmuskelzellen zu untersuchen. Zunächst wurden die Stoffe mittels Epifluoreszenzverfahren an isolierten Herzmuskelzellen der Ratte charakterisiert. Diejenigen SERCA2a-Modulatoren, die in dieser Versuchsreihe als direktes Maß für eine Steigerung der SERCA2a-Funktion eine Beschleunigung der Relaxation und Kalziumelimination oder eine Tendenz zur positiven Inotropie als indirektes Maß zeigten, wurden weitergehend mittels Messung des SR $\mathrm{Ca}^{2+}$-Gehaltes und Muskelstreifenexperimenten am humanen, insuffizienten Myokard untersucht.

Im Einzelnen ergaben sich folgende Fragestellungen:

I. Charakterisierung mittels Epifluoreszenzverfahren an isolierten Herzmuskelzellen der Ratte

1. Führen die SERCA2a-Modulatoren zu Veränderungen der Kontraktilität?

2. Haben die SERCA2a-Modulatoren Auswirkungen auf die $\mathrm{Ca}^{2+}$-Transienten-Amplitude?

3. Führen die SERCA2a-Modulatoren zu Änderungen im Relaxationsverhalten der Zellen?

4. Haben die SERCA2a-Modulatoren Auswirkungen auf die $\mathrm{Ca}^{2+}$-Abfallgeschwindigkeit?

5. Führen die SERCA2a-Modulatoren zu einem veränderten $\mathrm{SR} \mathrm{Ca}^{2+}$-Gehalt?

II. Charakterisierung mittels Muskelstreifenexperiment am humanen, insuffizienten Myokard

1. Haben die SERCA2a-Modulatoren Einfluss auf die Kontraktilität?

2. Führen die SERCA2a-Modulatoren zu Änderungen im Relaxationsverhalten der Muskelstreifen? 


\section{Material und Methoden}

\subsection{Epifluoreszenzexperimente}

\subsubsection{Isolation ventrikulärer Kardiomyozyten aus Rattenherzen}

Für die Epifluoreszenzexperimente wurden ventrikuläre Kardiomyozyten aus sechs Monate alten männlichen Wistar-Ratten verwendet. Als Voraussetzung lag eine Genehmigung der niedersächsischen Tierschutzbehörde vor (AZ T14.06). Die im Folgenden beschriebene Methode zur Myozytenisolation kommt bereits seit mehreren Jahren erfolgreich zur Anwendung (Maier et al. 2003; Kohlhaas 2006; Rokita 2008).

Zur Explantation der Herzen wurde die zu untersuchende Ratte zunächst in einer luftdichten Kammer mit einer ihrem Gewicht entsprechenden Menge des Inhalationsnarkotikums Isofluran (Abbott $\mathrm{GmbH}$, Wiesbaden) anästhesiert und anschließend durch zervikale Dislokation getötet. Im nächsten Schritt wurde die Bauchdecke mit einer Präparierschere eröffnet, das Zwerchfell durchtrennt und das Herz vom Perikard befreit. Um eine Thrombusbildung im Herzen zu vermeiden, wurden anschließend 0,5 ml (2500 I.E.) HeparinNatrium (Ratiopharm, Ulm) in das linke Herzohr injiziert. Unter Belassen eines möglichst großen Aortenstumpfes wurden nun die Gefäße des Herzens durchtrennt und das Herz in einer Petrischale mit $\mathrm{Ca}^{2+}$-haltiger Isolationstyrode $\left(0,75 \mathrm{mM} \mathrm{CaCl}_{2}\right.$, Temperatur: $0^{\circ} \mathrm{C}$, siehe Tabelle 2.1) vorsichtig ausgedrückt, um restliches Blut zu entfernen. Anschließend wurde unter einem binokularen Mikroskop die Aorta ascendens über eine Injektionskanüle gestülpt und mithilfe einer kleinen Gefäßklemme und eines Fadens an dieser fixiert. Danach erfolgte das Anschließen des kanülierten Herzens an eine Langendorff-Perfusionsapparatur (Langendorff 1895), die in Abbildung 2.1 schematisch dargestellt ist.

Das an das Langendorff-Setup angeschlossene Herz wurde nun zunächst hinsichtlich seiner Vitalität geprüft: Durch etwa 5-10minütige Perfusion mit $\mathrm{Ca}^{2+}$-haltiger Isolationstyrode $(1,25$ $\mathrm{mM} \mathrm{CaCl} 2$, Temperatur: $37^{\circ} \mathrm{C}$, Begasung mit $100 \%$ Sauerstoff) bei einem Fluss von $8 \mathrm{ml} / \mathrm{h}$ wurde das Herz zum Schlagen angeregt. Anschließend wurde auf $\mathrm{Ca}^{2+}$-freie Isolationstyrode gewechselt, bis nach etwa 20 Minuten die Muskelkontraktionen aussetzten. Dieser Wechsel diente einerseits zur Reduktion des Energieverbrauchs der Herzmuskelzellen, andererseits zur Auflösung $\mathrm{Ca}^{2+}$-abhängiger interzellulärer Verbindungen, die z. B. durch Cadherine oder Integrine vermittelt werden. Im nächsten Schritt wurde das nicht mehr kontrahierende Herz mit Enzymlösung (siehe Tabelle 2.1) perfundiert, bis sich das Herzgerüst auflöste. Als Zeichen für einen hinreichenden Verdau galten ein Farbwechsel des Herzens von vorher rot zu muskatbraun und eine abnehmende Festigkeit des Myokards. Anschließend wurde das Herz vom Langendorff-Setup entfernt und in eine Petrischale mit erwärmter Enzymlösung (Temperatur: $37^{\circ} \mathrm{C}$ ) überführt. Hier wurden die Vorhöfe entfernt und die Ventrikel mit einer Schere vorsichtig in kleine Teile geschnitten. Nach kurzem Schwenken im Wasserbad wurde 
die so entstandene Zellsuspension zum Entfernen von Fettzellen und Zellverbänden durch eine Nylon-Gaze (Porengröße $200 \mu \mathrm{m}$ ) gefiltert und die Herzmuskelzellen in ein FalconRöhrchen überführt. Nun erfolgte ein langsamer Kalzium-Aufbau, um die Zellen wieder an Kalzium zu gewöhnen: Nach erster Sedimentation wurde der Überstand abgesaugt und die Zellen in Isolationstyrode mit 0,125 mM Kalzium resuspendiert, um sie anschließend wieder sedimentieren zu lassen. Diese Schritte wurden insgesamt drei Mal mit jeweils steigender Kalzium-Konzentration wiederholt $(0,25 \mathrm{mM} ; 0,5 \mathrm{mM} ; 1 \mathrm{mM})$. Nach der letzten Sedimentation wurden die Zellen in ca. $15 \mathrm{ml}$ eines modifizierten M199-Nährmediums (siehe Tabelle 2.1) gegeben und waren nach Zählung in einer Neubauer Zählkammer messbereit.

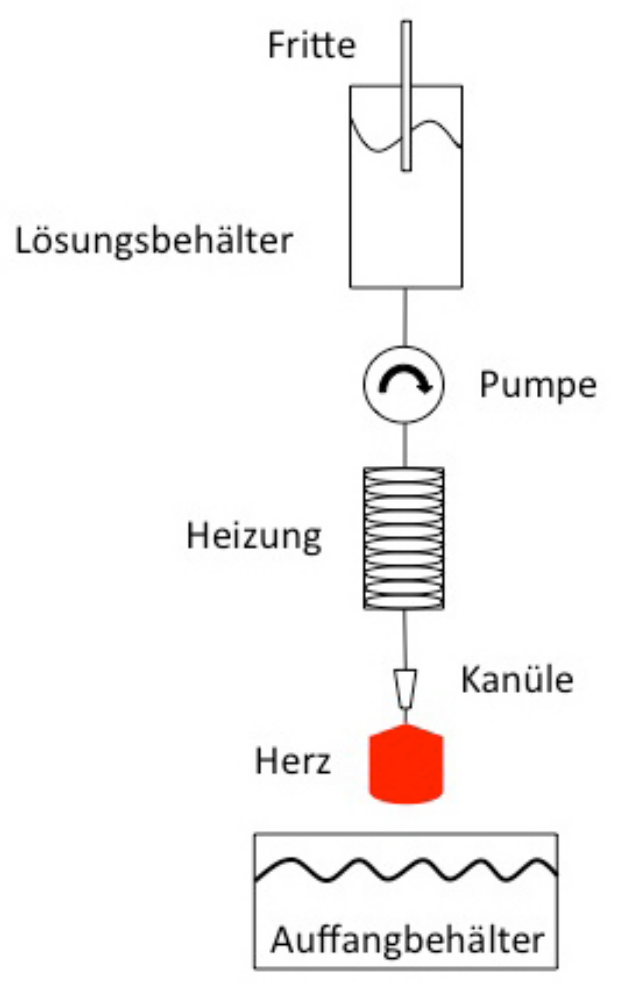

\begin{abstract}
Abb. 2.1 Schematische Darstellung der Langendorff-Perfusionsanlage.

Das kanülierte Herz wird mit der in dem temperierten Lösungsbehälter und unter Begasung stehender Enzymlösung perfundiert und das Zellmaterial in einem zweiten Behälter aufgefangen. Der Fluss wird über eine Pumpe reguliert.
\end{abstract}

\title{
2.1.2 Messung von intrazellulären $\mathrm{Ca}^{2+}$-Transienten und der Myozyten- verkürzung
}

Eine der verwendeten Messmethoden dieser Arbeit stellte die Epifluoreszenz-Mikroskopie dar, mithilfe derer die simultane Messung von fraktioneller Verkürzung der Sarkomerlänge der Kardiomyozyten einerseits und von intrazellulären Kalziumkonzentrationsveränderungen als Funktion der Zeit, dem sog. intrazellulären $\mathrm{Ca}^{2+}$-Transienten, andererseits ermöglicht wurde. Im Folgenden soll dieses Verfahren näher beschrieben werden. 


\subsubsection{Grundlagen des Epifluoreszenzverfahrens}

Die Epifluoreszenz-Mikroskopie ist eine Form der Auflicht-Mikroskopie, bei der das zu untersuchende Objekt mit fluoreszierenden Farbstoffen, sogenannten Fluorochromen, beladen wird. Werden diese Farbstoffe mit Licht einer bestimmten Wellenlänge angeregt (sog. Anregungslicht), so emittieren sie Licht geringerer Energie, d. h. einer größeren Wellenlänge. Diesem Verhalten liegt die strukturelle Eigenschaft vieler Fluoreszenzfarbstoffe zugrunde, aromatische Ringstrukturen mit delokalisierten Elektronen zu besitzen, die leicht mit der Umgebung wechselwirken können. Durch Absorption von Energie in Form von Photonen gelangen die Elektronen auf ein höheres Energieniveau, fallen jedoch gleich wieder auf ihr ursprüngliches Energieniveau zurück. Die aufgenommene Energie wird hierbei wieder freigesetzt in Form von Fluoreszenzlicht (Emissionslicht). Allerdings wird nicht die gesamte aufgenommene Energie in Lichtenergie umgewandelt, so dass das emittierte Licht etwas energieärmer, d. h. langwelliger ist. Die Differenz der beiden Wellenlängen zwischen ein- und ausgehenden Photonen wird als Stokes'sche Verschiebung bezeichnet (Lakowicz 1983; Grynkiewicz et al. 1985).

\subsubsection{Eigenschaften des Kalzium-sensitiven Farbstoffs Fluo-3 AM}

In dieser Arbeit wurde der Kalzium-sensitive Farbstoff Fluo-3 AM verwendet (Firma MoBiTec, Göttingen, Deutschland) (Minta et al. 1989). Wie auch andere Kalzium-sensitive Farbstoffe (z. B. Fura-2 und Indo-1) leitet sich Fluo-3 AM von Kalzium-Chelatoren ab. Durch Bindung von $\mathrm{Ca}^{2+}$-lonen und anschließender Bestrahlung mit Licht einer bestimmten Wellenlänge kommt es zu einer Fluoreszenz, dessen Intensität um das Hundertfache gesteigert ist und eng mit der Kalziumkonzentration der Zelle korreliert. Diese Eigenschaft macht man sich zunutze, um Kalziumkonzentrationsverschiebungen in Herzmuskelzellen während eines Kontraktionszyklus sichtbar zu machen.

Da Fluo-3 an sich ein hydrophiler Farbstoff ist und somit die Membran der Kardiomyozyten nicht überwinden könnte, wird er in seiner Herstellung an einen Azetoxymethylester (AM) gekoppelt. In dieser lipophilen Form kann er die Zellmembran passieren. Zytosolische Esterasen spalten den Azetoxymethylester ab, so dass der nun wieder hydrophile Farbstoff die Zelle nicht verlassen kann.

Bei den Fluoreszenzfarbstoffen unterscheidet man ratiometrische von nicht-ratiometrischen Farbstoffen. Fluo-3 AM gehört zu den nicht-ratiometrischen Farbstoffen. Als solcher besitzt er feste Absorptions- und Emissionsmaxima, die sich nicht in Abhängigkeit von der Kalziumkonzentration verändern. Im Gegensatz zu ratiometrischen Farbstoffen wie z. B. Indo-1 AM oder Fura-2 AM lässt er also keine quantitativen Aussagen über Kalziumkonzentrationen zu. Als Vorteil bietet Fluo-3 aber ein sehr gutes Verhältnis von Fluoreszenzsignal zu Hintergrundrauschen und ermöglicht somit saubere Messsignale. Das 
Absorptionsmaximum von Fluo-3 AM liegt bei $488 \mathrm{~nm}$, das mithilfe eines geeigneten Anregungsfilters aus dem Licht einer Xenonlampe erzeugt werden kann. Sein Emissionsmaximum liegt im Wellenlängenbereich von $525 \mathrm{~nm}$ (siehe Abb. 2.2).

A

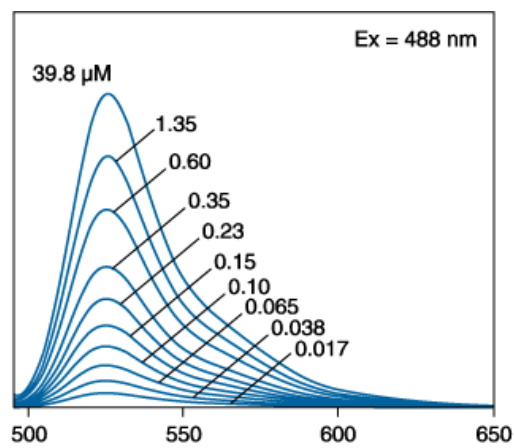

B

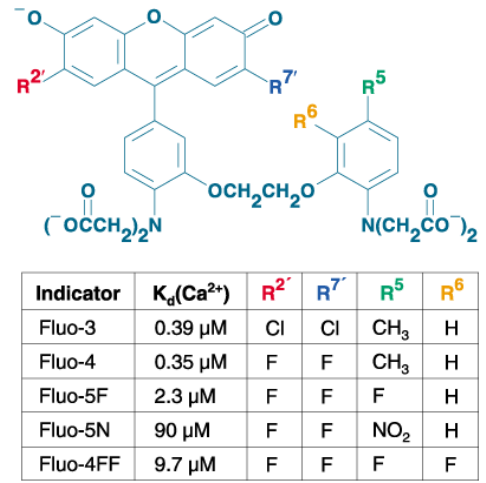

Abb. 2.2 A: Emissionspektrum von Fluo-3

X-Achse: Emissionswellenlänge in nm. Y-Achse: Intensität der Emission. Die Zahlen im Diagrammen entsprechen der freien $\mathrm{Ca}^{2+}-$ Konzentration.

B: Strukturformel unterschiedlicher Fluo-Analoga.

(Modifiziert nach "The Molecular Probes Handbook" 2010, Abschnitt 19.3; mit freundlicher Genehmigung durch Thermo Fisher Scientific Inc.)

\subsubsection{Das Epifluoreszenz-Setup}

Das in dieser Arbeit verwendete Epifluoreszenz-Setup der Firma IonOptix (IonOptix, Milton, USA) ermöglichte die zeitgleiche Aufzeichnung und Darstellung der Längenänderung der Sarkomere einerseits und der Änderung der Kalziumkonzentration während der Myozytenverkürzungen andererseits. Im Folgenden soll die Erzeugung und Verarbeitung beider Messsignale näher beschrieben werden. Abbildung 2.3 bietet einen schematischen Überblick über das Epifluoreszenz-Setup und den Strahlengang durch das Mikroskop. 


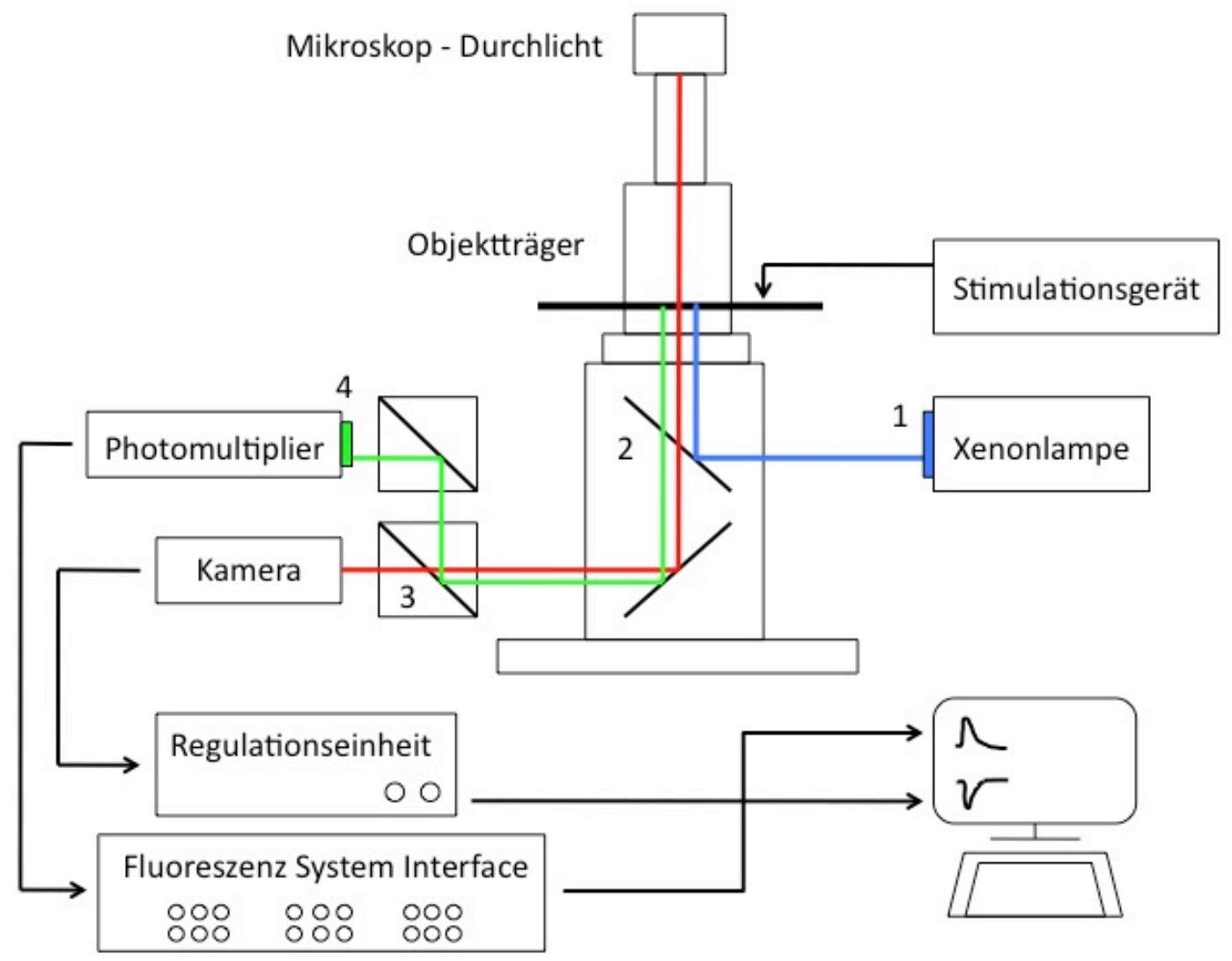

Abb. 2.3 Schema des Epifluoreszenz-Setups und des Strahlenganges im Mikroskop

Die schwarzen Pfeile deuten die Vernetzung der Geräte untereinander an. Die blaue Linie stellt das Anregungslicht und die grüne Linie das Emissionslicht dar. Die rote Linie repräsentiert das Durchlicht, welches von der Kamera aufgenommen wird.

1. Filter (D480 $\pm 15 \mathrm{~nm}$ ); 2. Dichroitischer Spiegel (D505 DCLP); 3. Dichroitischer Spiegel (685 DCLP);

4. Filter $(535 \pm 20 \mathrm{~nm})$.

\section{Messung der $\mathrm{Ca}^{2+}-$ Transienten während der Myozytenverkürzung:}

Zur maximalen Anregung des Farbstoffes Fluo-3 AM (488nm) wurde mithilfe eines Anregungsfilters (D480 $\pm 15 \mathrm{~nm}$ ) aus dem Weißlicht einer Xenonlampe (Xenon Short Arc Lamp Typ UXL-75XE, Ushio Inc., Japan) ein Anregungslicht mit adäquater Wellenlänge erzeugt. Über einen dichroitischen Spiegel (505 DCLP) wurde das Anregungslicht auf das Myozytenpräparat abgelenkt, während das langwelligere emittierte Licht des Farbstoffs $(\sim 535 \pm 20 \mathrm{~nm})$ zusammen mit dem Durchlicht des Mikroskops (Nikon Eclipse TE 2000-U, Firma Nikon Instruments Europe BV, Amsterdam, Niederlande) diesen Spiegel passieren konnte und über einen Seitenausgang des Mikroskops auf einen weiteren dichroitischen Spiegel (685 DCLP) weitergeleitet wurde. Dieser diente zur Trennung des Durchlichtes, das zur Bestimmung der Myozytenverkürzung in eine Kamera geleitet wurde, vom Emissionslicht des Farbstoffs, das auf einen Photomultiplier (electron tubes limited, USA) gelenkt wurde. 
Entsprechend dem Emissionmaximum des Fluo-3 von 525 nm war dem Photomultiplier noch ein Filter (D $535 \pm 20 \mathrm{~nm}$ ) vorgeschaltet, um Streulicht heraus zu filtern.

Hersteller aller erwähnten Filter ist die Firma Chroma Technology Corp, Bellows Falls, USA. Das optische $\mathrm{Ca}^{2+}$-Fluoreszenz-Signal wurde nun im Photomultiplier in ein elektrisches transformiert, vom Fluoreszenz System Interface (Ion Optix, Milton, USA) in für den Computer lesbare Daten umgeschrieben und schließlich durch eine Software (lonWizard Version 5.0, Firma IonOptix, Milton, USA) auf dem Computerbildschirm dargestellt.

\section{Messung der fraktionellen Myozytenverkürzung:}

Im Sinne eines Durchlichtmikroskops wurde der Kardiomyozyt mit rotem Licht einer Wellenlänge von >650 nm durchleuchtet, welches anschließend einer Myozytenkamera (MyoCam $^{\mathrm{TM}}$, Firma lonOptix, Milton, USA) zugeleitet wurde. Durch diese wurden die Sarkomerlängen des Kardiomyozyten visualisiert und vermessen und durch das lonWizard Programm am Computer graphisch dargestellt. Mittels der Software lonWizard Analyze wurden die gemittelten Sarkomerlängen bezüglich ihrer fraktionellen Zellverkürzung sowie ihrer Relaxationskinetik ausgewertet.

\subsubsection{Versuchsdurchführung}

Zunächst wurden die Versuchskammern - Spezialanfertigungen aus einem Kunststoffrahmen mit dünnem Glasboden (siehe Abb. 2.4) - gründlich gereinigt, mit $2 \mu$ des Adhäsionsproteins Laminin (Sigma-Aldrich, St. Louis, USA) zum Fixieren der Zellen beschichtet und bei Raumluft fünf Minuten getrocknet.

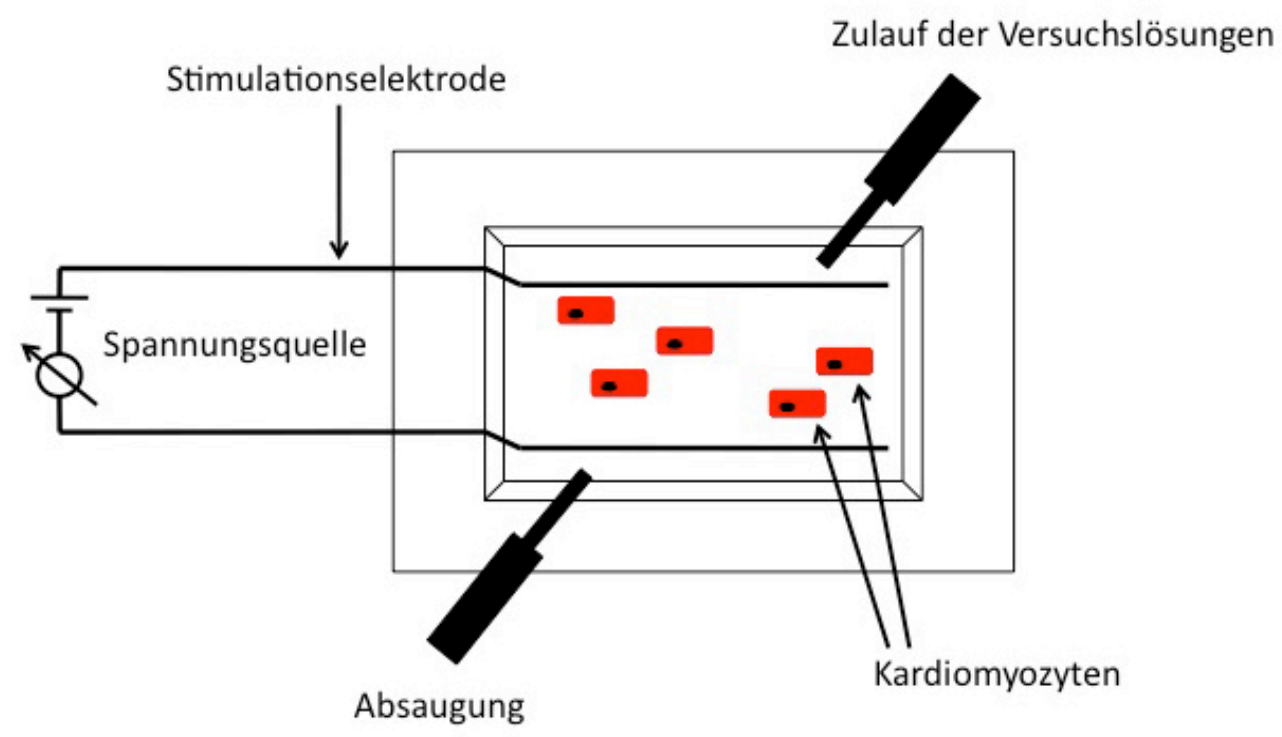

Abb. 2.4 Schematische Darstellung einer Versuchkammer 
Nun wurden $200 \mu \mathrm{l}$ der isolierten Herzmuskelzellen auf eine Versuchskammer ausplattiert. Nach ca. zehnminütiger Sedimentationszeit wurden der nicht fixierte Zellüberstand abpipettiert und anschließend die fixierten Zellen mit $200 \mu \mathrm{l}$ des Fluo-3 AM - Farbstoffs (siehe Tabelle 2.2) lichtgeschützt im Inkubationsschrank $\left(37^{\circ} \mathrm{C}\right.$ bei $5 \% \mathrm{CO}_{2}$ und $95 \%$ iger Luftfeuchtigkeit) für 15 Minuten inkubiert.

Nach der Inkubation wurde die Versuchskammer in die Halterung des Mikroskops gelegt, der Zulauf der Versuchslösungen und die Absaugung an den vorgesehenen Öffnungen angebracht und die Stimulationselektroden am Versuchskammerrahmen befestigt. Über einen Temperaturfühler einer externen Heizung am Zulauf wurde eine Versuchskammertemperatur von $35 \pm 2^{\circ} \mathrm{C}$ eingestellt.

Nach dem Einsetzen der Versuchskammer in das Mikroskop konnte mit der Stimulation (Myopacer, Firma lonOptix, Milton, USA) begonnen werden. Die Spannung betrug hierbei ca. $20-25 \mathrm{mV}$, was einem Wert von etwa $25 \%$ über der Reizschwelle entsprach. Da die Herzmuskelzellen von Ratten auf eine Stimulationsfrequenz von $1 \mathrm{~Hz}$ mit starken Schwankungen in der Myozytenverkürzung reagierten (siehe Abb. 2.5), wurde mit einer Frequenz von $2 \mathrm{~Hz}$ stimuliert, bei der diese Schwankungen nicht auftraten. Nur bei den Messungen der koffeininduzierten $\mathrm{Ca}^{2+}$-Transienten (siehe unten) wurde zur besseren Handhabung eine Stimulationsfrequenz von $1 \mathrm{~Hz}$ gewählt.

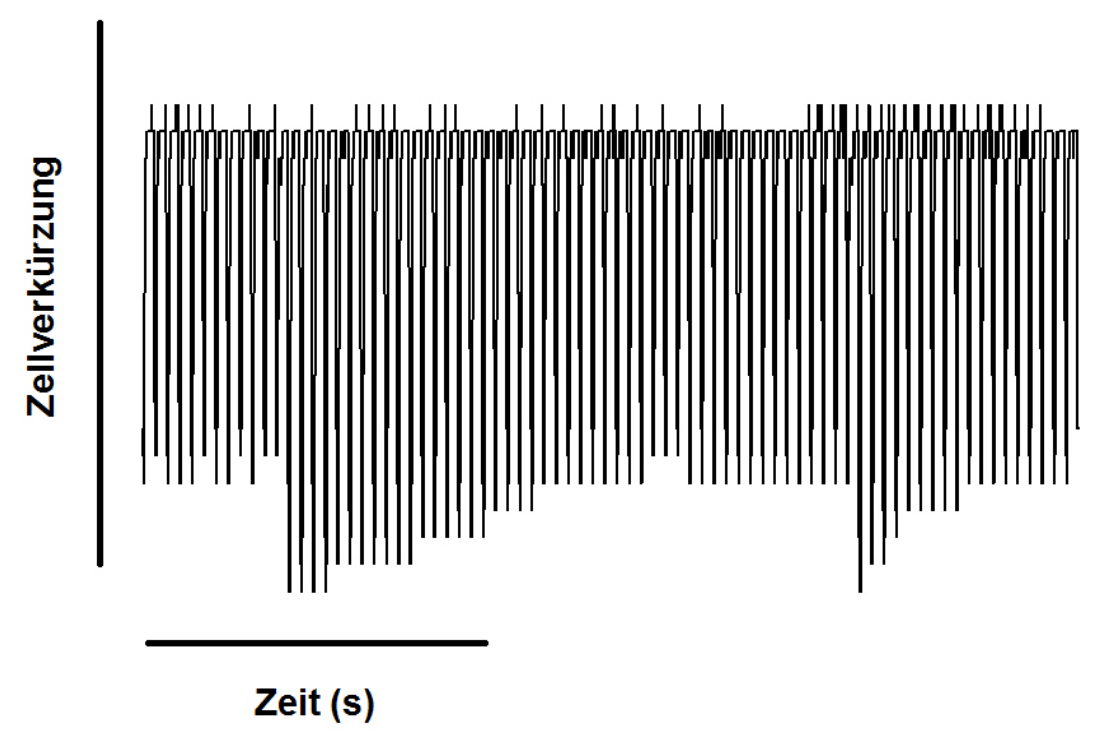

Abb. 2.5 Originalregistrierung der Zellverkürzung einer Kardiomyozyte bei Stimulation mit $1 \mathrm{~Hz}$ Es zeigen sich starke Schwankungen in der Myozytenverkürzung.

Zur Elimination überschüssigen Farbstoffs und störenden Zelldetritus wurden die Zellen zunächst fünf Minuten lang mit Normaltyrode (siehe Tabelle 2.3) bei einer konstanten Flussgeschwindigkeit von $40 \mathrm{ml} / \mathrm{h}$ gespült. Währenddessen wurde eine geeignete Zelle aus der Versuchskammer ausgewählt und in dem Messfenster in Position gebracht. Als Auswahlkriterien galten eine gut sichtbare Querstreifung, eine fraktionelle Zellverkürzung von 
mindestens $1,5 \%$ und das Fehlen von Hinweisen auf beginnenden Zelltod, wie z. B. intrazellulären Verklumpungen.

\subsubsection{Messprotokoll}

Nachdem ein sogenanntes steady state der Zellverkürzung während des Spülens mit der Normaltyrode erreicht wurde, d. h. nachdem sich die Amplitude der Zellverkürzung nicht mehr änderte, wurde kurzzeitig der Fluoreszenzfilter zur Messung der $\mathrm{Ca}^{2+}$-Transienten eingedreht, um das Anregungslicht auf die Zellen zu lenken. Die Messung der $\mathrm{Ca}^{2+}-$ Transienten erstreckte sich nicht über den gesamten Zeitraum einer Messung, um ein Ausbleichen des Farbstoffs zu verhindern. Anschließend sollte das Verhalten der Zelle auf den zu untersuchenden Stoff bei steigender Konzentration $(0,1 \mu \mathrm{M}, 1 \mu \mathrm{M}$ und $10 \mu \mathrm{M})$ beobachtet werden (siehe Tabelle 2.4). Hierzu wurden die Zellen im ersten Schritt mit 0,1 $\mu \mathrm{M}$ - Stofflösung bis zum Erreichen des steady states, mindestens aber für 5 Minuten, superfundiert und abschließend wieder die Fluoreszenz kurzzeitig gemessen.

Mit den $1 \mu \mathrm{M}$ - und $10 \mu \mathrm{M}$ - Stofftyroden wurde ebenso verfahren. Da alle in dieser Arbeit zu untersuchenden Stoffe in DMSO gelöst waren, wurde der Normaltyrodenlösung der Kontrollzellen entsprechend 0,1 $\mathrm{M}, 1 \mu \mathrm{M}$ bzw. $10 \mu \mathrm{M}$ DMSO hinzugefügt.

Stoffe, die in dieser Versuchsreihe Hinweise auf eine Beschleunigung der Relaxation oder einen positiv inotropen Effekt ergaben, wurden in folgenden Experimenten näher untersucht. In diesen Experimenten wurde bei den oben als interessant herausgefilterten Stoffen zur Bestimmung des Kalziumgehaltes des sarkoplasmatischen Retikulums Messungen der koffeininduzierten $\mathrm{Ca}^{2+}$-Transienten durchgeführt. Zur Messung des $\mathrm{SR} \mathrm{Ca}^{2+}$-Gehaltes mittels koffeininduzierter $\mathrm{Ca}^{2+}$-Transienten wurde nach Erreichen des steady states bei $1 \mathrm{~Hz}$ die elektrische Stimulation unterbrochen und eine Sekunde nach dem letzten Stimulationsimpuls mithilfe einer kleinen Injektionsnadel ein Tropfen koffeinhaltiger Tyrode (10 mM, siehe Tabelle 2.4) direkt auf die Zelle gegeben. Koffein bewirkt eine Öffnung der $\mathrm{Ca}^{2+}$-Freisetzungskanäle des SR (RyR) und damit eine Entleerung des gesamten Kalziums ins Zytosol. Somit stellt die Amplitude des Koffein-induzierten $\mathrm{Ca}^{2+}$-Transienten einen geeigneten Indikator für den SR $\mathrm{Ca}^{2+}$-Gehalt dar (BERS 2001).

\subsubsection{Datenauswertung}

Die Auswertung der erhobenen Daten wurde mithilfe einer speziellen Software (Ion Wizard Analyze Version 5.0, Firma IonOptix, Milton, USA) ermöglicht. Die hiermit erstellten Rohdaten wurden in das Programm Microsoft Excel (Microsoft Office Version 2003, Microsoft Corporation, Redmond, USA) eingefügt und weiter ausgewertet. Aus den ausgewerteten Daten wurden anschließend Abbildungen mithilfe des Programms SigmaPlot Version 8.0 (Systat Software $\mathrm{GmbH}$, Erkrath) angefertigt. 


\subsubsection{Fraktionelle Zellverkürzung und $\mathrm{Ca}^{2+}$ - Transienten $\mathrm{F} / \mathrm{F}_{0}$}

Die fraktionelle Zellverkürzung errechnete sich als Verkürzung der Zelle in Prozent der Ausgangszellänge:

Fraktionelle Zellverkürzung in \% der Ruhezelllänge =

Diastolische Sarkomerlänge - Systolische Sarkomerlänge x100

Diastolische Sarkomerlänge

Formel 2.1 Berechnung der fraktionellen Zellverkürzung

Da es sich bei dem Farbstoff Fluo-3 AM um einen nicht-ratiometrischen Farbstoff handelte und somit die Fluoreszenzintensität von der Farbstoff- und Kalziumkonzentration abhing, konnte die absolute Kalziumkonzentration nur indirekt berechnet werden. Die Amplitude der $\mathrm{Ca}^{2+}$-Transienten $\mathrm{F} / \mathrm{F}_{0}$ ergab sich aus dem Quotienten der maximalen Fluoreszenzintensität während der Systole $\left(F_{\text {Peak }}\right)$ und der Fluoreszenz der relaxierten Zelle während der Diastole $\left(F_{\text {Baseline}}\right)$. Von beiden Werten musste jeweils noch die Hintergrundfluoreszenz, die in unmittelbarer Umgebung der Zelle gemessen worden war, abgezogen werden. Somit ergab sich folgende Formel für $F / F_{0}$ :

$$
F / F_{0}=\frac{F_{\text {Baseline }}-F_{\text {Hintergrund }}}{F_{\text {Peak }}-F_{\text {Hintergrund }}}
$$

Formel 2.2 Berechnung der Amplitude der $\mathrm{Ca}^{2+}$ - Transienten $\mathrm{F} / \mathrm{F}_{0}$

\subsubsection{Relaxationszeit}

Die Relaxationszeit kann als Maß für die Funktion der SERCA2a herangezogen werden, da diese bei der Ratte für die Ausschleusung von etwa 90\% des Kalziums aus dem Zytosol in das sarkoplasmatische Retikulum verantwortlich ist. Der NCX befördert die restlichen $10 \%$ des Kalziums aus der Zelle. In dieser Arbeit wurde diejenige Relaxationszeit bestimmt, die der Kardiomyozyt benötigt, um nach Kontraktion auf $50 \%$ der Ausgangszelllänge $\left(R Z_{50}\right)$ zu relaxieren. Zur Beurteilung der Geschwindigkeit der sarkoplasmatischen Kalziumaufnahme wurde der Abfallsexponent $\tau$ herangezogen. $\tau$ entspricht dem Krümmungsgrad der in Abb. 2.6 dargestellten Exponentialfunktion und gibt somit die Geschwindigkeit der $\mathrm{Ca}^{2+}$ Transienten-Abnahme an. Ein großer Wert für $\tau$ ergibt einen flachen Abfall der Exponentialfunktion, d. h. er beschreibt in diesem Fall eine langsame zytosolische Kalziumelimination bzw. eine geringe SERCA2a-Aktivität. Andersherum beschreibt ein kleiner $\tau$-Wert einen schnellen Abfall der Exponentialfunktion bzw. eine schnelle zytosolische Kalziumelimination und hohe SERCA2a-Aktivität. 


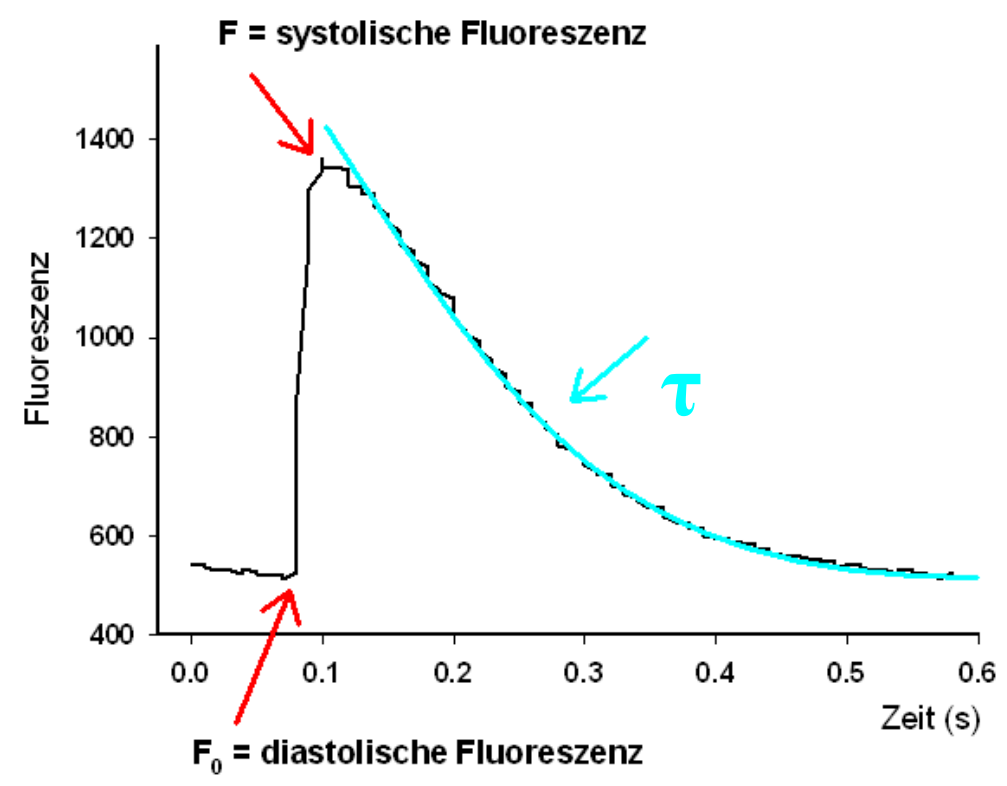

Abb. 2.6 Exemplarischer Kalziumtransient

Der Abfallsexponent $\tau$ entspricht dem Krümmungsgrad der türkis dargestellten Exponentialfunktion und beschreibt somit die Geschwindigkeit der $\mathrm{Ca}^{2+}$-Transienten -Abnahme

\subsubsection{Bestimmung des SR $\mathrm{Ca}^{2+}$-Gehaltes und der fraktionellen SR $\mathrm{Ca}^{2+}$-Freisetzung}

Wie oben beschrieben, wird der $\mathrm{SR} \mathrm{Ca}^{2+}$-Gehalt mithilfe der Koffein-induzierten $\mathrm{Ca}^{2+}$ Transienten bestimmt. Die Transienten nach der Koffein-Applikation werden direkt mit denen in der Grundstimulation ins Verhältnis gesetzt.

\subsection{Muskelstreifenexperimente}

\subsubsection{Gewinnung der humanen Muskelstreifen}

In der vorliegenden Arbeit wurden für die Muskelstreifenexperimente ausschließlich humane Muskelstreifen aus explantierten, terminal insuffizienten Herzen verwendet. Die Herzen stammten von Transplantationspatienten der Klinik für Thorax- und Kardiovaskularchirurgie des Herz- und Diabeteszentrums in Bad Oeynhausen (siehe Tab. 2.6 und Tab. 2.7). Alle in dieser Arbeit durchgeführten Muskelstreifenexperimente wurden von der lokalen Ethikkommission (Ifd. Antragsnummer 31/9/00) genehmigt.

Zur Präparation wurde das Herz in eine 2,3-Butandion-Monoxim (BDM)-haltige Lösung (siehe Präparierlösung, Tabelle 2.5) überführt (Mulieri et al. 1989). Indem es die Bindungsstelle für Kalzium am Troponin $C$ und die Kalziumkanäle blockiert, unterbindet BDM die elektromechanische Kopplung und trägt somit zur Reduktion des Energieverbrauchs bei. Um den $\mathrm{pH}$-Wert der BDM-Lösung zu regulieren und um das Herz mit ausreichend Sauerstoff zu 
versorgen, wurde die Lösung mit Carbogen $\left(95 \% \mathrm{O}_{2}, 5 \% \mathrm{CO}_{2}\right)$ begast. Carbogen bildet mit Hydrogencarbonat ein offenes Puffersystem.

Im folgenden Schritt wurden mithilfe einer kleinen Pinzette, einer Federschere und einem Binokular Trabekel aus dem rechten Ventrikel freipräpariert. Hierbei war darauf zu achten, dass die Trabekel möglichst schonend ohne Berührung und Dehnung behandelt wurden, um eine Schädigung der Muskelfasern zu verhindern. Außerdem sollten die Streifen möglichst eine rosige Farbe aufweisen und zur besseren Vergleichbarkeit folgende Dimensionen erfüllen, die mittels einer in das Mikroskop intregrierten Skala abgelesen werden konnten: Breite und Tiefe 0,25-1,3 mm; Länge 1,5-4 mm.

Zunächst wurden die Trabekel an beiden Seiten großzügig aus der Wand herausgeschnitten. Anschließend wurde das eine Ende des Trabekels zu einem kleinen rechteckigen Block geschnitten. Dieser sollte später zur Aufhängung in der Drahtöse dienen. Am anderen Ende wurde eine kleine Verlängerung in Form eines Stecknadelkopfes stehen gelassen, die zum Aufspießen auf den Haken genutzt wurde. Auf diese Weise wurde eine direkte Schädigung des Trabekels verhindert.

\subsubsection{Aufbau der Versuchsanlage}

Die Versuchsanlage der Muskelstreifenexperimente ermöglichte eine direkte Messung systolischer und diastolischer Kraft von Muskelzellverbänden und die Beobachtung von Auswirkungen verschiedener Versuchslösungen. Einen Überblick über den Aufbau der Versuchsanlage bietet Abbildung 2.7.

Die Anlage für isolierte Muskelstreifen, die einen geschlossenen Flüssigkeitskreislauf darstellte, bestand aus einem Organbad mit elektrischem Stimulator, einer Pumpe, einem Lösungsbehälter und einem System zur Temperaturregulation.

Das Organbad, eine aus Kunststoff hergestellte längliche Wanne, war über einen Zu- und einen Ablauf an den Flüssigkeitskreislauf angeschlossen. Zur Aufhängung des Muskelstreifens wurde auf der einen Seite ein gebogener Haken aus einem Insekten-Pin, der an einer Mikrometerschraube befestigt war, und auf der anderen Seite eine aus Platindraht gebogene Öse, die an einem Kraftabnehmer (Typ KG3, Firma Scientific Instruments, Heidelberg) fixiert war, genutzt. Beide Aufhängungseinrichtungen ragten so weit in das Becken des Organbades hinein, dass der Muskelstreifen vollständig von Flüssigkeit umgeben war.

Die Stimulation der Muskelstreifen erfolgte über zwei längs der Wanne eingelassene Platindrähte, die mit einem Stimulator (Scientific Instruments, Heidelberg) verbunden waren. Dieser generierte einen bipolaren elektrischen Rechteckimpuls, der in Frequenz, Spannung und Dauer variiert werden konnte. 


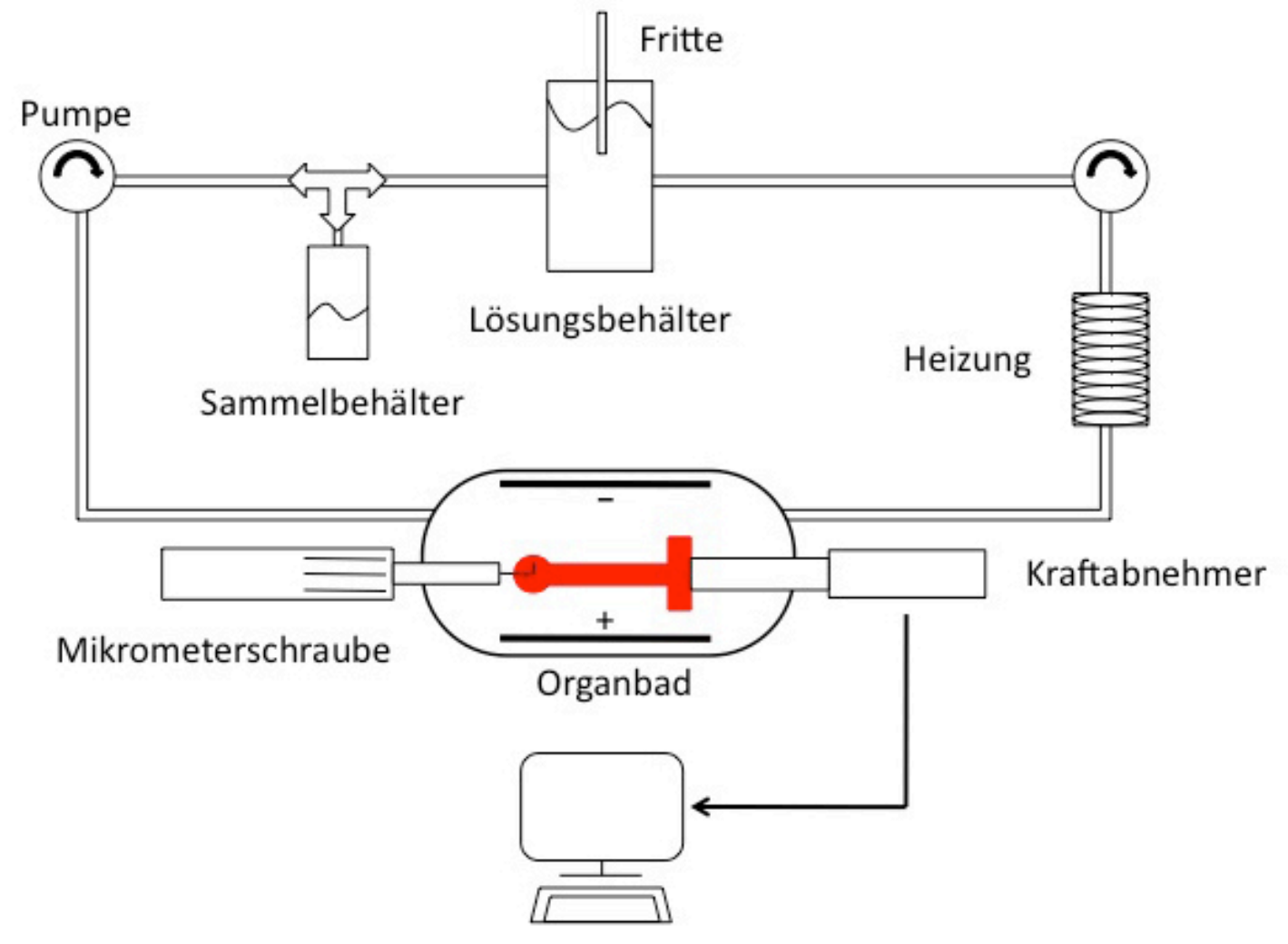

Abb 2.7 Aufbau der Versuchsanlage

\subsubsection{Zirkulation der Lösung}

Lösungsbehälter, Organbad und Verbindungsschläuche bildeten gemeinsam einen geschlossenen Kreislauf. Über zwei zwischengeschaltete Pumpen (Reglo, Firma Ismatec, Wertheim-Mondfeld), eine vor und eine hinter dem Organbad, wurde ein kontinuierlicher Fluss gewährleistet, wobei die Pumpkapazitäten manuell so eingestellt wurden, dass der Abfluss vom Organbad stets schneller war (8-11 $\mathrm{ml} / \mathrm{min}$ ) als der Zufluss (4-6 $\mathrm{ml} / \mathrm{min}$ ).

Als Lösungsbehälter diente ein etwa $150 \mathrm{ml}$ fassender, doppelwandiger Behälter aus Glas, in dem sich eine Fritte (Porosität I, Firma Schott) zur Carbogen-Begasung der Versuchslösung befand. Über eine Heizung wurde eine konstante, physiologische Temperatur von $37^{\circ} \mathrm{C}$ im Organbecken erzeugt. Sowohl die Doppelwand des Lösungsgefäßes als auch ein die Schläuche umgebender Mantel wurden mit dem Heizungswasser perfundiert, so dass die Wärme auf die Lösung übertragen werden konnte.

\subsubsection{Kraftabnehmer}

Über den Kraftabnehmer erfolgte die Übertragung der Muskelspannung, indem er die durch Muskelkontraktionen ausgelösten Auslenkungen in elektrische Spannungssignale transformierte. Über einen Brückenverstärker (Scientific Instruments, Heidelberg) wurden diese Spannungssignale amplifiziert und über einen analog/digitalen Wandler (Typ: $\mathrm{PCl}$ 
1200, Firma National Instruments, Austin/USA) an den Computer weitergeleitet. Für eine getrennte Zuordnung und Aufzeichnung einzelner Muskelkontraktionen gab der Stimulator außerdem fünf Millisekunden vor jeder Muskelstimulation einen Triggerimpuls über den A/DWandler an den Computer ab.

\subsubsection{Reinigung der Anlage}

Die Versuchsanlage wurde jeweils vor und nach jedem Versuch mit mindestens $100 \mathrm{ml}$ Aqua dest. und alle zwei bis drei Tage mit 30\%iger Essigsäure gespült.

\subsubsection{Datenverarbeitung}

Mithilfe der drei Programme „Collect", „Chart" und „Analyse“ der Software LabView (Firma National Instruments, Austin/USA) wurde die Erstellung, Speicherung und Bearbeitung der Daten ermöglicht. Alle drei Programme wurden von P. Janssen entwickelt.

Das Programm "Collect" diente zur Aufzeichnung und Beobachtung der Messwerte, wobei es ab dem Triggersignal des Stimulators für eine einzelne Kontraktion („Twitch“) jeweils 900 Datenpunkte pro Sekunde aufzeichnete.

Die Speicherung der Daten erfolgte einerseits in eine Chart-Datei und andererseits in eine Average-Datei. Die Chart-Datei enthielt den gesamten Versuchsablauf, d. h. eine kontinuierliche Kurve zwischen registrierten Minimalwerten (diastolischen Werten, Ruhespannung) und Maximalwerten (systolischen Werten) der entwickelten Kraft. Um eine genaue Analyse der Messwerte vornehmen zu können, wurden außerdem zu bestimmten Zeitpunkten des Messprotokolls Average-Dateien angelegt, in die jeweils fünf Kontraktionen gemittelt abgespeichert wurden. Zur späteren Identifikation bei der Auswertung wurden diese während der Messung mit verschiedenen Kommentaren versehen.

Bei der Speicherung der Average-Dateien wurden folgende Parameter automatisch erfasst: systolische Kraft $\left(F_{\text {sys }}\right.$ in $\left.\mathrm{mN} / \mathrm{mm}^{3}\right)$, diastolische Spannung $\left(F_{\text {dia }}\right)$, Zeit bis zum Kraftmaximum (TTP), maximale Kontraktions- und Relaxationsgeschwindigkeit, normalisiert auf die systolische Kraft, und die Zeit bis zur 50\%igen ( $\left.R T_{50}\right)$ und 90\%igen Relaxation ( $\left.R T_{90}\right)$.

Für eine bessere Vergleichbarkeit der Experimente wurden die systolische und die diastolische Kraft auf die Querschnittsfläche des Muskelstreifens normiert, die gemäß folgender Formel berechnet wurde:

$$
Q=D_{1} / 2 \times D_{2} / 2 \times \pi
$$

Formel 2.3 Berechnung der Querschnittsfläche eines Muskelstreifens

$D_{1}$ und $D_{2}$ : Durchmesser des Muskels 
Die beiden Analyseprogramme "Chart" und „Analyse“ dienten zur weiteren Bearbeitung der erhobenen Daten, so dass diese schließlich in einem entsprechenden Dateiformat in eine Tabellenkalkulation von Microsoft Excel überführt werden konnten.

\subsubsection{Versuchsdurchführung}

\subsubsection{Einspannen der Muskelstreifen}

Vor dem Einspannen des präparierten Muskelstreifens musste die Versuchsanlage zunächst mit $100 \mathrm{ml}$ destilliertem Wasser gespült werden. Anschließend wurden $150 \mathrm{ml}$ einer sogenannten Krebs-Henseleit-Lösung (KH-Lösung, siehe Tabelle 2.5) - einer Lösung, die in ihrer Elektrolytzusammensetzung annähernd der des Blutes entsprach - in den beheizten Lösungsbehälter gefüllt und zur pH-Regulation mit Carbogen begast. Danach wurde kurzzeitig die Umwälzpumpe eingeschaltet, bis sich das Organbad mit der KH-Lösung füllte. Anschließend wurde diese wieder entfernt und der Muskelstreifen mithilfe einer Plastikpipette mit wenigen Millilitern BDM-Lösung in das Becken befördert. Das Einspannen des Streifens erfolgte unter mikroskopischer Sicht mittels zweier Splitterpinzetten. Zunächst wurde das Kopf-Ende vorsichtig durch die Drahtöse gezogen, so dass der rechteckige Block in der Öse zum Liegen kam. Danach konnte das andere Ende auf den Haken aufgespießt werden. Hierbei war darauf zu achten, dass der Muskelstreifen schlaff und mit seiner Längsachse möglichst gerade, d. h. in Verlängerung des Kraftaufnehmers, in dem Bad eingehängt wurde.

\subsubsection{Ausspülen, Stimulation, Kalziumaufbau und Einschlagen}

Nach dem Einspannen wurde durch Öffnen des Kreislaufsystems die im Organbad befindliche BDM-Lösung mit $50 \mathrm{ml}$ KH-Lösung ausgepült, im Sammelbehälter aufgefangen und verworfen. Währenddessen wurde das Programm LabView geöffnet und die

Dimensionen des Muskelstreifens (Länge, Breite und Tiefe) eingegeben. Das Programm errechnete hieraus automatisch die auf den Muskelquerschnitt bezogenen Kräfte.

Nach Anschalten der biphasischen Stimulation (5 Volt) erfolgte der Kalziumaufbau. Über einen Zeitraum von 12 Minuten wurde die Ausgangskonzentration von 0,25 mM der $\mathrm{KH}$ Lösung alle 2 Minuten um 0,25 mM auf eine Endkonzentration von 2,0 mM gesteigert. Die langsame Steigerung des Kalziumgehaltes diente der Verhinderung einer Kontraktur des Muskelstreifens. Um sich von eventuellen Schädigungen während der Präparation regenerieren zu können, wurde der Muskelstreifen anschließend für etwa 30 Minuten im nicht gedehnten Zustand stimuliert. 


\subsubsection{Dehnung des Muskelstreifens}

Nach dem dreißigminütigen Einschlagen erfolgte die Dehnung des Muskelstreifens mithilfe der Mikrometerschraube. Durch die Dehnung gewann der Streifen gemäß des FrankStarling-Mechanismus schrittweise an Kraft. Der Muskelstreifen wurde so lange gedehnt, bis diejenige Länge mit der maximalen Kraftentwicklung $\left(L_{\max }\right)$ erreicht wurde. Da sich durch die Dehnung die Dimensionen des Muskelstreifens änderten, wurden diese erneut ausgemessen und im Programm eingegeben. Nach Erreichen einer konstanten Kraft, $d . h$. nach Erreichen des steady states, erfolgte die erste Speicherung der Werte in eine AverageDatei.

\subsubsection{Messprotokoll}

Nach Erreichen des steady states sollte der Effekt des zu untersuchenden SERCA2aModulators auf die Kontraktilität bei steigender Konzentration $(0,1 \mu \mathrm{M}, 1 \mu \mathrm{M}$ und $10 \mu \mathrm{M})$ beobachtet werden (siehe Tabelle 2.5). Hierzu wurden jeweils entsprechende Mengen des gelösten Stoffes in den Lösungsbehälter pipettiert und jeweils bis zum erneuten steady state, mindestens aber für den Zeitraum von 15 Minuten, gewartet. Abschließend erfolgte nach jedem der drei Schritte eine Speicherung der Werte in die Average-Datei.

\subsection{Statistik}

In den erstellten Abbildungen des Ergebnisteils werden die Mittelwerte der erhobenen Daten dargestellt. Die Fehlerbalken repräsentieren den Standardfehler der Mittelwerte (S.E.M.), der folgendermaßen berechnet wird:

$$
S . E . M=\sqrt{\frac{\sigma^{2}}{n}}=\frac{\sigma}{\sqrt{n}}
$$

Formel 2.4 Berechnung des Standardfehlers des Mittelwertes (S.E.M.)

$\mathrm{n}$ : Anzahl; $\sigma:$ Standardabweichung; $\sigma^{2}$ : Varianz

Mithilfe des Statistikprogramms SigmaStat 2.03 (Access Softec Inc., San Rafael, USA) wurden zur Prüfung auf Signifikanz der Daten Student`s T-tests, je nach Bedarf gepaart oder ungepaart, und für wiederholte Messungen zur Analyse von Longitudinaldaten mehrerer Gruppen Zwei-Wege-Varianzanalysen (ANOVA) durchgeführt. Als statistisch signifikant wurde eine Irrtumswahrscheinlichkeit von $p<0,05$ festgelegt. 


\subsection{Lösungen und Chemikalien}

\section{Zu 2.1.1 Isolation ventrikulärer Kardiomyozyten aus Rattenherzen}

Tab. 2.1 Lösungen zur Isolation ventrikulärer Kardiomyozyten aus Rattenherzen

\begin{tabular}{|c|c|c|c|}
\hline Isolationstyrode & $\begin{array}{c}\mathrm{NaCl} \text { (Merck,Darmstadt,Deutschland) } \\
\mathrm{KCl} \text { (Merck) } \\
\mathrm{MgSO}_{4} \cdot 7 \mathrm{H}_{2} \mathrm{O} \text { (Merck) } \\
\mathrm{Na}_{2} \mathrm{HPO}_{4} \cdot 12 \mathrm{H}_{2} \mathrm{O} \text { (Merck) } \\
\text { HEPES (Sigma-Aldrich,St.Louis,USA) } \\
\text { Glukose (Merck) }\end{array}$ & $\begin{array}{l}137 \mathrm{mM} \\
5,4 \mathrm{mM} \\
1,2 \mathrm{mM} \\
1,2 \mathrm{mM} \\
20 \mathrm{mM} \\
15 \mathrm{mM}\end{array}$ & $\begin{array}{c}\text { gelöst in } \mathrm{ddH}_{2} \mathrm{O} ; \\
\text { pH bei RT mit } \mathrm{NaOH} \\
\text { auf } 7,55 \text { titrieren }\end{array}$ \\
\hline $\begin{array}{l}\mathrm{Ca}^{2+} \text {-freie } \\
\text { Isolationstyrode }\end{array}$ & $\begin{array}{l}\text { 100-fach Penicillin/ Streptomycin } \\
\text { (Biochrom AG, Berlin, Deutschland) }\end{array}$ & $8,3 \mathrm{ml} / \mathrm{l}$ & $\begin{array}{l}\text { gelöst in } 1 \text { Liter } \\
\text { Isolationstyrode }\end{array}$ \\
\hline Enzymlösung & $\begin{array}{l}\text { Kollagenase II (Biochrom AG) } \\
\text { Protease XIV (Sigma-Aldrich) } \\
\qquad \mathrm{CaCl}_{2} \text { (Sigma-Aldrich) }\end{array}$ & $\begin{array}{l}230 \mathrm{U} / \mathrm{ml} \\
0,5 \mathrm{U} / \mathrm{ml} \\
0,1 \mathrm{mM}\end{array}$ & $\begin{array}{l}\text { gelöst in } 1 \text { Liter } \\
\text { Isolationstyrode }\end{array}$ \\
\hline $\begin{array}{l}\text { Modifiziertes } \\
\qquad \text { M199- } \\
\text { Nährmedium }\end{array}$ & $\begin{array}{c}\text { M199 Medium (Sigma-Aldrich) } \\
\text { Taurin (Sigma-Aldrich) } \\
\text { D,L- Carnitin (Sigma-Aldrich) } \\
\text { Kreatin (Sigma-Aldrich) } \\
\text { 100-fach Penicillin/Streptomycin } \\
\text { (Biochrom AG) } \\
\text { 100-fach L-Glutamin (Biochrom AG) }\end{array}$ & $\begin{array}{c}500 \mathrm{ml} \\
312,5 \mathrm{mg} \\
500 \mathrm{mg} \\
327,5 \mathrm{mg} \\
5,0 \mathrm{ml} \\
\\
5,0 \mathrm{ml}\end{array}$ & $\begin{array}{l}\text { steril filtriert und bei } \\
\qquad 4^{\circ} \mathrm{C} \text { gelagert }\end{array}$ \\
\hline
\end{tabular}

\section{Zu 2.1.3 Versuchsdurchführung}

Tab 2.2 Herstellung der Fluo 3 AM - Farbstofflösung

\begin{tabular}{|c|c|c|c|}
\hline Lösung & Substanz & Menge & \\
\hline Pluronic- Lösung & Pluronic F-68 (Sigma-Aldrich) & $20 \% \mathrm{w} / \mathrm{v}$ & gelöst in DMSO \\
\hline $\begin{array}{l}\text { Fluo } 3 \mathrm{AM}- \\
\text { Vorratslösung } \\
\quad(1 \mathrm{mM})\end{array}$ & $\begin{array}{c}\text { Fluo } 3 \text { AM (MoBiTec, Göttingen) } \\
\text { DMSO (Sigma-Aldrich) }\end{array}$ & $\begin{array}{l}1 \mathrm{mg} \\
885 \mu \mathrm{l}\end{array}$ & $\begin{array}{l}\text { Lagerung bei } \\
\qquad-20^{\circ} \mathrm{C}\end{array}$ \\
\hline $\begin{array}{l}\text { Fluo } 3 \mathrm{AM}- \\
\text { Farbstofflösung } \\
\qquad(10 \mu \mathrm{M})\end{array}$ & $\begin{array}{l}\text { Fluo } 3 \text { AM - Vorratslösung } \\
\text { Pluronic- Lösung } \\
\text { Normaltyrode mit } 2 \text { mM Ca }{ }^{2+}\end{array}$ & $\begin{array}{l}50 \mu \mathrm{l} \\
5 \mu \mathrm{l} \\
5 \mathrm{ml}\end{array}$ & $\begin{array}{l}\text { Lichtgeschützte } \\
\text { Lagerung bei } \\
-20^{\circ} \mathrm{C}\end{array}$ \\
\hline
\end{tabular}


Tab 2.3 Zusammensetzung der Normaltyrode

\begin{tabular}{|c|c|c|c|}
\hline Lösung & Substanz & Menge & \\
\hline Normaltyrode & $\begin{array}{c}\mathrm{NaCl} \text { (Merck) } \\
\mathrm{KCl} \text { (Merck) } \\
\mathrm{MgCl}_{2} \text { (Merck) } \\
\text { HEPES (Sigma-Aldrich) } \\
\mathrm{Glukose} \text { (Merck) }_{\mathrm{CaCl}_{2} \text { (Sigma-Aldrich) }}\end{array}$ & $\begin{array}{c}140 \mathrm{mM} \\
4 \mathrm{mM} \\
1 \mathrm{mM} \\
5 \mathrm{mM} \\
10 \mathrm{mM} \\
2 \mathrm{mM}\end{array}$ & $\begin{array}{c}\text { gelöst in } \mathrm{ddH}_{2} \mathrm{O} \text {; } \\
\text { pH bei } 37^{\circ} \mathrm{C} \text { mit } \\
\mathrm{NaOH} \text { auf } 7,4 \\
\text { titrieren }\end{array}$ \\
\hline
\end{tabular}

\section{Zu 2.1.4 Messprotokoll}

Tab 2.4 Herstellung der Messtyroden

\begin{tabular}{|c|c|c|c|}
\hline Lösung & Substanz & Menge & \\
\hline Stoff-Vorratslösung I & SERCA2a-Modulator & $0,1 \mathrm{M}$ & gelöst in DMSO \\
\hline $\begin{array}{l}\text { Stoff-Vorratslösung II } \\
\text { (aufgrund von } \\
\text { Nichtlöslichkeit der } \\
\text { Stoffe GPZ000876 } \\
\text { und GPZ001441 in } \\
\text { DMSO) }\end{array}$ & $\begin{array}{c}\text { Stofflösung I der SERCA2a- } \\
\text { Modulatoren GPZ000876 bzw. } \\
\text { GPZ001441 }\end{array}$ & $0,01 \mathrm{M}$ & gelöst in $\mathrm{ddH}_{2} \mathrm{O}$ \\
\hline Stoff-Tyrode & Stoffvorratslösung I bzw. II & $\begin{array}{c}0,1 \mu \mathrm{M} \\
\text { bzw. } \\
1 \mu \mathrm{M} \\
\text { bzw. } \\
10 \mu \mathrm{M}\end{array}$ & $\begin{array}{c}\text { gelöst in } \\
\text { Normaltyrode }\end{array}$ \\
\hline Kontrolltyrode & DMSO (Sigma-Aldrich) & $\begin{array}{c}0,1 \mu \mathrm{M} \\
\text { bzw. } \\
1 \mu \mathrm{M} \\
\text { bzw. } \\
10 \mu \mathrm{M}\end{array}$ & $\begin{array}{c}\text { gelöst in } \\
\text { Normaltyrode }\end{array}$ \\
\hline Koffeinhaltige Tyrode & Koffein (Sigma-Aldrich) & $10 \mathrm{mM}$ & $\begin{array}{c}\text { gelöst in } \\
\text { Normaltyrode }\end{array}$ \\
\hline
\end{tabular}




\section{Zu 2.2 Muskelstreifenexperimente}

Tab. 2.5 Zusammensetzung von Krebs-Henseleit- und Präparierlösung für Muskelstreifenexperimente

\begin{tabular}{|c|c|c|c|}
\hline Lösung & Substanz & Menge & \\
\hline $\begin{array}{c}\text { Krebs-Henseleit- } \\
\text { Lösung }\end{array}$ & $\begin{array}{c}\mathrm{NaCl} \text { (Merck) } \\
\mathrm{KCl} \text { (Merck) } \\
\mathrm{MgCl}_{2} \cdot 6 \mathrm{H}_{2} \mathrm{O} \text { (Merck) } \\
\mathrm{Na}_{2} \mathrm{SO}_{4} \text { (Merck) } \\
\mathrm{NaH}_{2} \mathrm{PO}_{4} \cdot 1 \mathrm{H}_{2} \mathrm{O} \text { (Merck) } \\
\mathrm{Glukose} \text { (Merck) }_{\mathrm{NaHCO}_{3} \text { (Merck) }} \mathrm{CaCl}_{2} \text { (Sigma-Aldrich) }\end{array}$ & $\begin{array}{c}116,1 \mathrm{mM} \\
5,0 \mathrm{mM} \\
1,2 \mathrm{mM} \\
1,2 \mathrm{mM} \\
2,0 \mathrm{mM} \\
10 \mathrm{mM} \\
20 \mathrm{mM} \\
0,25 \mathrm{mM}\end{array}$ & gelöst in $\mathrm{ddH}_{2} \mathrm{O}$ \\
\hline Präparierlösung & $\mathrm{BDM}\left(\mathrm{C}_{4} \mathrm{H}_{7} \mathrm{NO}_{2}\right)$ & $20 \mathrm{mM}$ & $\begin{array}{l}\text { gelöst in Krebs- } \\
\text { Henseleit-Lösung }\end{array}$ \\
\hline Stoff-Lösung & $\begin{array}{l}\text { Stoff-Vorratslösung I bzw. II } \\
\text { (siehe Tabelle 2.4) }\end{array}$ & $\begin{array}{c}0,1 \mu \mathrm{M} \\
\text { bzw. } \\
1 \mu \mathrm{M} \\
\text { bzw. } \\
10 \mu \mathrm{M}\end{array}$ & $\begin{array}{l}\text { gelöst in Krebs- } \\
\text { Henseleit-Lösung }\end{array}$ \\
\hline
\end{tabular}


Tab. 2.6 Herztransplantationspatienten (DCM = Dilatative Kardiomyopathie; ICM = Ischämische Kardiomyopathie; LVAD = Linksventrikuläres Unterstützungssystem; EF = Ejektionsfraktion)

\begin{tabular}{|c|c|c|c|c|c|}
\hline Patient & Geschlecht & Alter & Ätiologie & LVAD & EF $(\%)$ \\
\hline 1 & $\mathrm{~m}$ & 53 & ICM & + & 14 \\
\hline 2 & $\mathrm{~m}$ & 69 & ICM & - & 35 \\
\hline 3 & $\mathrm{~m}$ & 63 & ICM & + & 20 \\
\hline 4 & w & 50 & ICM & - & 25 \\
\hline 5 & $\mathrm{~m}$ & 51 & DCM & + & 20 \\
\hline 6 & w & 35 & Pulmonalatresie & - & 27 \\
\hline 7 & $\mathrm{~m}$ & 58 & DCM & + & 10 \\
\hline 8 & $\mathrm{~m}$ & 69 & $\mathrm{DCM}$ & + & 13 \\
\hline 9 & w & 57 & $\mathrm{DCM}$ & + & 29 \\
\hline 10 & $\mathrm{~m}$ & 66 & $\mathrm{DCM}$ & + & 10 \\
\hline 11 & $\mathrm{~m}$ & 47 & $\mathrm{ICM}$ & + & 22 \\
\hline 12 & $\mathrm{~m}$ & 56 & ICM & + & 15 \\
\hline 13 & $\mathrm{~m}$ & 47 & $\mathrm{ICM}$ & - & 15 \\
\hline 14 & $\mathrm{~m}$ & 42 & $\mathrm{DCM}$ & - & 18 \\
\hline 15 & $\mathrm{~m}$ & 56 & $\mathrm{DCM}$ & + & 20 \\
\hline 16 & $\mathrm{~m}$ & 60 & ICM & - & 31 \\
\hline
\end{tabular}

Tab. 2.7 Medikation der Herztransplantationspatienten

\begin{tabular}{|c|c|c|c|c|c|c|c|}
\hline Patient & $\begin{array}{c}\text { Katechol } \\
\text {-amine }\end{array}$ & Digitalis & $\begin{array}{c}\boldsymbol{\beta}- \\
\text { Blocker }\end{array}$ & $\begin{array}{c}\text { ACE- } \\
\text { Inhibitor }\end{array}$ & Diuretika & Nitrate & $\begin{array}{c}\text { Antiar- } \\
\text { rythmika }\end{array}$ \\
\hline 1 & - & - & + & + & + & - & - \\
2 & - & - & + & + & + & + & - \\
3 & - & - & + & + & + & - & + \\
4 & - & - & + & + & + & + & - \\
5 & - & - & + & + & + & - & + \\
6 & + & + & + & - & + & - & + \\
7 & - & - & + & + & + & - & + \\
8 & - & - & + & - & + & - & - \\
9 & - & - & - & - & + & - & - \\
10 & - & - & + & + & + & - & - \\
11 & - & - & + & + & + & - & + \\
12 & - & - & + & + & + & - & + \\
13 & + & - & + & + & + & - & - \\
14 & - & + & + & + & + & + & + \\
15 & - & - & + & + & + & - & - \\
16 & - & - & + & + & + & - & + \\
\hline
\end{tabular}




\section{Ergebnisse}

\subsection{Screening der SERCA2a-Modulatoren an Einzelzellen}

Für das Screening am Epifluoreszenz-Mikroskop wurden folgende Konzentrationen der in Tyrode gelösten SERCA2a-Modulatoren untersucht: $0,1 \mu \mathrm{M}, 1 \mu \mathrm{M}$ und $10 \mu \mathrm{M}$. Die Relaxationszeit der Zelle ( $\left.\mathrm{RT}_{50}\right)$ bzw. die Geschwindigkeit der Kalziumelimination aus dem Zytosol ( $\tau_{\mathrm{Ca}}$ ) wurde als Maß für die SERCA2a-Aktivität herangezogen.

\subsubsection{ENF018}

Die konzentrationsabhängige Untersuchung des SERCA2a-Modulators ENF018 ergab, dass bei der fraktionellen Zellverkürzung im Vergleich zur Kontrollgruppe keine signifikanten Veränderungen vorliegen. Sowohl bei ENF018 als auch bei der Kontrolle nimmt die Kontraktilität der Zellen, normalisiert auf die durchschnittliche Kontraktilität unter Ausgangsbedingungen mit Normaltyrode (NT), über den Zeitraum des Versuches kontinuierlich ab. Tendenziell ist bei $1 \mu \mathrm{M}$ eine verringerte Zellverkürzung gegenüber der Kontrolle zu beobachten.

Die Amplituden der $\mathrm{Ca}^{2+}$-Transienten nehmen mit steigender Konzentration zunehmend und im Vergleich zur Kontrollgruppe stärker ab. Bei $10 \mu \mathrm{M}$ des SERCA2a-Modulators ENF018 beträgt die $\mathrm{Ca}^{2+}$-Amplitude $\mathrm{F} / \mathrm{F}_{0}$ in Prozent des Ausgangswertes bei Normaltyrode $56,4 \% \pm$ $6,3 \%$ während sie bei der Kontrolle $82,2 \% \pm 6,4 \%$ beträgt. Damit ist die $\mathrm{Ca}^{2+}-$ Amplitude bei $10 \mu \mathrm{M}$ im Vergleich zur Kontrolle signifikant reduziert $(p=0,02)$.

Die statistische Untersuchung des Relaxationsverhaltens von ENF018 ergibt im Vergleich zur Kontrolle keine signifikanten Unterschiede. In beiden Gruppen bleibt die $\mathrm{RT}_{50}$ bei allen Konzentrationen in etwa konstant. Sehr ähnlich verhält sich der Abfall der $\mathrm{Ca}^{2+}$-Transienten. Auch hier sind kaum Unterschiede zwischen den Abfallsexponenten $\tau$ von ENF018 und der Kontrolle feststellbar (Abb. 3.1). 
A

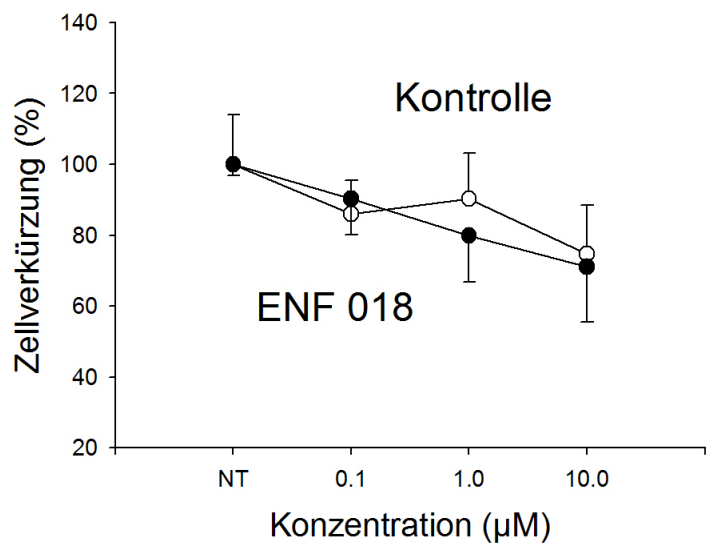

C

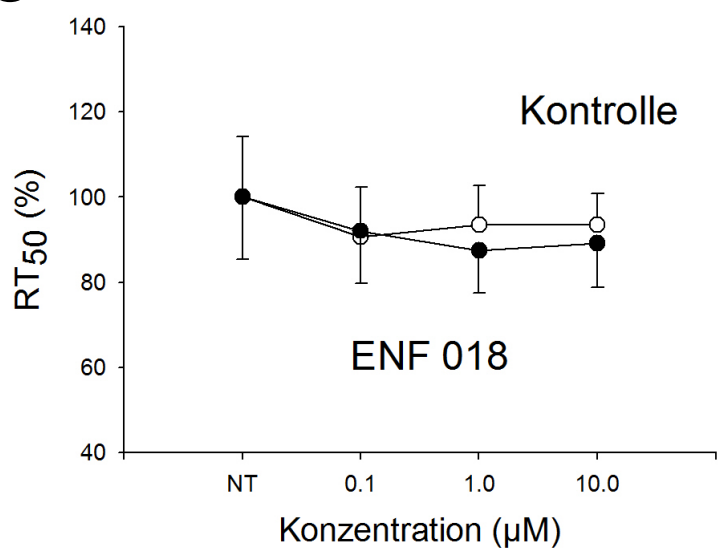

B

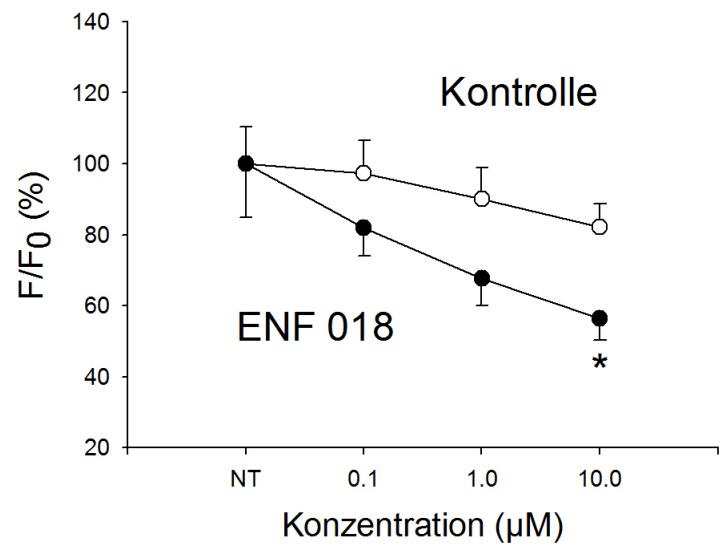

D

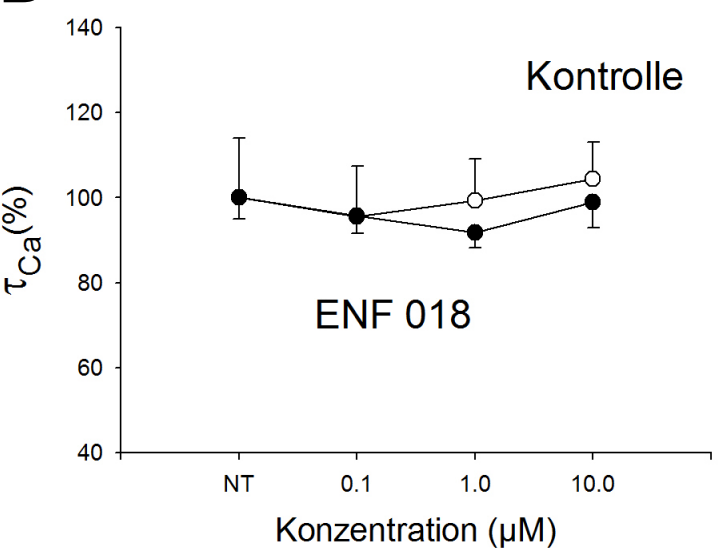

Abb. 3.1 Screeningergebnisse von ENF018 $(n=6)$ vs. Kontrolle $(n=6)$

A: Relative Zellverkürzung in Prozent der durchschnittlichen Zellverkürzung unter NT; B: Relative $\mathrm{Ca}^{2+}-$ Transienten in Prozent des durchschnittlichen $\mathrm{Ca}^{2+}-$ Transienten unter NT; C: Relative Relaxationszeit in Prozent der durchschnittlichen Relaxationszeit unter NT; D: Relativer Abfallsexponent in Prozent des durchschnittlichen Abfallsexponenten unter NT;

* Signifikanz mit $p=0,02$ zwischen ENF018 und Kontrolle 


\subsubsection{ENG020}

Wie Abb. 3.2 zeigt, ist bereits in den Originalregistrierungen bei steigender Konzentration des SERCA2a-Modulators ENG020 eine zunehmend beeinträchtigte Kontraktilität der Zellen im Vergleich zur Kontrolle erkennbar.

A

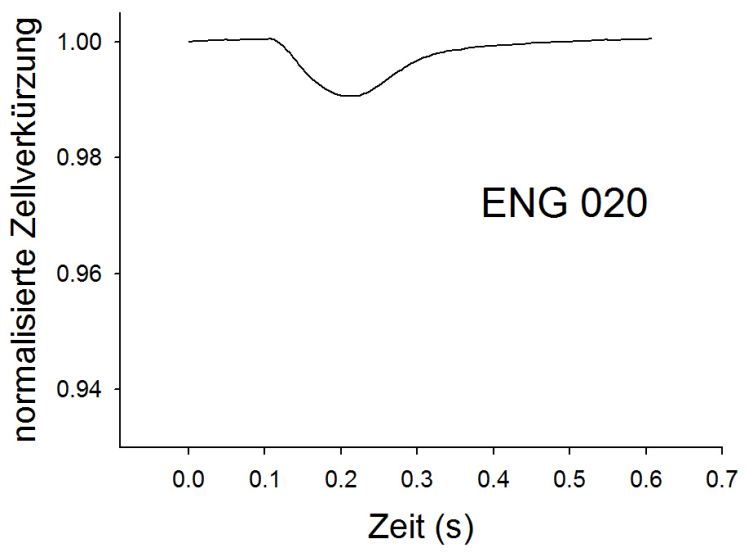

B

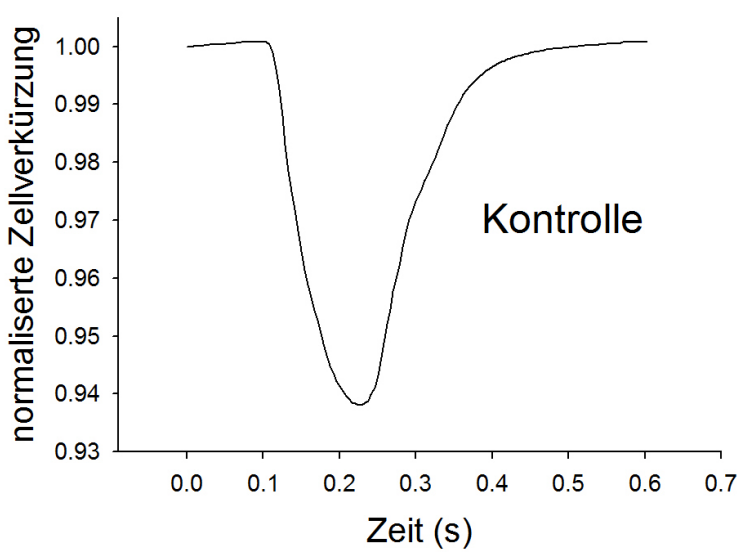

Abb. 3.2 Exemplarische Originalregistrierung der normalsierten Zellverkürzung einer ENG020- Zelle (A) und einer Kontroll-Zelle (B) unter Stimulation von $2 \mathrm{~Hz}$

Während die Zellverkürzung bei den Konzentrationen $0,1 \mu \mathrm{M}$ und $1 \mu \mathrm{M}$ im Vergleich zur Kontrollgruppe nur leicht abnimmt ( $p=n . s$.$) , ist sie bei der höchsten Konzentration von 10 \mu \mathrm{M}$ im Vergleich zur Kontrollgruppe signifikant reduziert $(p=0,02)$.

Ein ähnliches Bild zeigt sich bei den Amplituden $F / F_{0}$ der $\mathrm{Ca}^{2+}$-Transienten: Der konzentrationsabhängige Vergleich der $\mathrm{Ca}^{2+}$-Amplituden zeigt signifikant reduzierte Amplituden bei höchster und mittlerer Konzentration im Vergleich zur Kontrolle (10 $\mu \mathrm{M}$ : $p=0,001 ; 1 \mu \mathrm{M}: \mathrm{p}=0,02)$.

In dem Relaxationsverhalten der Zellen sind beim Vergleich der $\mathrm{RT}_{50}$ keine signifikanten Unterschiede zwischen der ENG020- und der Kontrollgruppe feststellbar. Tendenziell ist eine geringe Beschleunigung der Relaxation bei $1 \mu \mathrm{M}$ ENG 020 im Vergleich zur Kontrolle zu beobachten ( $p=n . s$.). Auch in der Betrachtung der Abfallsexponenten $\tau$ der $\mathrm{Ca}^{2+}$ - Amplituden ergeben sich keine Unterschiede zwischen beiden Gruppen. In der Tendenz ist die Kalziumelimination aus dem Zytosol bei mittlerer und höchster Konzentration im Vergleich zur Kontrolle verlangsamt (Abb. 3.3). 
A

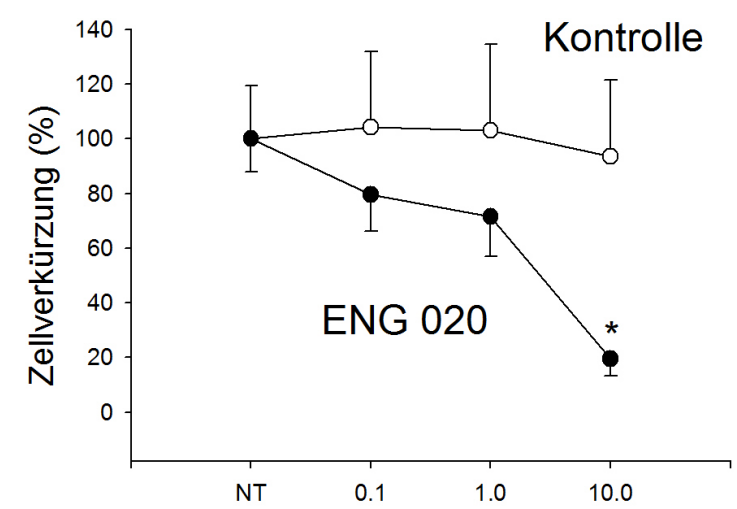

C

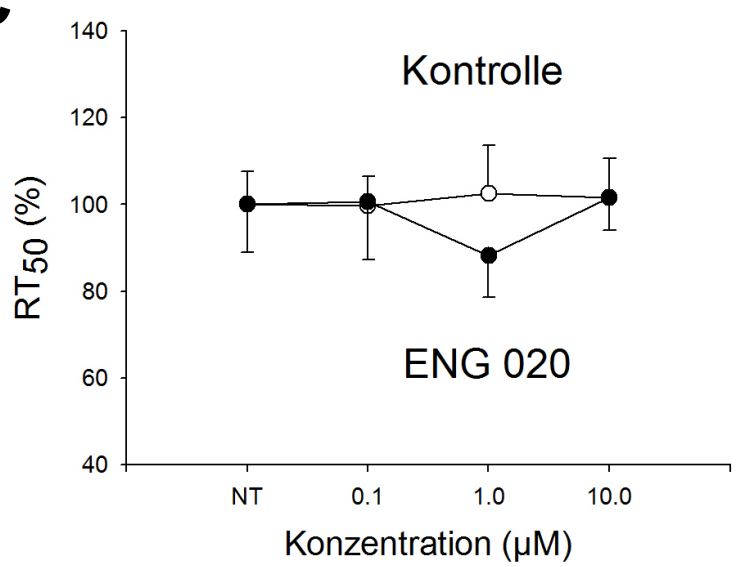

B

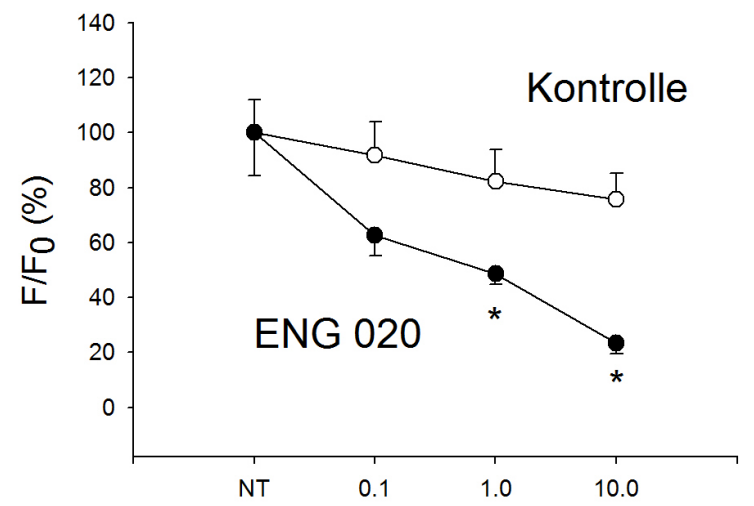

D

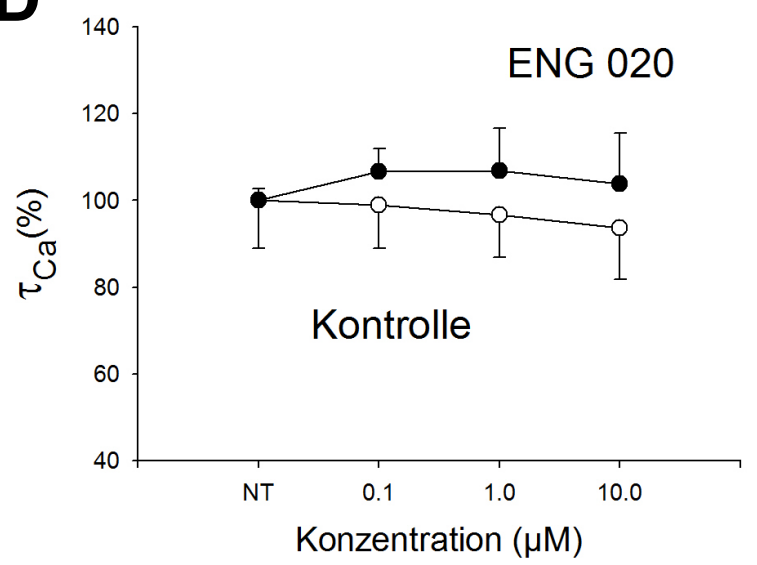

Abb. 3.3 Screeningergebnisse von ENG020 $(n=6)$ vs. Kontrolle $(n=7)$

A: Relative Zellverkürzung in Prozent der durchschnittlichen Zellverkürzung unter NT; B: Relative $\mathrm{Ca}^{2+}$-Transienten in Prozent des durchschnittlichen $\mathrm{Ca}^{2+}-$ Transienten unter NT; C: Relative Relaxationszeit in Prozent der durchschnittlichen Relaxationszeit unter NT; D: Relativer Abfallsexponent in Prozent des durchschnittlichen Abfallsexponenten unter NT;

* Signifikanz mit $p \leq 0,02$ zwischen ENG 020 und Kontrolle

\subsubsection{ENH036}

Während die fraktionelle Zellverkürzung bei niedrigster Konzentration des SERCA2aModulators ENH036 $(0,1 \mu \mathrm{M})$ noch nahezu unbeeinflusst bleibt, sinkt sie bei höchster Konzentration $(10 \mu \mathrm{M})$ auf $0,5 \% \pm 0,3 \%$ des Ausgangswertes bei Normaltyrode ab. Dieser eindeutig negativ inotrope Effekt bei $10 \mu \mathrm{M}$ ist bereits in den Originalregistrierungen zu sehen, in denen die Zellverkürzung bei den meisten Zellen auf nahezu Null sinkt. Somit zeigt der statistische Vergleich von ENH036 und Kontrolle eine signifikant reduzierte Kontraktilität $(p=0,001)$ bei $10 \mu M($ Abb. 3.4 A).

Der negativ inotrope Effekt spiegelt sich auch in den $\mathrm{Ca}^{2+}$-Transienten wider, mit im Vergleich zur Kontrolle signifikant reduzierter Amplitude bei $10 \mu \mathrm{M}(\mathrm{p}=0,001)$.

Auch bei der Betrachtung der Relaxationszeit ergibt sich ein entsprechendes Bild: Bei $10 \mu \mathrm{M}$ ENH036 ist die $\mathrm{RT}_{50}$ im Vergleich zur Kontrolle signifikant verlängert $(p=0,001)$. In den 
meisten Fällen war diese sogar durch die enorm kleine Zellverkürzung bei $10 \mu \mathrm{M}$ nicht mehr messbar. Die Abfallsexponenten $\tau$ der $\mathrm{Ca}^{2+}$-Amplituden unterscheiden sich bei allen Konzentrationen kaum von der der Kontrollgruppe $(p=n . s$.). Tendenziell ist auch hier die zytosolische Kalziumelimination bei $10 \mu \mathrm{M}$ im Vergleich zur Kontrolle leicht verlangsamt. Insgesamt sprechen diese Ergebnisse also eher für eine verminderte SERCA2a-Aktivität durch ENH036 bei $10 \mu \mathrm{M}$ (Abb.3.4)

A

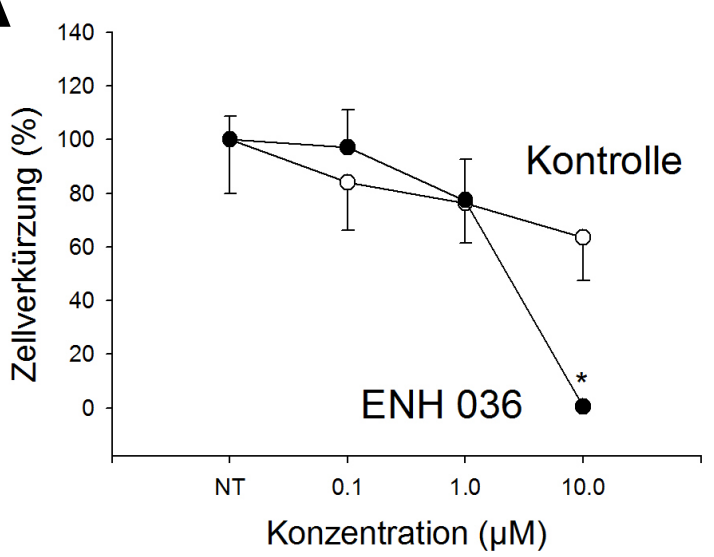

C

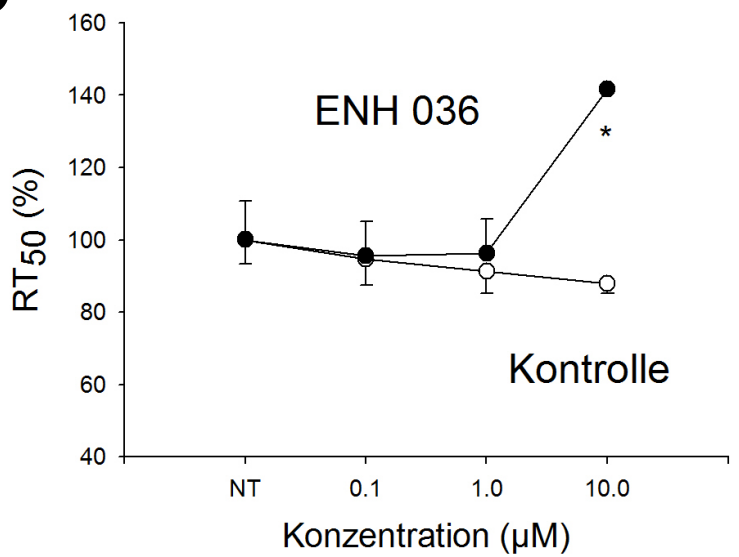

B

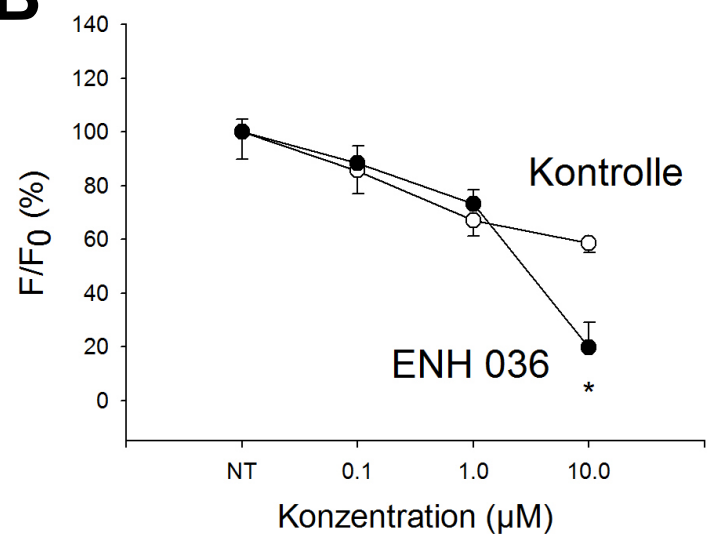

D

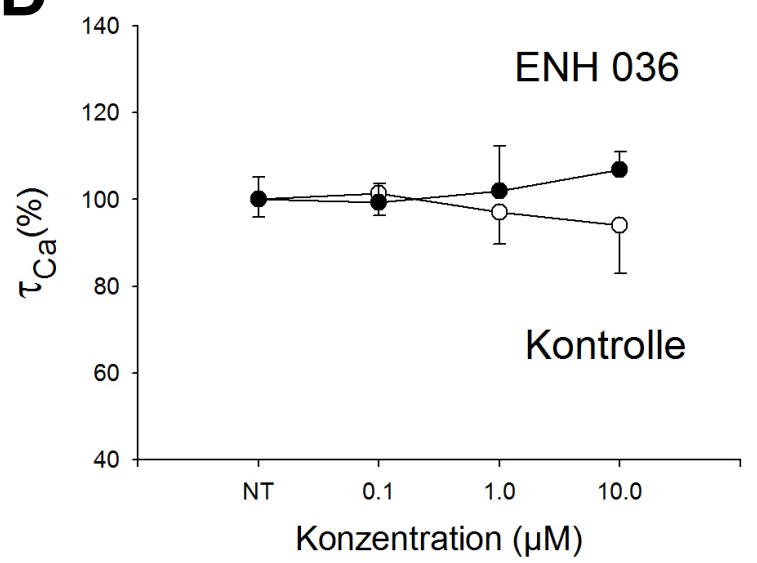

Abb. 3.4 Screeningergebnisse von ENH036 $(n=7)$ vs. Kontrolle $(n=6)$

A: Relative Zellverkürzung in Prozent der durchschnittlichen Zellverkürzung unter NT; B: Relative $\mathrm{Ca}^{2+}$-Transienten in Prozent des durchschnittlichen $\mathrm{Ca}^{2+}-$ Transienten unter NT; C: Relative Relaxationszeit in Prozent der durchschnittlichen Relaxationszeit unter NT; bei $10 \mu \mathrm{M}$ ENH036 minimiert sich die Anzahl der berechenbaren Relaxationszeiten auf $n=2$, da der Großteil der Zellen bei $10 \mu \mathrm{M}$ nicht mehr kontrahiert; D: Relativer Abfallsexponent in Prozent des durchschnittlichen Abfallsexponenten unter NT; bei $10 \mu \mathrm{M}$ ENH036 minimiert sich die Anzahl der berechenbaren Abfallsexponenten auf $n=3$;

* Signifikanz mit $p=0,001$ zwischen ENH036 und Kontrolle 


\subsubsection{ENL055}

Bei 0,1 $\mu \mathrm{M}$ des SERCA2a-Modulators ENL055 ist im Vergleich zum Ausgangswert und zur Kontrolle eine tendenzielle Zunahme der fraktionellen Zellverkürzung zu sehen, die im Vergleich zur Kontrolle aber nicht signifikant ist. Bei den darauf folgenden Konzentrationen nimmt die Kontraktilität bei ENL055 wie bei der Kontrolle kontinuierlich ab.

Die Amplitude der $\mathrm{Ca}^{2+}$-Transienten wird von dem SERCA2a-Modulator ENL055 kaum bis gar nicht beeinflusst. Wie in Abb. 3.7 B dargestellt, reduziert sich die Amplitude der ENL055Gruppe bei steigender Konzentration in einem etwa gleichen Umfang wie die der Kontrollgruppe.

In dem Relaxationsverhalten der Zellen sind beim Vergleich der $\mathrm{RT}_{50}$ keine signifikanten Unterschiede zwischen der ENL055- und der Kontrollgruppe feststellbar. Bei der statistischen Untersuchung der Geschwindigkeit der zytosolischen $\mathrm{Ca}^{2+}$-Elimination ergeben sich ebenfalls keine signifikanten Unterschiede im Vergleich zur Kontrolle (Abb. 3.5).
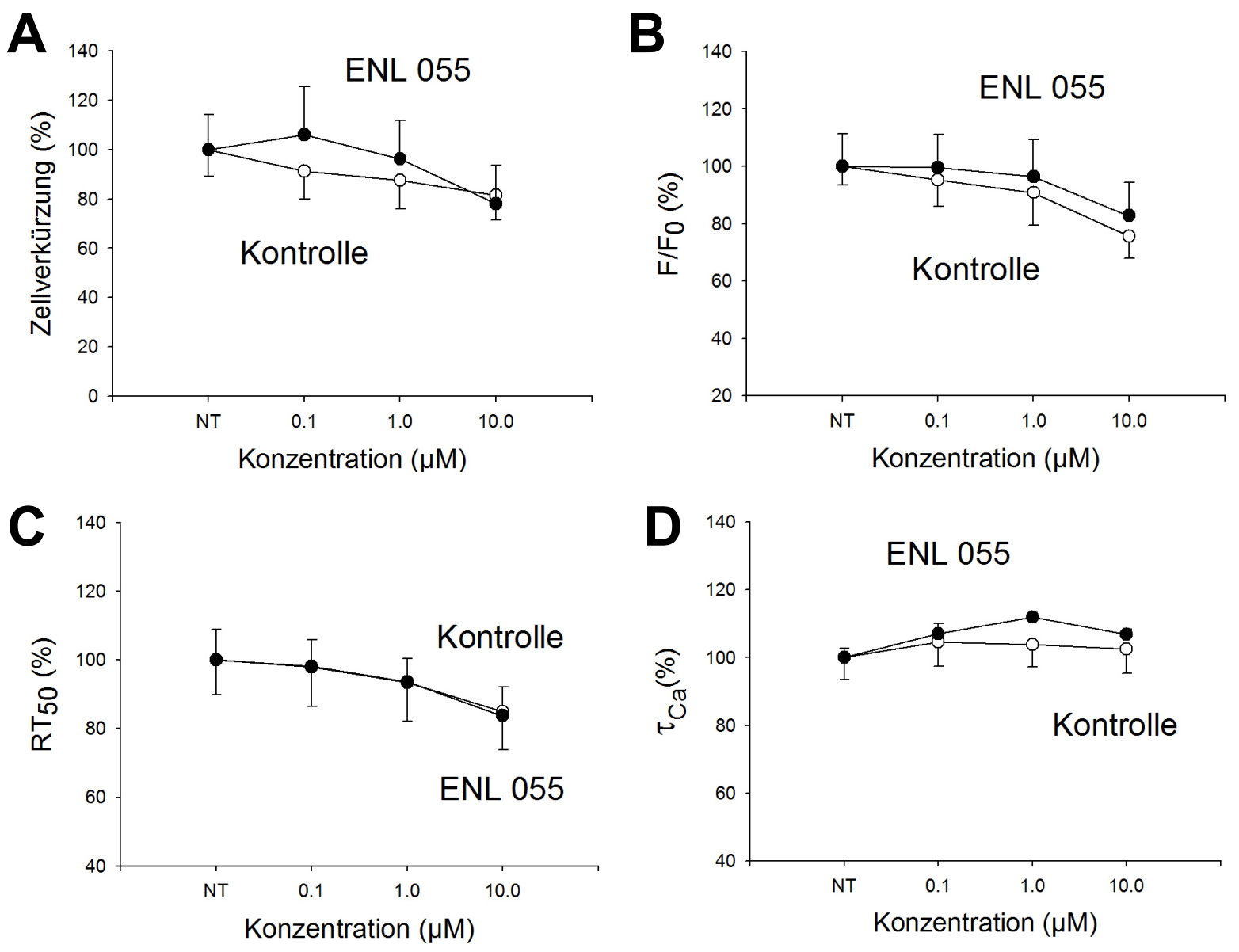

Abb. 3.5 Screeningergebnisse von ENL055 $(n=7)$ vs. Kontrolle $(n=8)$

A: Relative Zellverkürzung in Prozent der durchschnittlichen Zellverkürzung unter NT; B: Relative $\mathrm{Ca}^{2+}$-Transienten in Prozent des durchschnittlichen $\mathrm{Ca}^{2+}-$ Transienten unter NT; C: Relative Relaxationszeit in Prozent der durchschnittlichen Relaxationszeit unter NT; D: Relativer Abfallsexponent in Prozent des durchschnittlichen Abfallsexponenten unter NT; Signifikanzen: keine 


\subsubsection{ENL056}

Wie in Abb. 3.6 A dargestellt, nimmt die Kontraktilität durch den SERCA2a-Modulator ENL056 mit steigender Konzentration zunehmend und im Vergleich zur Kontrollgruppe stärker ab, im Vergleich zur Kontrolle aber in nicht signifikantem Umfang. Bei den $\mathrm{Ca}^{2+}-$ Amplituden $\mathrm{F} / \mathrm{F}_{0}$ und bei der Relaxationszeit $\mathrm{RT}_{50}$ sind keinerlei Unterschiede zwischen ENL056 und der Kontrollgruppe erkennbar. Der Abfallsexponent $\tau$ nimmt mit steigender Konzentration des Stoffes ENL056 immer mehr zu, d.h. die Kalziumelimination aus dem Zytosol wird mit steigender Konzentration verlangsamt, im Vergleich zur Kontrolle bei allen Konzentrationen jedoch nicht signifikant (bei $10 \mu \mathrm{M} p=0,07$ ).
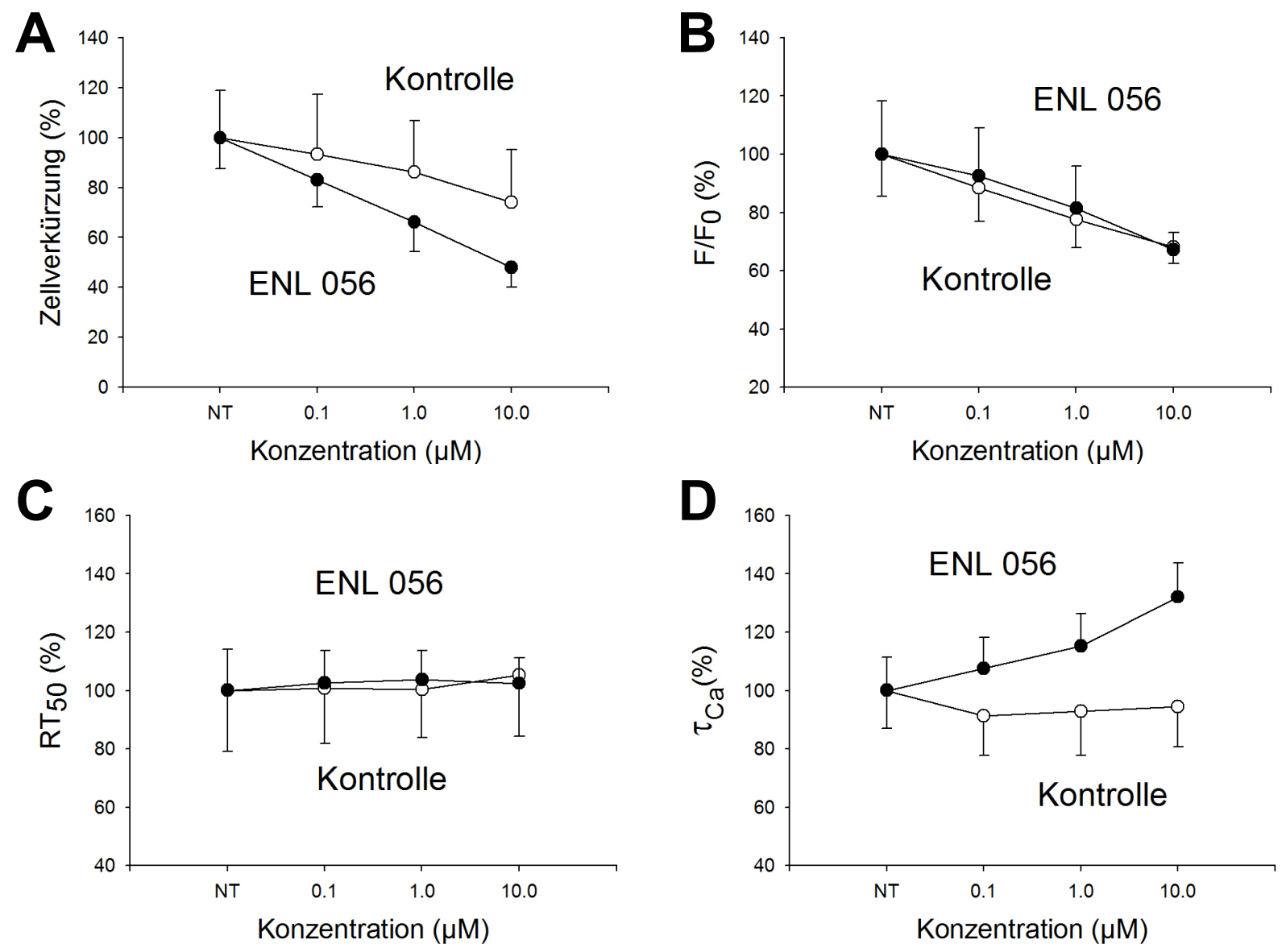

Abb. 3. 6 Screeningergebnisse von ENL056 $(n=7)$ vs. Kontrolle $(n=7)$

A: Relative Zellverkürzung in Prozent der durchschnittlichen Zellverkürzung unter NT; B: Relative $\mathrm{Ca}^{2+}$-Transienten in Prozent des durchschnittlichen $\mathrm{Ca}^{2+}-$ Transienten unter NT; C: Relative Relaxationszeit in Prozent der durchschnittlichen Relaxationszeit unter NT; D: Relativer Abfallsexponent in Prozent des durchschnittlichen Abfallsexponenten unter NT; Signifikanzen: keine 


\subsubsection{ENO107}

Die Kontraktilität der Zellen nimmt mit steigender Konzentration des SERCA2a-Modulators ENO107 zu. Allerdings weist diesbezüglich der statistische Vergleich zwischen ENO107 und der Ausgangssituation mit Normaltyrode sowie der Vergleich mit der Kontrolle mittels 2Wege-ANOVA aufgrund der hohen Variabilität, die sich in den Standardfehlern darstellt, keine signifikanten Unterschiede auf. Die Betrachtung der $\mathrm{Ca}^{2+}$-Amplituden $\mathrm{F} / \mathrm{F}_{0}$ ergibt keine signifikanten Unterschiede zwischen ENO107 und der Kontrollgruppe. Allenfalls ist eine tendenzielle Reduktion der Amplituden bei 0,1 $\mu \mathrm{M}$ und $1 \mu \mathrm{M}$ EN0107 im Vergleich zur Kontrolle erkennbar. Die statistische Untersuchung des Relaxationsverhaltens von ENO107 ergibt im Vergleich zur Kontrolle keine signifikanten Unterschiede. In der ENO107-Gruppe bleibt die $\mathrm{RT}_{50}$ bei allen Konzentrationen in etwa konstant, bei 0,1 $\mu \mathrm{M}$ ist sie im Vergleich zur Kontrolle tendenziell leicht beschleunigt, bei $10 \mu \mathrm{M}$ hingegen verlangsamt. Der Abfall der $\mathrm{Ca}^{2+}$-Transienten ist bei höchster ENO107-Konzentration $(10 \mu \mathrm{M})$ gegenüber der Kontrolle ebenfalls leicht verlangsamt, jedoch in nicht signifikantem Ausmaß (Abb.3.7).
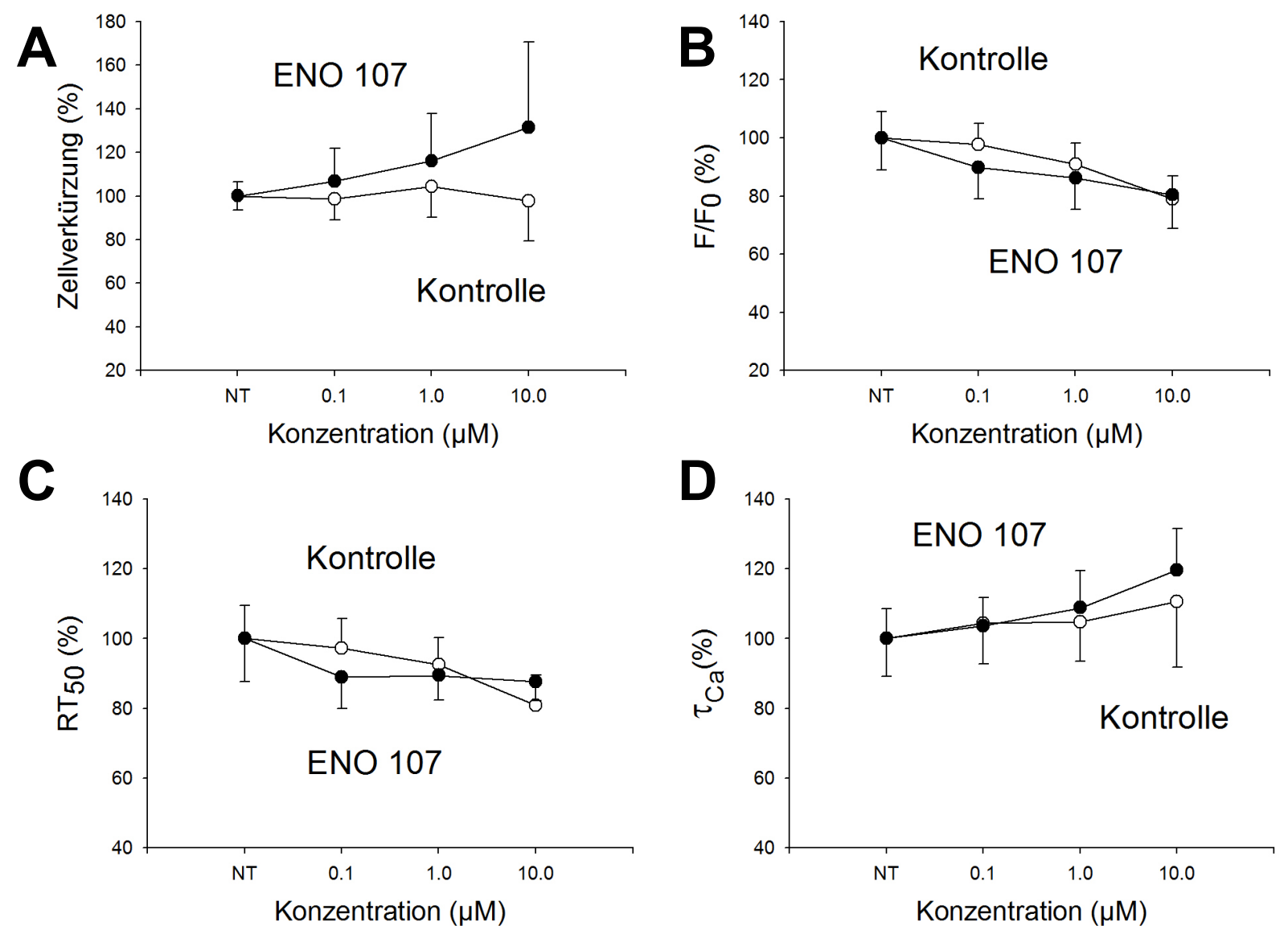

Abb. 3.7 Screeningergebnisse von ENO107 $(n=7)$ vs. Kontrolle $(n=8)$

A: Relative Zellverkürzung in Prozent der durchschnittlichen Zellverkürzung unter NT; B: Relative $\mathrm{Ca}^{2+}$-Transienten in Prozent des durchschnittlichen $\mathrm{Ca}^{2+}$-Transienten unter NT; C: Relative Relaxationszeit in Prozent der durchschnittlichen Relaxationszeit unter NT; D: Relativer Abfallsexponent in Prozent des durchschnittlichen Abfallsexponenten unter NT; Signifikanzen: keine 


\subsubsection{ENO114}

Während bei niedrigster und mittlerer Konzentration $(0,1 \mu \mathrm{M}$ bzw. $1 \mu \mathrm{M})$ des SERCA2aModulators ENO114 noch keine eindeutigen Veränderungen der fraktionellen Zellverkürzung zu sehen sind, nimmt diese bei der $10 \mu \mathrm{M}$-Lösung im Vergleich zur Kontrolle signifikant zu $(p=0,01)$. Dieser positiv inotrope Effekt bei $10 \mu \mathrm{M}$ ist bereits optisch in den Originalregistrierungen festzustellen. In der unten stehenden Abbildung 3.8 sind zwei exemplarische Originalaufzeichnungen der Zellverkürzung bei $10 \mu \mathrm{M}$ dargestellt. Bei $10 \mu \mathrm{M}$ des SERCA2aModulators ENO114 beträgt die fraktionelle Zellverkürzung in Prozent des Ausgangswertes bei Normaltyrode 149,8\% $\pm 14,4 \%$, während sie bei der Kontrolle $87,4 \% \pm 13,8 \%$ beträgt.
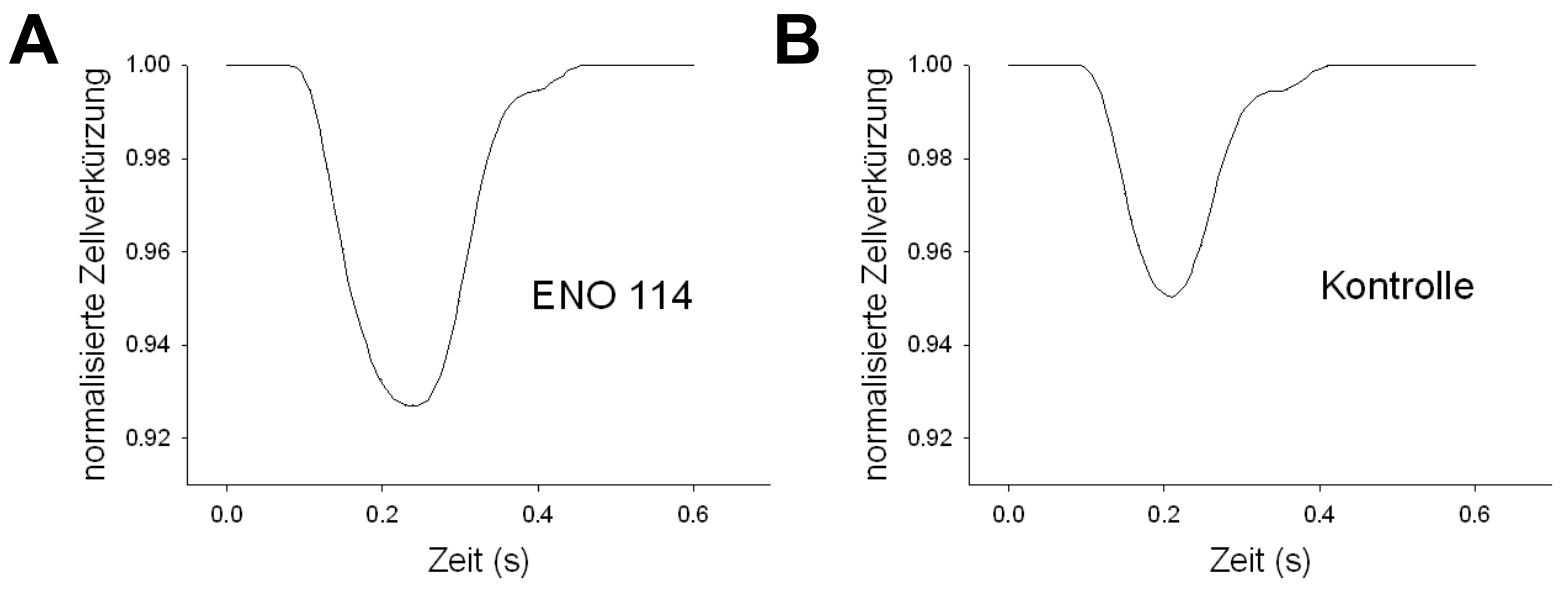

Abb. 3.8 Examplarische Originalregistrierung der normalsierten Zellverkürzung einer ENO114 - Zelle (A) und einer Kontroll-Zelle (B) unter Stimulation von $2 \mathrm{~Hz}$

Bemerkenswerter Weise wurden 3 der 8 gemessenen Zellen unter höchster ENO114 Konzentration von $10 \mu \mathrm{M}$ kurzzeitig arrhythmisch, wie Abb. 3.9 exemplarisch zeigt.

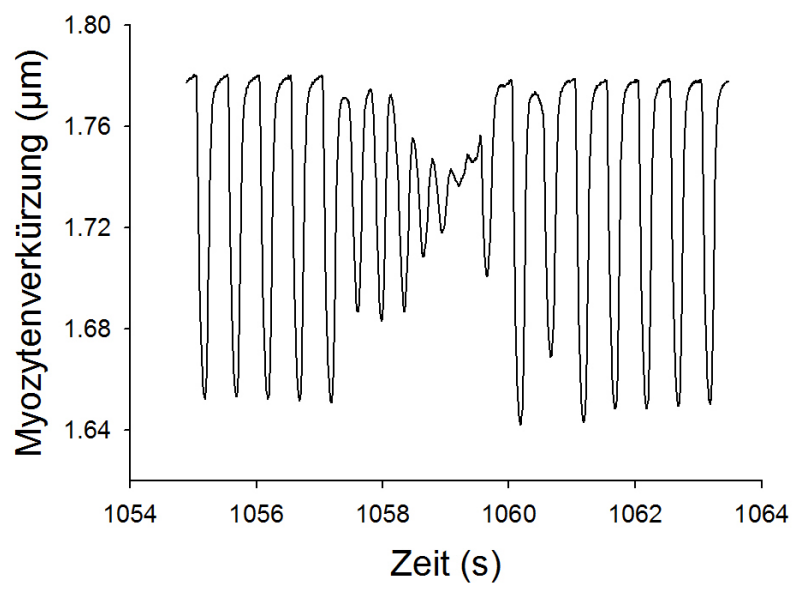

Abb. 3.9 Exemplarische Originalregistrierung einer kurzzeitigen Arrhythmie unter $10 \mu \mathrm{M}$ des SERCA2a-Modulators ENO114. Dargestellt ist die Myozytenverkürzung im Verlauf der Zeit.

Die Amplitude der $\mathrm{Ca}^{2+}$-Transienten wird von dem SERCA2a-Modulator ENO114 nicht signifikant beeinflusst, tendenziell ist der $\mathrm{Ca}^{2+}$-Transienten bei $10 \mu \mathrm{M}$ etwas größer als bei der Kontrolle. 
Die Relaxationszeit $\mathrm{RT}_{50}$ bleibt bei allen Konzentrationen von ENO114 konstant, im Vergleich zur Kontrolle ist allenfalls eine leichte Verlangsamung mit zunehmender Konzentration zu sehen. Auch bezüglich der Geschwindigkeit der zytosolischen Kalziumelimination $\tau$ gibt es keine signifikanten Unterschiede zwischen Stoff und Kontrolle. Tendenziell ist der Abfallsexponent $\tau$ bei $1 \mu \mathrm{M}$ und $10 \mu \mathrm{M}$ ENO114 etwas größer als bei der Kontrolle, $\mathrm{d}$. $\mathrm{h}$. die zytosolische Kalziumelimination leicht verlangsamt (Abb. 3.10).

A
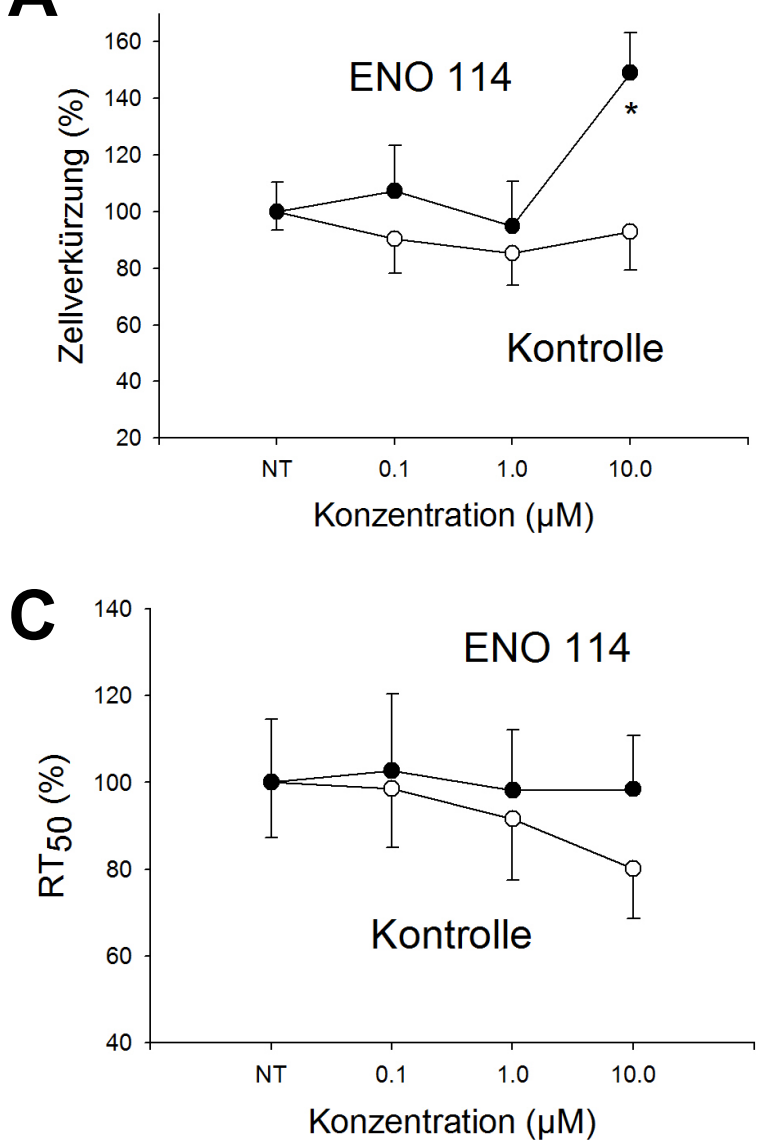

B
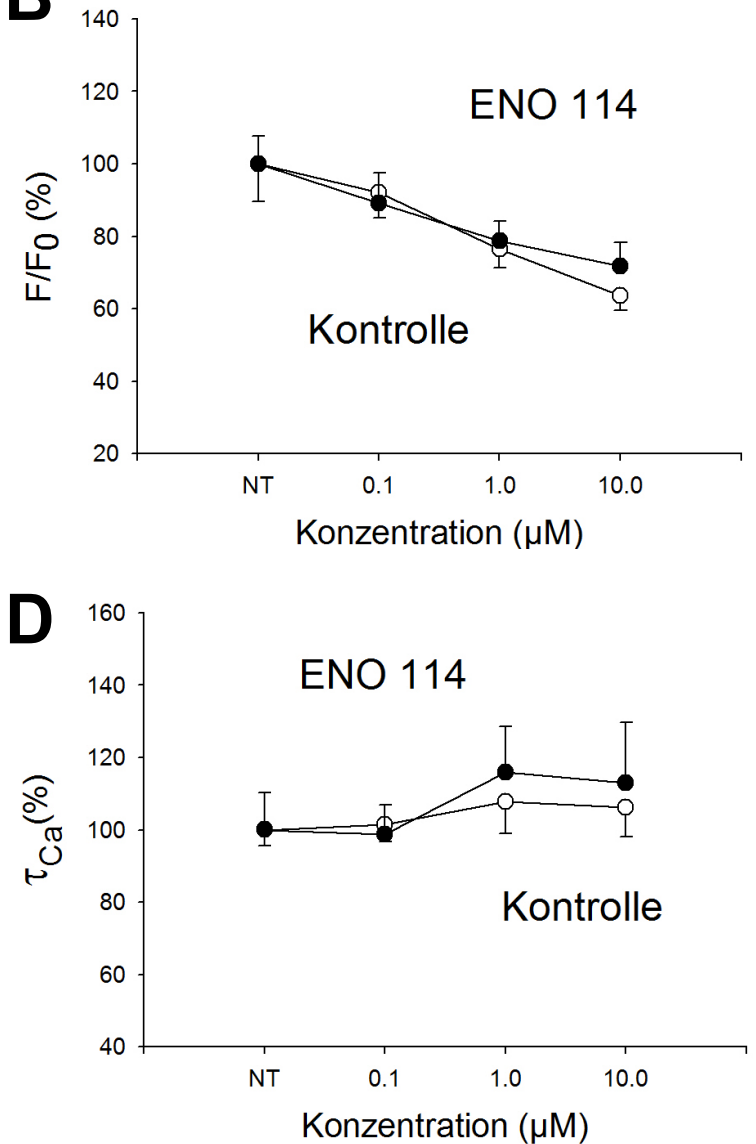

Abb. 3.10 Screeningergebnisse von ENO114 $(n=8)$ vs. Kontrolle $(n=8)$

A: Relative Zellverkürzung in Prozent der durchschnittlichen Zellverkürzung unter NT; B: Relative $\mathrm{Ca}^{2+}$-Transienten in Prozent des durchschnittlichen $\mathrm{Ca}^{2+}$-Transienten unter NT; C: Relative Relaxationszeit in Prozent der durchschnittlichen Relaxationszeit unter NT; D: Relativer Abfallsexponent in Prozent des durchschnittlichen Abfallsexponenten unter NT;

* Signifikanz mit $p=0,01$ zwischen ENO114 und Kontrolle 


\subsubsection{ENO166}

Wie aus Abb. 3.11 A ersichtlich, zeigt der SERCA2a-Modulator ENO166 weder einen Effekt auf die Kontraktilität noch auf die $\mathrm{Ca}^{2+}$-Transienten der Zellen. Im Vergleich zur Kontrollgruppe liegen bezüglich dieser Messgrößen keine signifikanten Veränderungen vor.

Die statistische Untersuchung des Relaxationsverhaltens von ENO166 ergibt im Vergleich zur Kontrolle weder tendenzielle noch signifikante Unterschiede. Der Abfall der $\mathrm{Ca}^{2+}$ Amplituden ist bei höchster ENO166-Konzentration $(10 \mu \mathrm{M})$ tendenziell langsamer als der der Kontrolle, mit $p=0,16$ allerdings nicht signifikant.
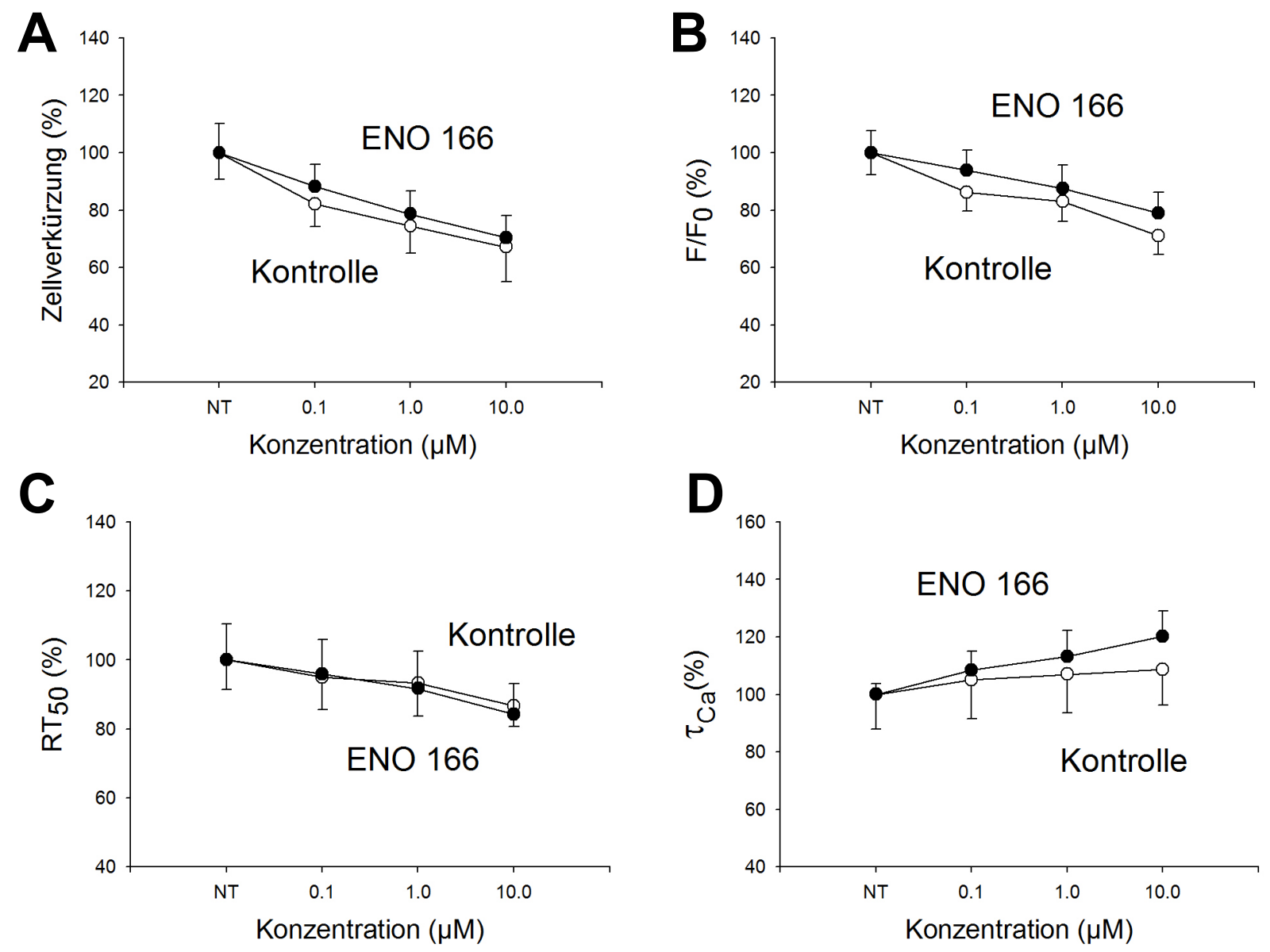

Abb. 3.11 Screeningergebnisse von ENO166 $(n=7)$ vs. Kontrolle $(n=8)$

A: Relative Zellverkürzung in Prozent der durchschnittlichen Zellverkürzung unter NT; B: Relative $\mathrm{Ca}^{2+}-$ Transienten in Prozent des durchschnittlichen $\mathrm{Ca}^{2+}{ }_{-}$Transienten unter NT; C: Relative Relaxationszeit in Prozent der durchschnittlichen Relaxationszeit unter NT; D: Relativer Abfallsexponent in Prozent des durchschnittlichen Abfallsexponenten unter NT; Signifikanzen: keine 


\subsubsection{ENO 185}

Bei $0,1 \mu \mathrm{M}$ und $1 \mu \mathrm{M}$ des SERCA2a-Modulators ENO185 ist im Vergleich zum Ausgangswert und zur Kontrolle eine tendenzielle Zunahme der fraktionellen Zellverkürzung zu sehen, die im Vergleich zur Kontrolle aber jeweils nicht signifikant ist. Bei der Betrachtung der $\mathrm{Ca}^{2+}$ Amplituden $\mathrm{F} / \mathrm{F}_{0}$ fällt auf, dass diese bei $1 \mu \mathrm{M}$ und $10 \mu \mathrm{M}$ ENO185-Lösung im Vergleich zur Kontrolle zunehmen, jedoch nicht signifikant (bei $10 \mu \mathrm{M} p=0,07$ ).

In der Tendenz ist die Relaxationszeit $\mathrm{RT}_{50}$ bei $1 \mu \mathrm{M}$ und $10 \mu \mathrm{M}$ gegenüber der Kontrolle etwas verlängert. Ebenso ist die zytosolische $\mathrm{Ca}^{2+}$-Elimination bei $10 \mu \mathrm{M}$ im Vergleich zur Kontrolle tendenziell verlangsamt ( $p=n . s$.), erkennbar am vergrößerten Abfallsexponenten $\tau$ (Abb. 3.12).
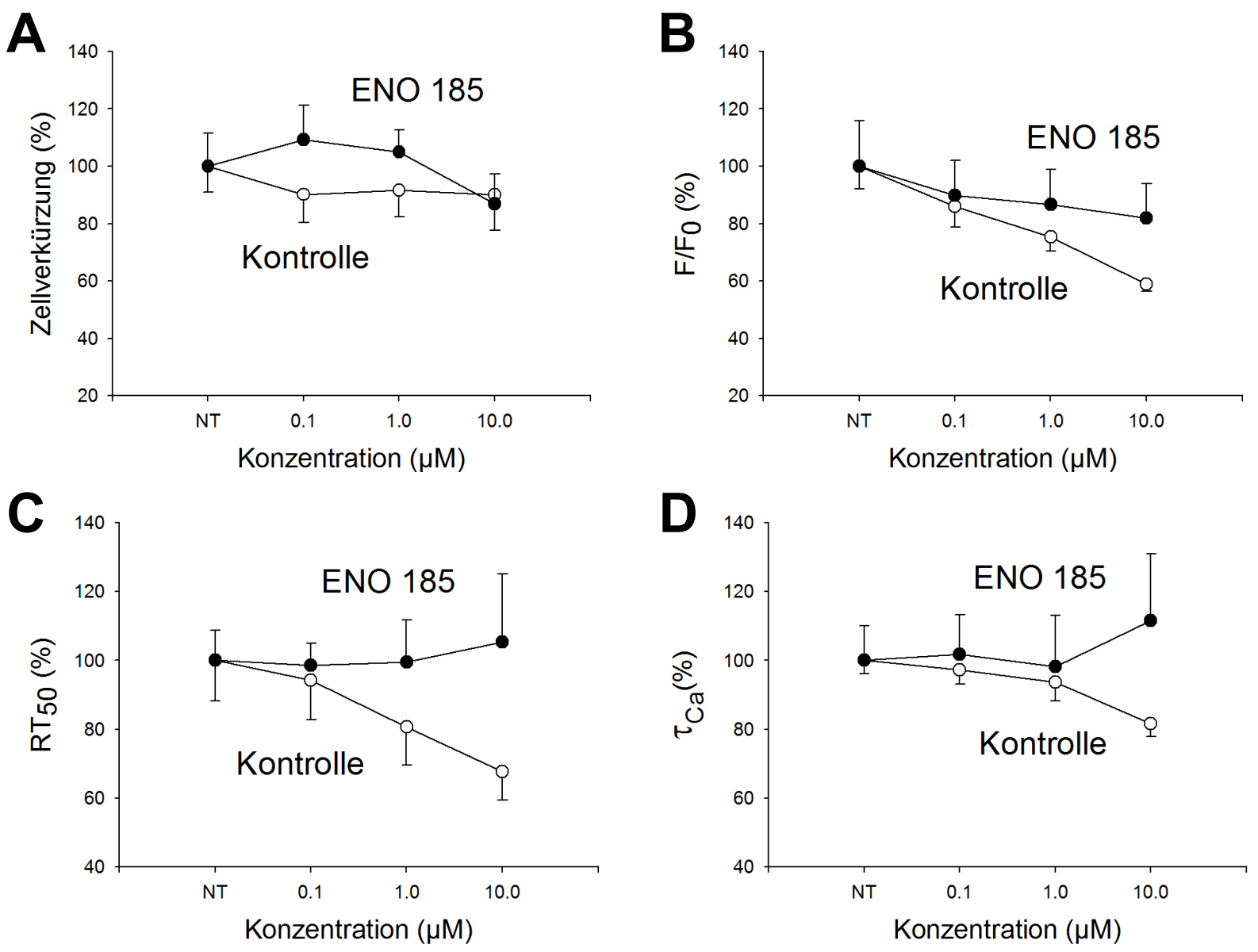

Abb. 3.12 Screeningergebnisse von ENO185 $(n=7)$ vs. Kontrolle $(n=7)$

A: Relative Zellverkürzung in Prozent der durchschnittlichen Zellverkürzung unter NT; B: Relative $\mathrm{Ca}^{2+}-$ Transienten in Prozent des durchschnittlichen $\mathrm{Ca}^{2+}{ }_{-}$Transienten unter NT; C: Relative Relaxationszeit in Prozent der durchschnittlichen Relaxationszeit unter NT; D: Relativer Abfallsexponent in Prozent des durchschnittlichen Abfallsexponenten unter NT; Signifikanzen: keine 


\subsubsection{ENO187}

Der SERCA2a-Modulator ENO187 zeigt weder einen Effekt auf die Kontraktilität noch auf die $\mathrm{Ca}^{2+}$-Transienten der Zellen. Im Vergleich zur Kontrollgruppe liegen bezüglich dieser Messgrößen keine signifikanten Veränderungen vor.

Auch die statistische Untersuchung des Relaxationsverhaltens und des Abfalls der $\mathrm{Ca}^{2+}$ Amplituden ergeben im Vergleich zur Kontrolle keine signifikanten Unterschiede. Allenfalls ist bei beiden Messgrößen eine minimale Verlangsamung erkennbar.
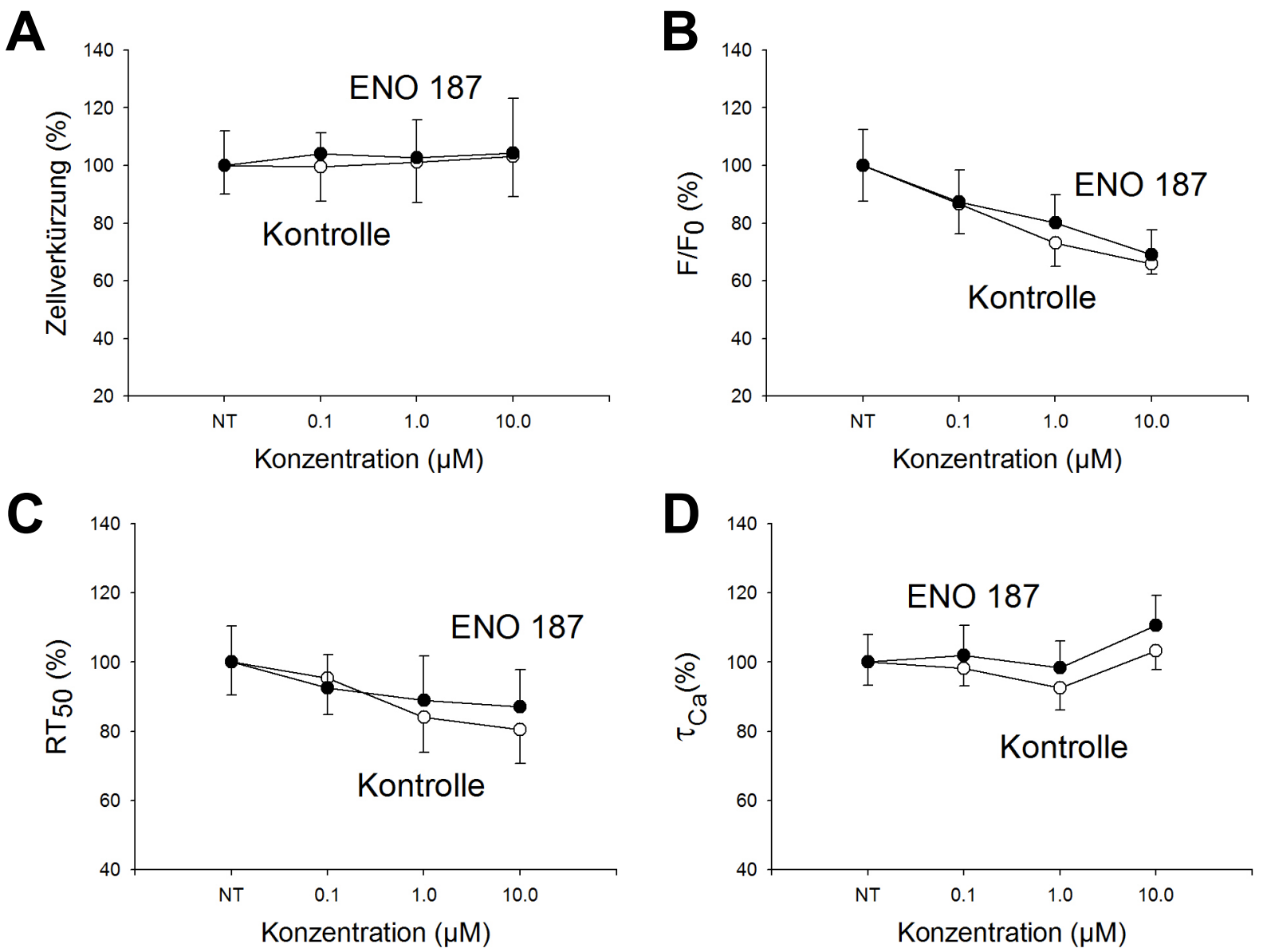

Abb. 3.13 Screeningergebnisse von ENO187 $(n=6)$ vs. Kontrolle $(n=7)$

A: Relative Zellverkürzung in Prozent der durchschnittlichen Zellverkürzung unter NT; B: Relative $\mathrm{Ca}^{2+}-$ Transienten in Prozent des durchschnittlichen $\mathrm{Ca}^{2+}{ }_{-}$Transienten unter NT; C: Relative Relaxationszeit in Prozent der durchschnittlichen Relaxationszeit unter NT; D: Relativer Abfallsexponent in Prozent des durchschnittlichen Abfallsexponenten unter NT; Signifikanzen: keine 


\subsubsection{ENO207}

Die konzentrationsabhängige Untersuchung des SERCA2a-Modulators ENO207 ergab, dass bei der fraktionellen Zellverkürzung und bei den $\mathrm{Ca}^{2+}$-Transienten im Vergleich zur Kontrollgruppe keine signifikanten Veränderungen vorliegen. Sowohl bei ENO207 als auch bei der Kontrolle nehmen beide Messgrößen über den Zeitraum des Versuches kontinuierlich und in etwa gleichem Umfang ab.

Auch bezüglich der Relaxationszeit $\mathrm{RT}_{50}$ und des $\mathrm{Ca}^{2+}$-Abfall-Exponenten $\tau$ sind keine Veränderungen nachweisbar.
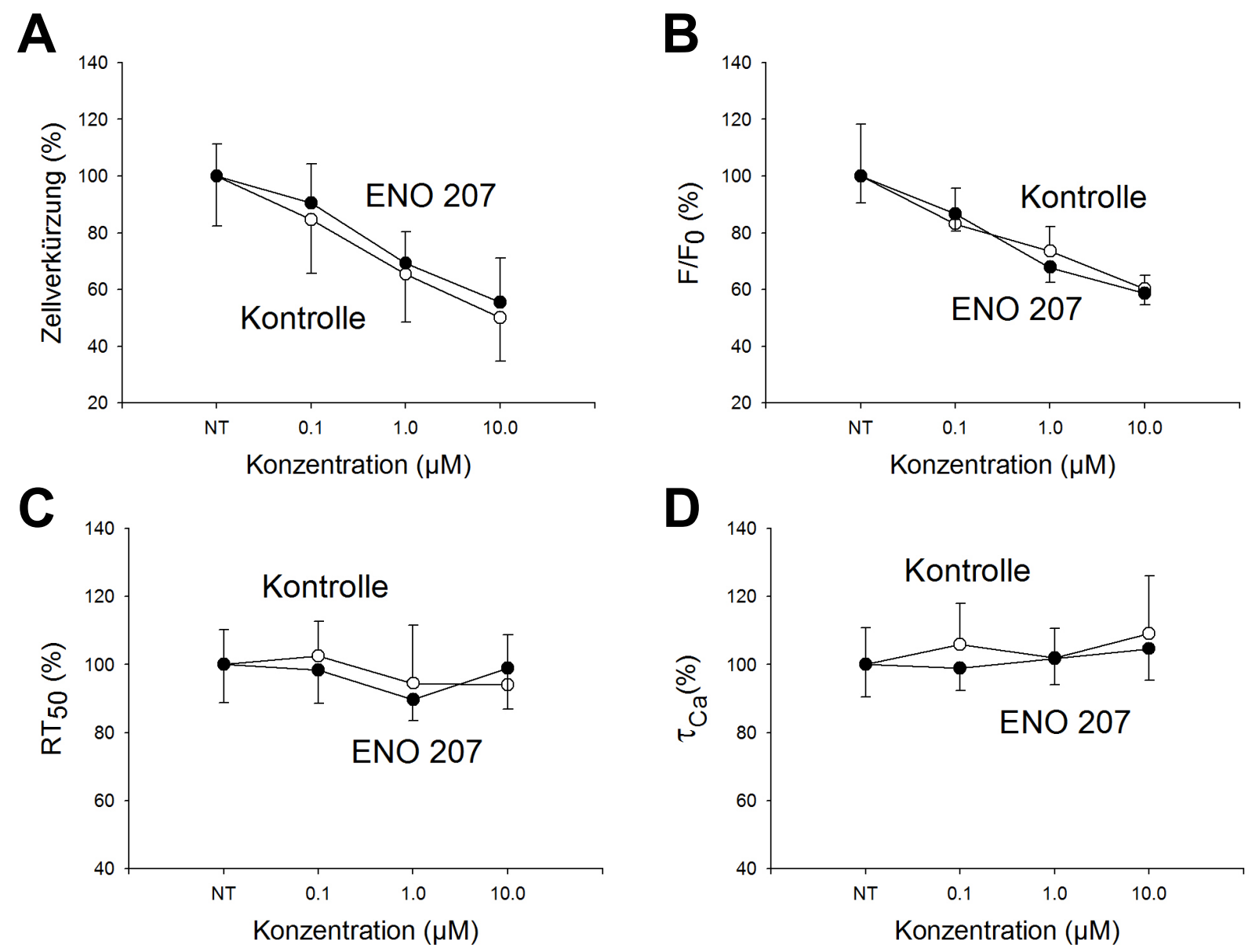

Abb. 3.14 Screeningergebnisse von ENO207 (n=7) vs. Kontrolle $(n=6)$

A: Relative Zellverkürzung in Prozent der durchschnittlichen Zellverkürzung unter NT; B: Relative $\mathrm{Ca}^{2+}-$ Transienten in Prozent des durchschnittlichen $\mathrm{Ca}^{2+}-$ Transienten unter NT; C: Relative Relaxationszeit in Prozent der durchschnittlichen Relaxationszeit unter NT; D: Relativer Abfallsexponent in Prozent des durchschnittlichen Abfallsexponenten unter NT; Signifikanzen: keine 


\subsubsection{ENO209}

Wie aus Abb. 3.15 ersichtlich, bewirkt der SERCA2a-Modulator ENO209 hinsichtlich der Kontraktilität und der $\mathrm{Ca}^{2+}$-Amplituden der Zellen keine signifikanten Änderungen im Vergleich zur Kontrolle.

Auch die Relaxationszeit der Zellen bleibt von ENO209 unbeeinflusst, ohne signifikante Unterschiede zur Kontrollgruppe. Der Abfallsexponent $\tau$ der $\mathrm{Ca}^{2+}$ - Amplituden ist bei mittlerer und höchster ENO209-Konzentration ( $1 \mu \mathrm{M}$ und $10 \mu \mathrm{M})$ tendenziell größer als die der Kontrolle, d. h. die Kalziumelimination unter ENO209 etwas langsamer, statistisch jedoch in nicht signifikantem Umfang.

A

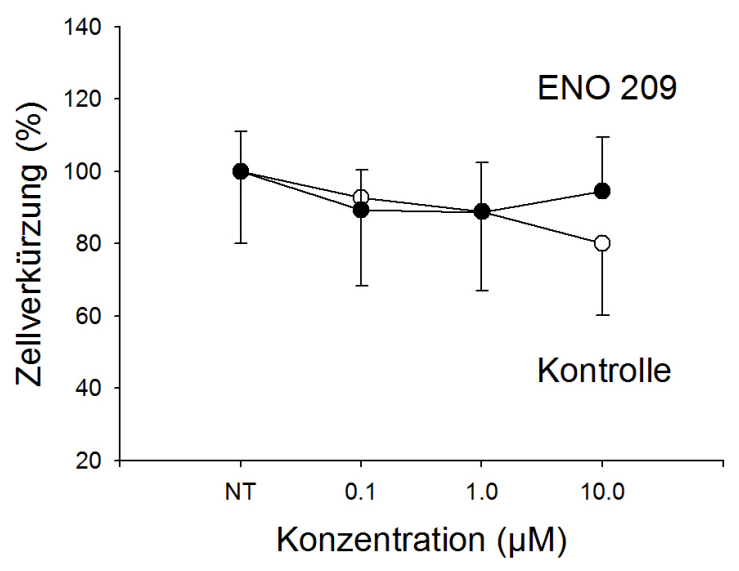

C

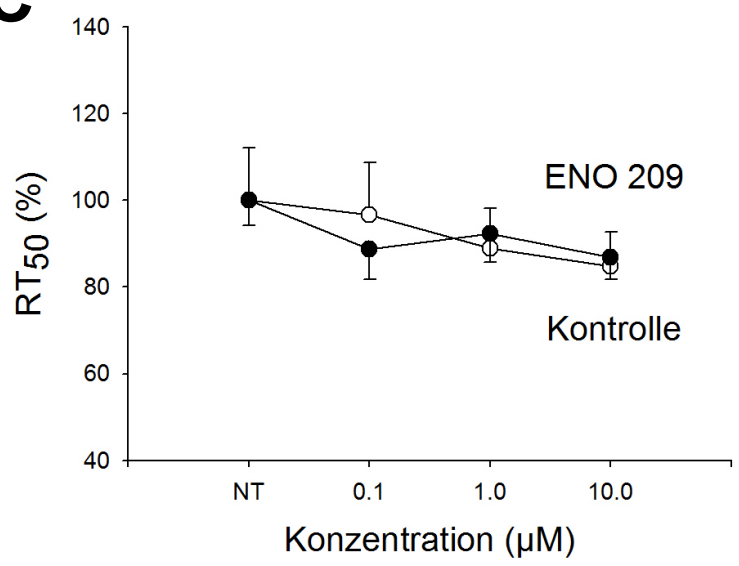

B

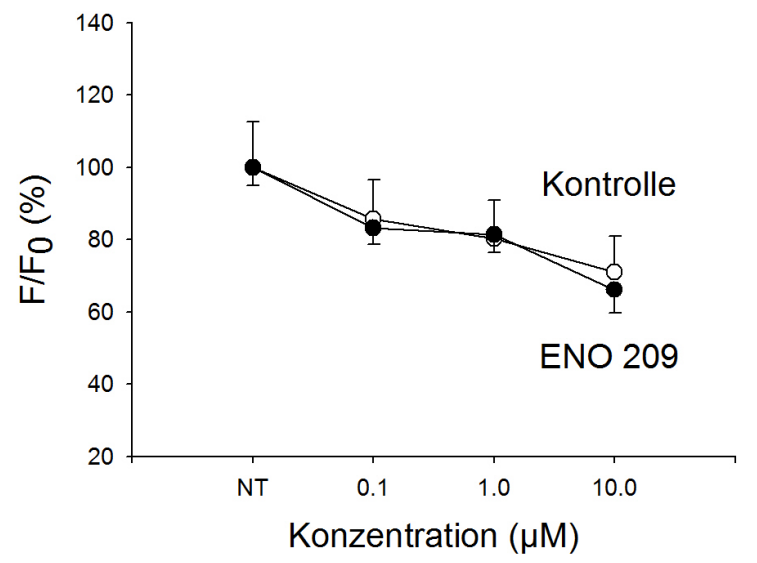

D

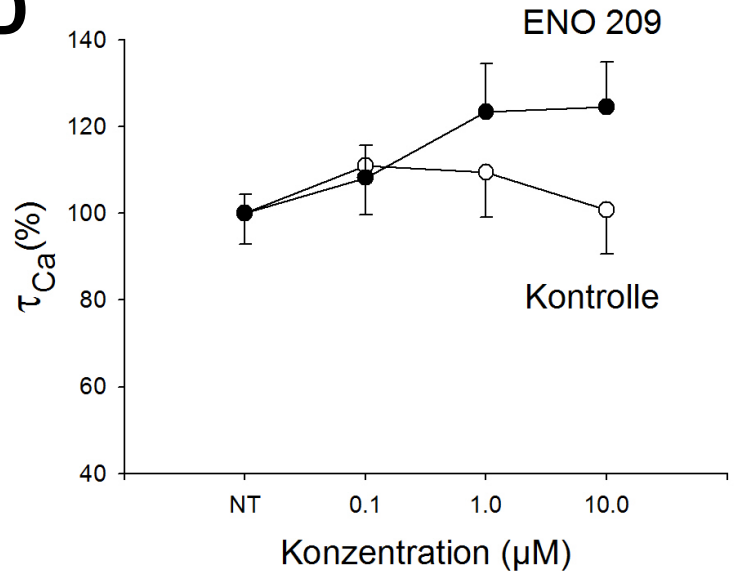

Abb. 3.15 Screeningergebnisse von ENO209 $(n=7)$ vs. Kontrolle $(n=7)$

A: Relative Zellverkürzung in Prozent der durchschnittlichen Zellverkürzung unter NT; B: Relative $\mathrm{Ca}^{2+}$-Transienten in Prozent des durchschnittlichen $\mathrm{Ca}^{2+}-$ Transienten unter NT; C: Relative Relaxationszeit in Prozent der durchschnittlichen Relaxationszeit unter NT; D: Relativer Abfallsexponent in Prozent des durchschnittlichen Abfallsexponenten unter NT; Signifikanzen: keine 


\subsubsection{GPZ000876}

Der SERCA2a-Modulator GPZ000876 bewirkt hinsichtlich der Kontraktilität der Zellen keine signifikanten Änderungen im Vergleich zur Kontrolle.

Auch bei der Untersuchung der $\mathrm{Ca}^{2+}$-Amplituden, der Relaxationszeit $\mathrm{RT}_{50}$ und der zytosolischen Kalziumelimination ergeben sich, wie in Abb. 3.16 dargestellt, keine Unterschiede im Vergleich zur Kontrolle.

A

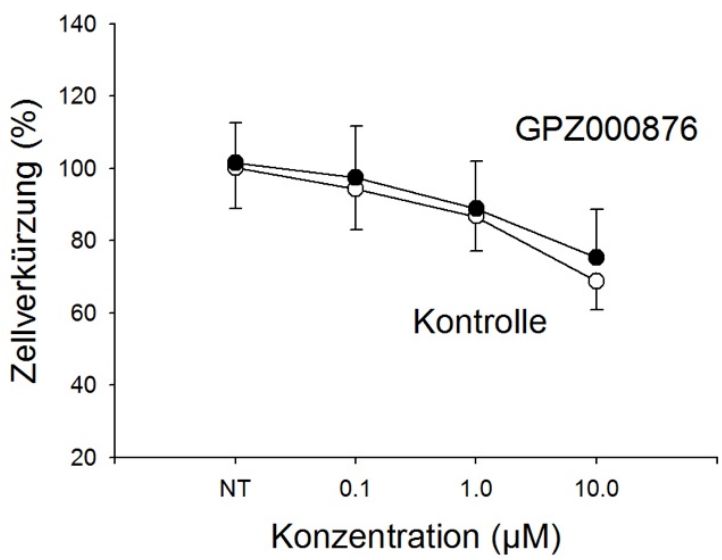

C

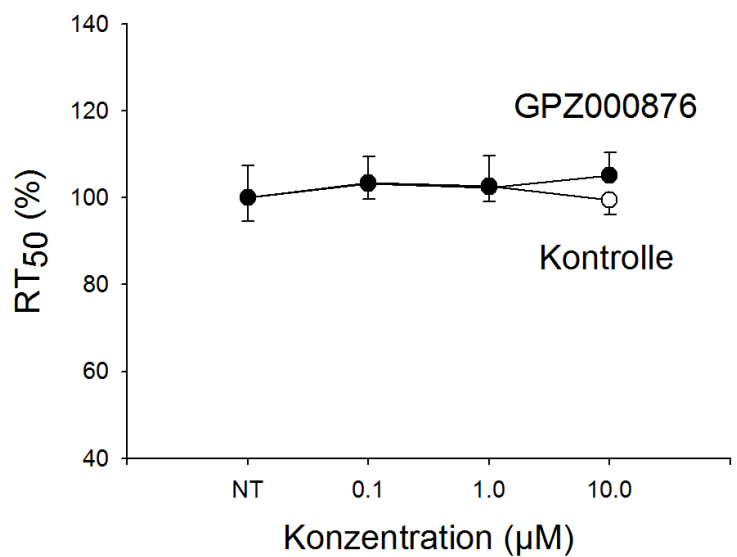

B

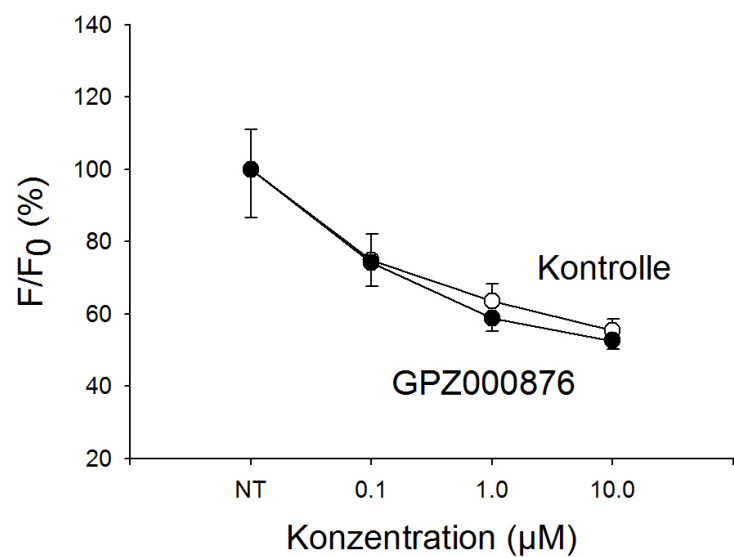

D

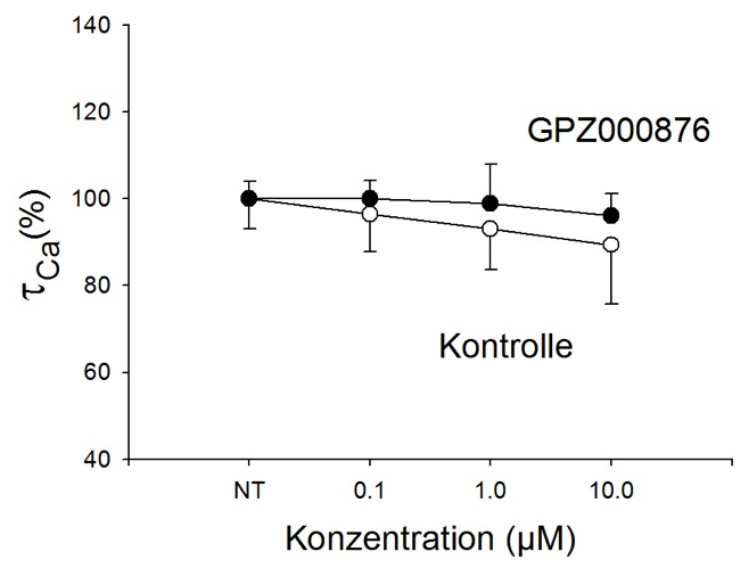

Abb. 3.16 Screeningergebnisse von GPZ000876 $(n=7)$ vs. Kontrolle $(n=7)$

A: Relative Zellverkürzung in Prozent der durchschnittlichen Zellverkürzung unter NT; B: Relative $\mathrm{Ca}^{2+}$-Transienten in Prozent des durchschnittlichen $\mathrm{Ca}^{2+}-$ Transienten unter NT; C: Relative Relaxationszeit in Prozent der durchschnittlichen Relaxationszeit unter NT; D: Relativer Abfallsexponent in Prozent des durchschnittlichen Abfallsexponenten unter NT; Signifikanzen: keine 


\subsubsection{GPZ001441}

Wie aus Abb. 3.17 ersichtlich, zeigt der SERCA2a-Modulator GPZ001441 weder einen Effekt auf die Kontraktilität noch auf die $\mathrm{Ca}^{2+}$-Transienten der Zellen. Im Vergleich zur Kontrollgruppe liegen bezüglich dieser Messgrößen keine signifikanten Veränderungen vor. In gleicher Weise verhalten sich die Relaxationszeit und der Abfall der $\mathrm{Ca}^{2+}-$ Amplituden: Beide Messgrößen bleiben von GPZ001441 unbeeinflusst, ohne signifikante Unterschiede zur Kontrollgruppe. Tendenziell ist die Relaxation bei $10 \mu \mathrm{M}$ gegenüber der Kontrolle etwas verlangsamt.
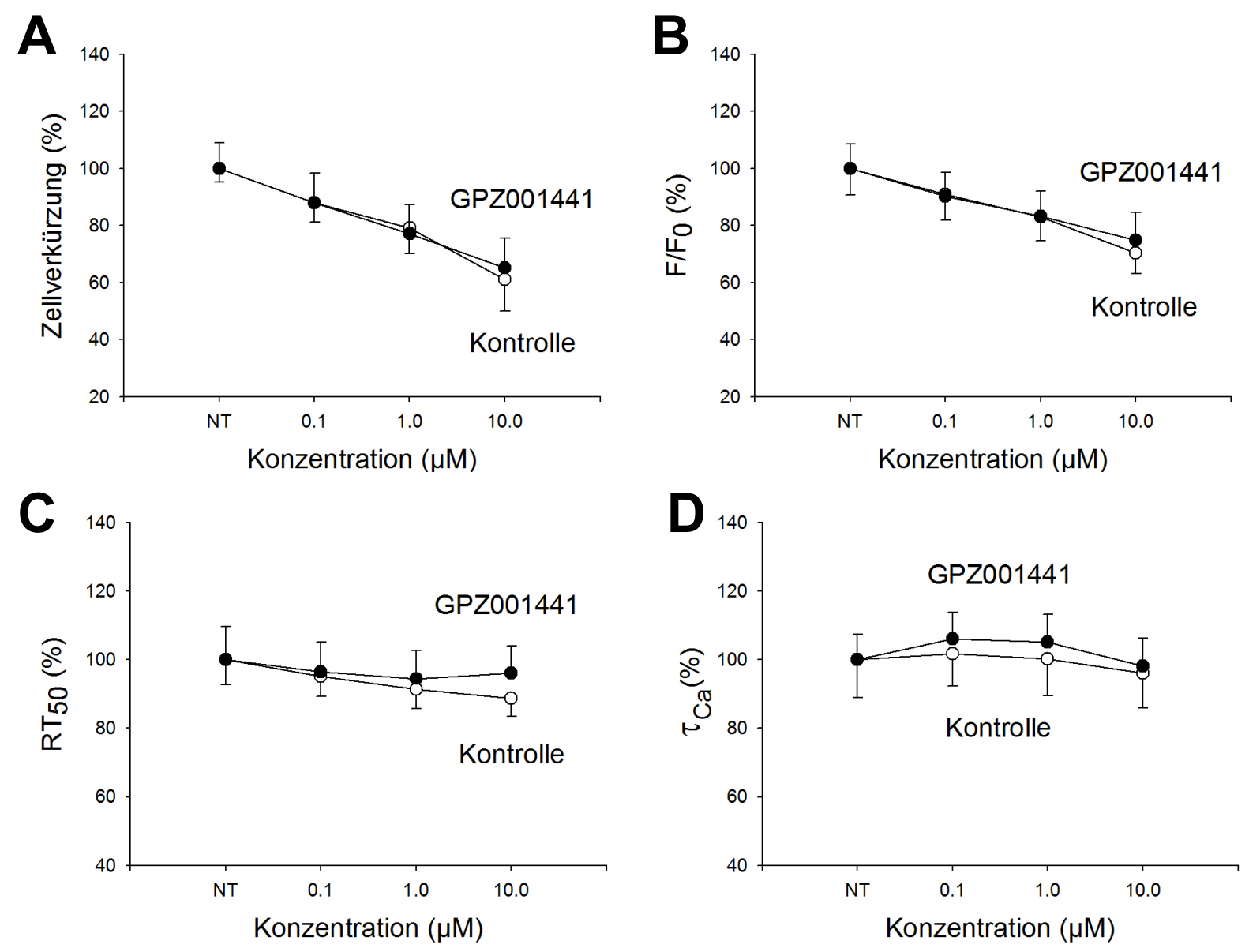

Abb. 3.17 Screeningergebnisse von GPZ001441 $(n=7)$ vs. Kontrolle $(n=7)$

A: Relative Zellverkürzung in Prozent der durchschnittlichen Zellverkürzung unter NT; B: Relative $\mathrm{Ca}^{2+}$-Transienten in Prozent des durchschnittlichen $\mathrm{Ca}^{2+}-$ Transienten unter NT; C: Relative Relaxationszeit in Prozent der durchschnittlichen Relaxationszeit unter NT; D: Relativer Abfallsexponent in Prozent des durchschnittlichen Abfallsexponenten unter NT; Signifikanzen: keine 


\subsubsection{GPZ003362}

Im Vergleich zur Kontrolle zeigt der SERCA2a-Modulator GPZ003362 bei allen Konzentrationen eine tendenzielle Zunahme der Kontraktilität, aufgrund der hohen Standardfehler ist diese bei allen Konzentrationen jedoch nicht signifikant.

Die Amplitude der $\mathrm{Ca}^{2+}$-Transienten wird von dem SERCA2a-Modulator GPZ003362 in keiner Weise beeinflusst. Wie in Abb. 3.18 B dargestellt, reduziert sich die Amplitude der GPZ003362-Gruppe bei steigender Konzentration in gleichem Umfang wie die der Kontrollgruppe.

Auch in der Relaxationszeit $\mathrm{RT}_{50}$ und der Geschwindigkeit der zytosolischen Kalziumelimination zeigen sich keine signifikanten Veränderungen zwischen GPZ003362 und Kontrolle. In der Tendenz ist die Kalziumelimination bei allen Konzentrationen des Stoffes GPZ003362 im Vergleich zur Kontrolle minimal beschleunigt.
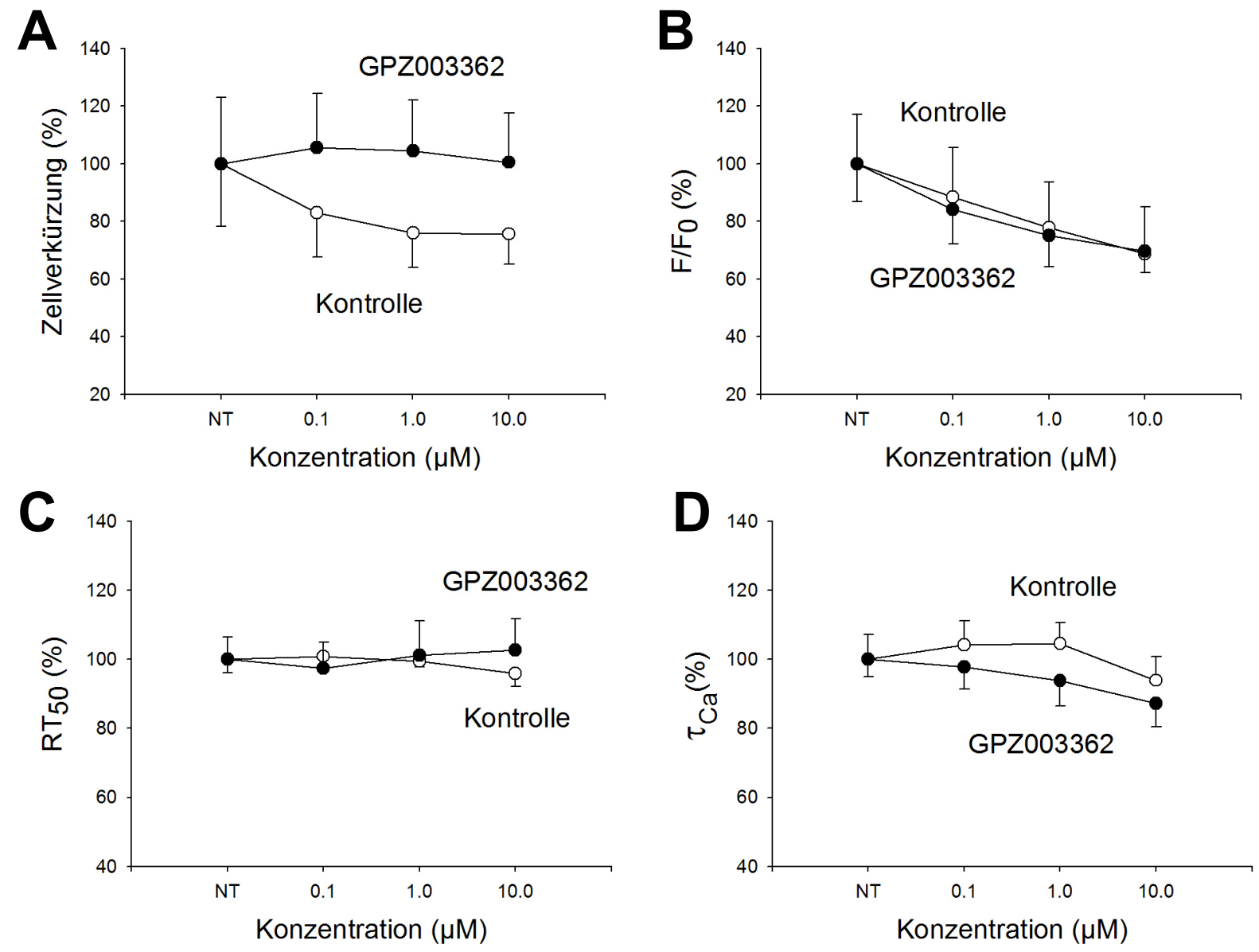

Abb. 3.18 Screeningergebnisse von GPZ003362 $(n=7)$ vs. Kontrolle $(n=6)$

A: Relative Zellverkürzung in Prozent der durchschnittlichen Zellverkürzung unter NT; B: Relative $\mathrm{Ca}^{2+}-$ Transienten in Prozent des durchschnittlichen $\mathrm{Ca}^{2+}{ }_{-}$Transienten unter NT; C: Relative Relaxationszeit in Prozent der durchschnittlichen Relaxationszeit unter NT; D: Relativer Abfallsexponent in Prozent des durchschnittlichen Abfallsexponenten unter NT; Signifikanzen: keine 


\subsubsection{GPZ006800}

Wie in Abb. 3.19 A dargestellt, nimmt die Kontraktilität durch den SERCA2a-Modulator GPZ006800 mit steigender Konzentration zunehmend und im Vergleich zur Kontrollgruppe stärker ab, jedoch in nicht signifikantem Umfang.

Die Amplituden der $\mathrm{Ca}^{2+}$-Transienten dagegen nehmen im Verlauf des Versuches weniger ab als die der Kontrollgruppe. Im statistischen Vergleich weisen beide Gruppen bezüglich dieser Messgröße jedoch keine signifikanten Unterschiede auf.

Beim Vergleich der $\mathrm{RT}_{50}$ sind zwischen SERCA2a-Modulator und Kontrolle keine tendenziellen und signifikanten Unterschiede feststellbar.

Der Abfallsexponent $\tau$ der $\mathrm{Ca}^{2+}$ - Amplituden ist bei allen Konzentrationen von GPZ006800 größer als der der Kontrolle, d. h. die Kalziumelimination tendenziell verlangsamt, statistisch jedoch ohne Signifikanz.
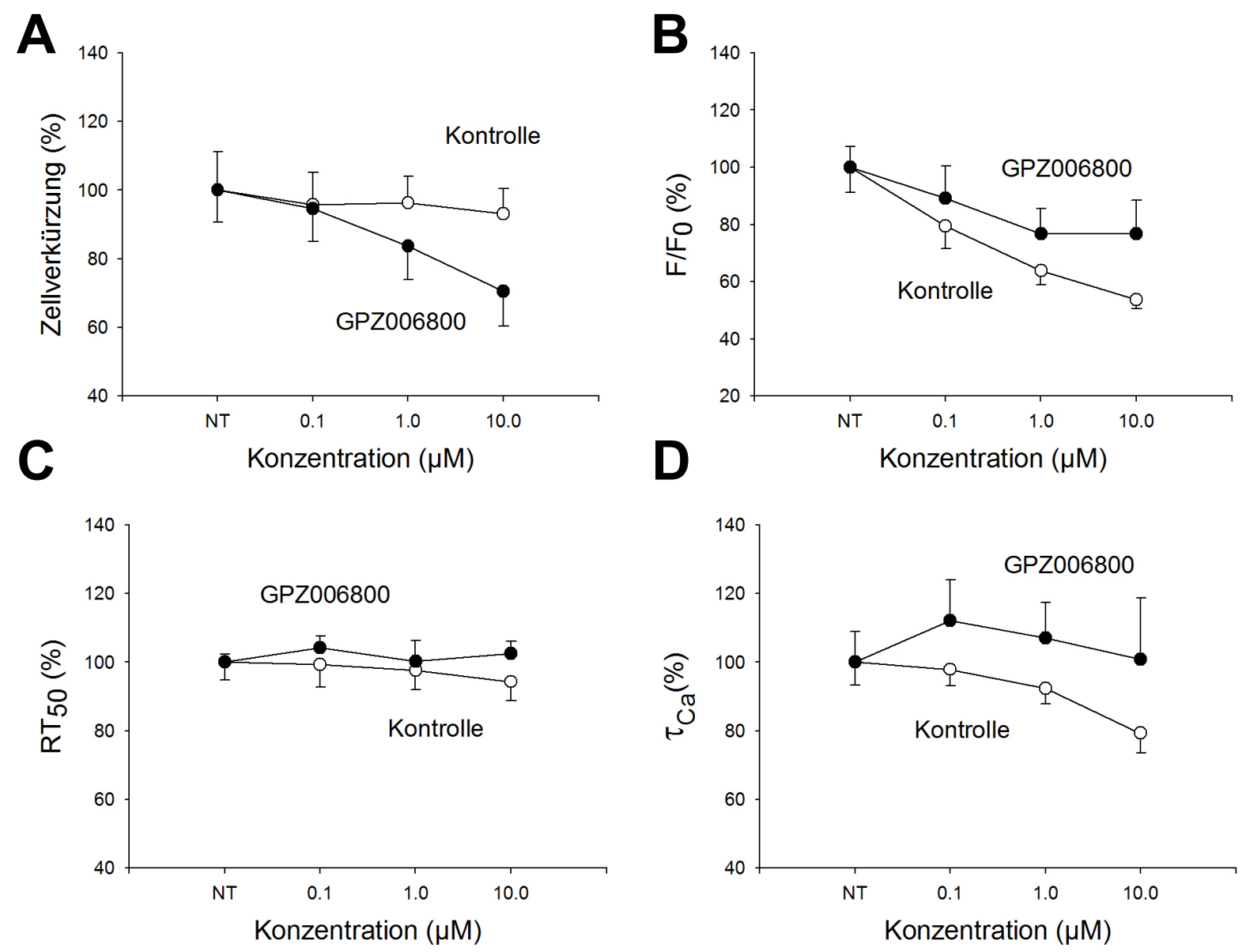

Abb. 3.19 Screeningergebnisse von GPZ006800 $(n=6)$ vs. Kontrolle $(n=6)$

A: Relative Zellverkürzung in Prozent der durchschnittlichen Zellverkürzung unter NT; B: Relative $\mathrm{Ca}^{2+}-$ Transienten in Prozent des durchschnittlichen $\mathrm{Ca}^{2+}{ }_{-}$Transienten unter NT; C: Relative Relaxationszeit in Prozent der durchschnittlichen Relaxationszeit unter NT; D: Relativer Abfallsexponent in Prozent des durchschnittlichen Abfallsexponenten unter NT; Signifikanzen: keine 


\subsubsection{GPZ007738}

Die konzentrationsabhängige Untersuchung des SERCA2a-Modulators GPZ007738 ergab, dass er weder einen Effekt auf die Kontraktilität noch auf die $\mathrm{Ca}^{2+}{ }_{-}$Transienten der Zellen zeigt. Im Vergleich zur Kontrollgruppe liegen bezüglich dieser Messgrößen keine signifikanten Veränderungen vor.

Auch die statistische Untersuchung des Relaxationsverhaltens und des Abfalls der $\mathrm{Ca}^{2+}$ Amplituden ergeben im Vergleich zur Kontrolle keine signifikanten Unterschiede. Beide Messgrößen weisen eher auf eine tendenziell geringere SERCA2a-Aktivität unter GPZ007738 hin als unter Kontrolle, wie Abb. 3.20 zeigt, wie oben beschrieben jedoch ohne Effekt auf Kontraktilität und $\mathrm{Ca}^{2+}-$ Transienten.
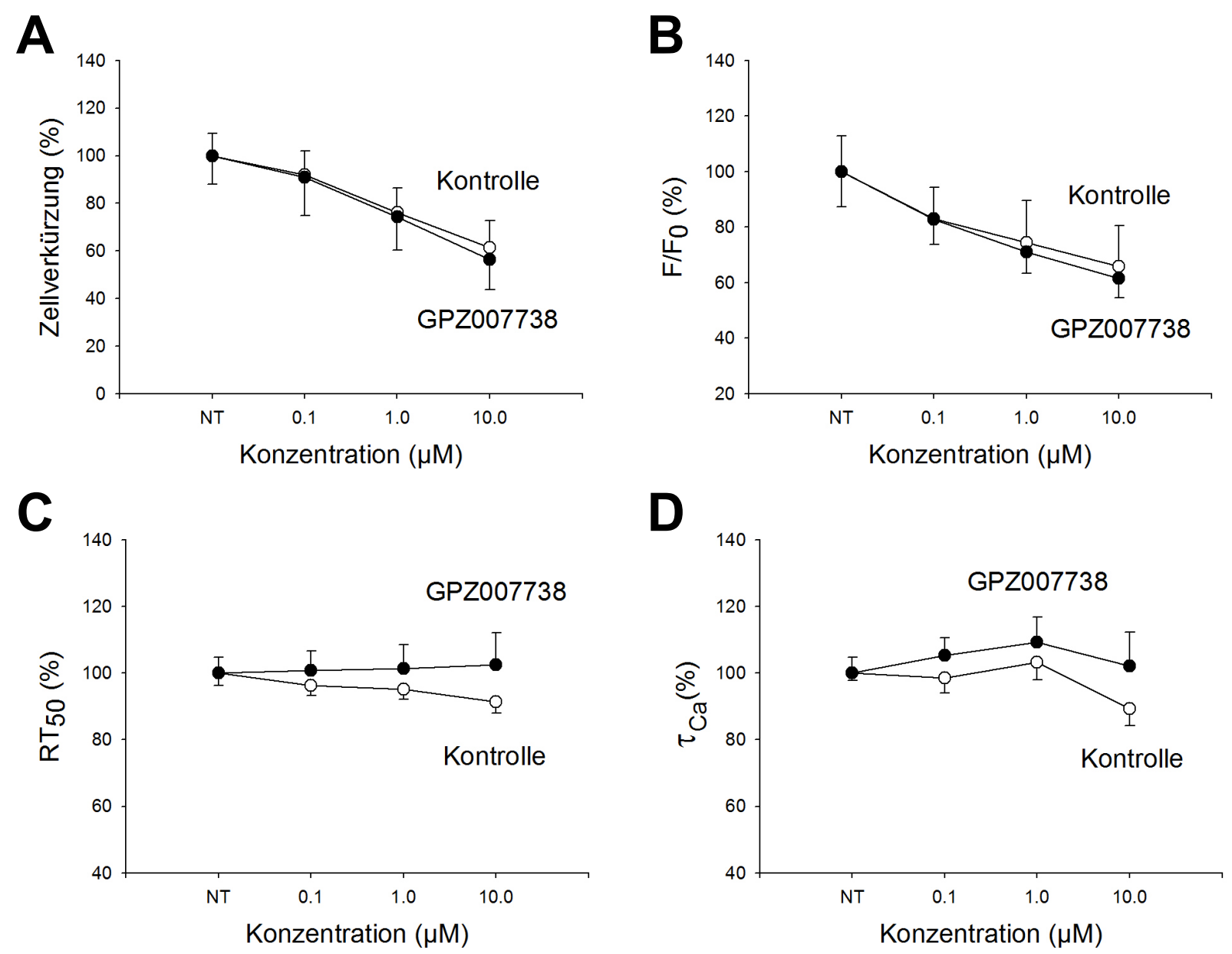

Abb. 3.20 Screeningergebnisse von GPZ007738 $(n=7)$ vs. Kontrolle $(n=8)$

A: Relative Zellverkürzung in Prozent der durchschnittlichen Zellverkürzung unter NT; B: Relative $\mathrm{Ca}^{2+}-$ Transienten in Prozent des durchschnittlichen $\mathrm{Ca}^{2+}-$ Transienten unter NT; C: Relative Relaxationszeit in Prozent der durchschnittlichen Relaxationszeit unter NT; D: Relativer Abfallsexponent in Prozent des durchschnittlichen Abfallsexponenten unter NT; Signifikanzen: keine 


\subsubsection{Zusammenfassung des Screenings}

Aufgrund der Zielsetzung dieser Arbeit, einen womöglich geeigneten Stoff zur Behandlung der Herzinsuffizienz zu finden, wurden diejenigen SERCA2a-Modulatoren, die eine Tendenz zur positiven Inotropie zeigten, hinsichtlich ihrer Auswirkung auf den SR-Kalziumgehalt und auf Muskelzellverbände näher untersucht. Zu den tendenziell positiv inotropen SERCA2aModulatoren zählen ENL055, ENO107, ENO114, ENO185, ENO209 und GPZ003362.

\subsection{Einfluss auf den SR $\mathrm{Ca}^{2+}-$ Gehalt}

Zur direkten Messung des SR $\mathrm{Ca}^{2+}$-Gehaltes mittels lokaler Koffein-Applikation wurde diejenige Konzentration des SERCA2a-Modulators gewählt, bei der die positive Inotropie in den Versuchen zuvor am deutlichsten ausgeprägt war.

\subsubsection{ENL055}

Wie aus Abb. 3.21 ersichtlich, fällt die koffeininduzierte $\mathrm{Ca}^{2+}$-Amplitude bei ENL055 etwas kleiner aus als bei der Kontrolle, im statistischen Vergleich jedoch nicht signifikant.
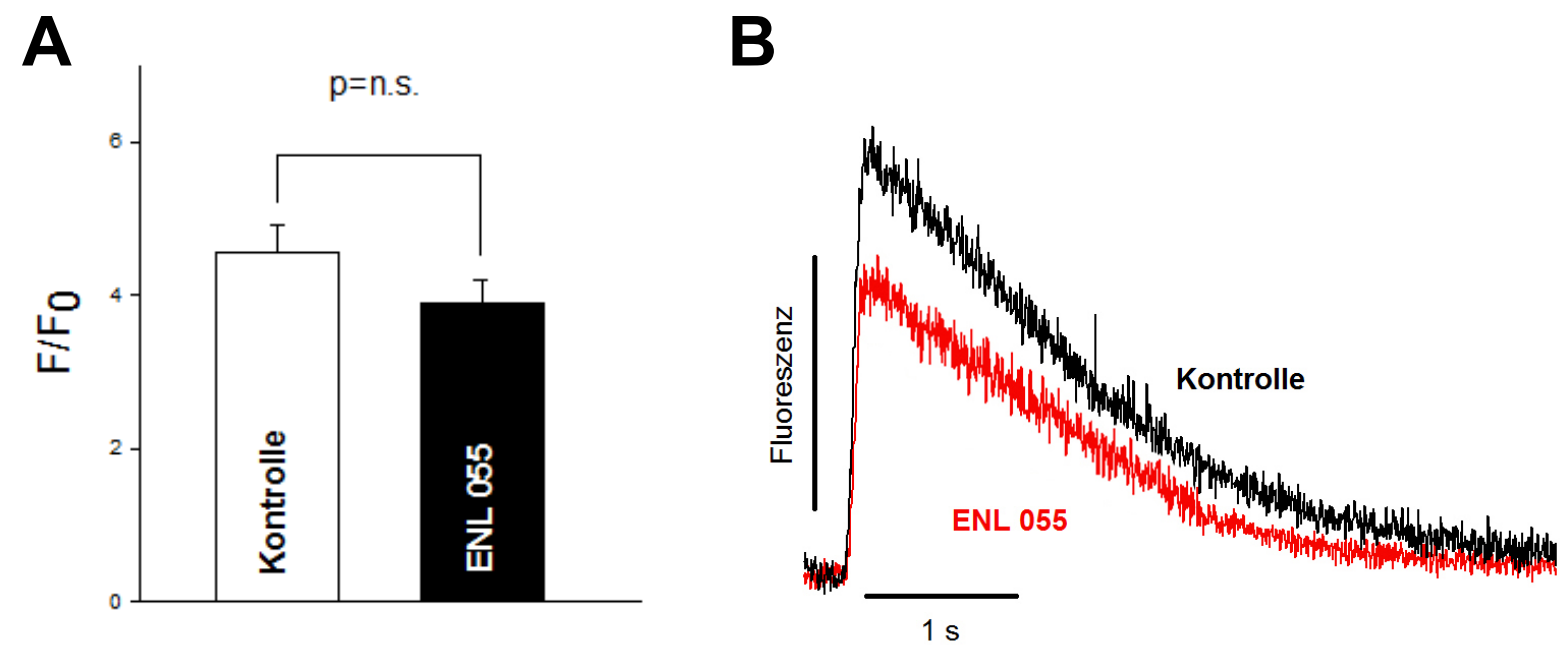

Abb 3.21 Auswirkungen von ENL055 auf den SR $\mathrm{Ca}^{2+}$-Gehalt von Ratten-Kardiomyozyten

A: Mittelwerte der koffeininduzierten $\mathrm{Ca}^{2+}$-Transienten-Amplitude $\mathrm{F} / \mathrm{F}_{0}$ von Kontrolle $(n=16)$ und ENL055 ( $\mathrm{n}=11)$; B: Repräsentative Originalregistrierung der $\mathrm{Ca}^{2+}-$ Transienten nach KoffeinApplikation; Signifikanzen: keine 


\subsubsection{ENO107}

Die Amplitude der Koffein-induzierten $\mathrm{Ca}^{2+}$-Transienten ist bei ENO107 größer als bei der Kontrolle, jedoch nicht signifikant, wie der Abb. 3.22 zu entnehmen ist.

A

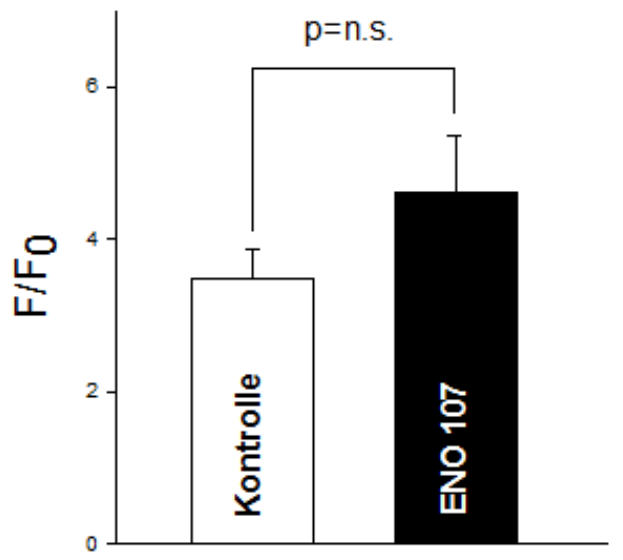

B

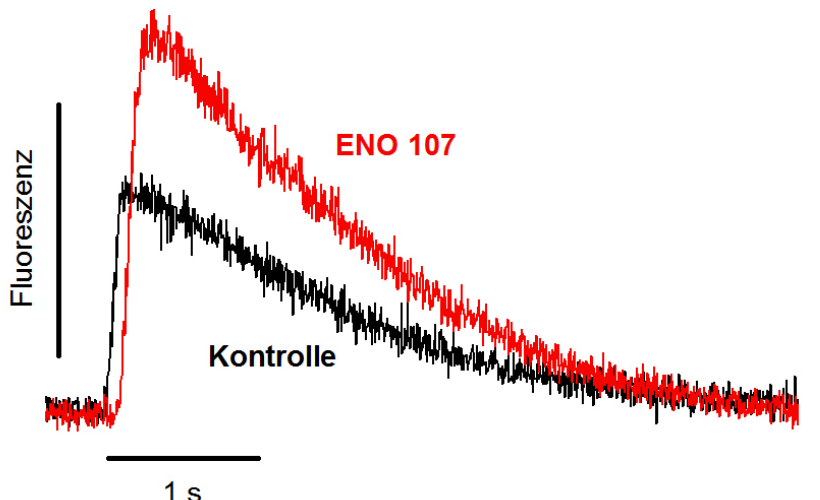

Abb 3.22 Auswirkungen von ENO107 auf den SR Ca ${ }^{2+}$-Gehalt von Ratten-Kardiomyozyten A: Mittelwerte der koffeininduzierten $\mathrm{Ca}^{2+}$-Transienten-Amplitude $F / F_{0}$ von Kontrolle $(n=11)$ und ENO107 ( $n=13)$; B: Repräsentative Originalregistrierung der $\mathrm{Ca}^{2+}-$ Transienten nach KoffeinApplikation; Signifikanzen: keine

\subsubsection{ENO114}

Die Amplitude der Koffein-induzierten $\mathrm{Ca}^{2+}$-Transienten nimmt durch ENO114 tendenziell zu, im Vergleich zur Kontrolle jedoch ohne signifikantes Niveau.
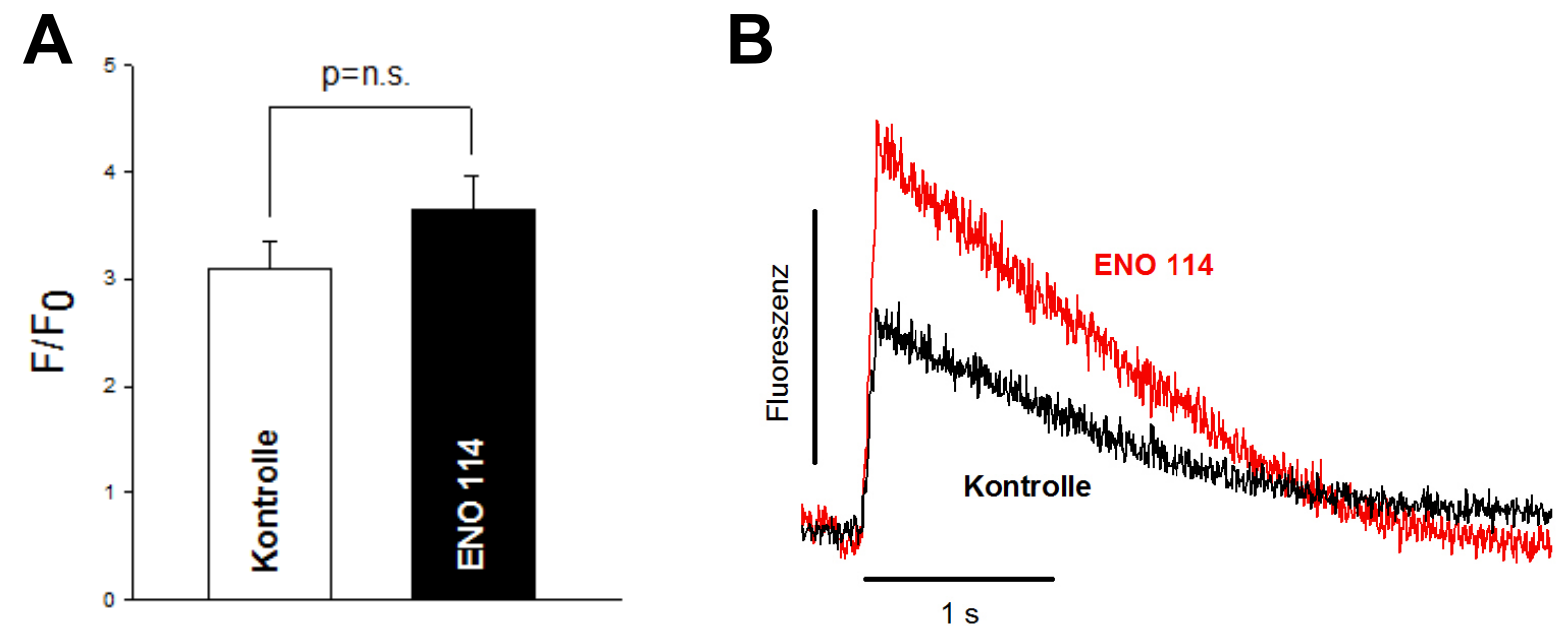

Abb 3.23 Auswirkungen von ENO114 auf den SR Ca ${ }^{2+}$-Gehalt von Ratten-Kardiomyozyten

A: Mittelwerte der koffeininduzierten $\mathrm{Ca}^{2+}$-Transienten-Amplitude $F / F_{0}$ von Kontrolle $(n=14)$ und ENO114 ( $n=15)$; B: Repräsentative Originalregistrierung der $\mathrm{Ca}^{2+}$-Transienten nach KoffeinApplikation; Signifikanzen: keine 


\subsubsection{ENO185}

Die Koffein-induzierten $\mathrm{Ca}^{2+}$-Amplituden fallen bei ENO185 und der Kontrolle etwa gleich groß aus, wie aus Abb. 3.24 ersichtlich.
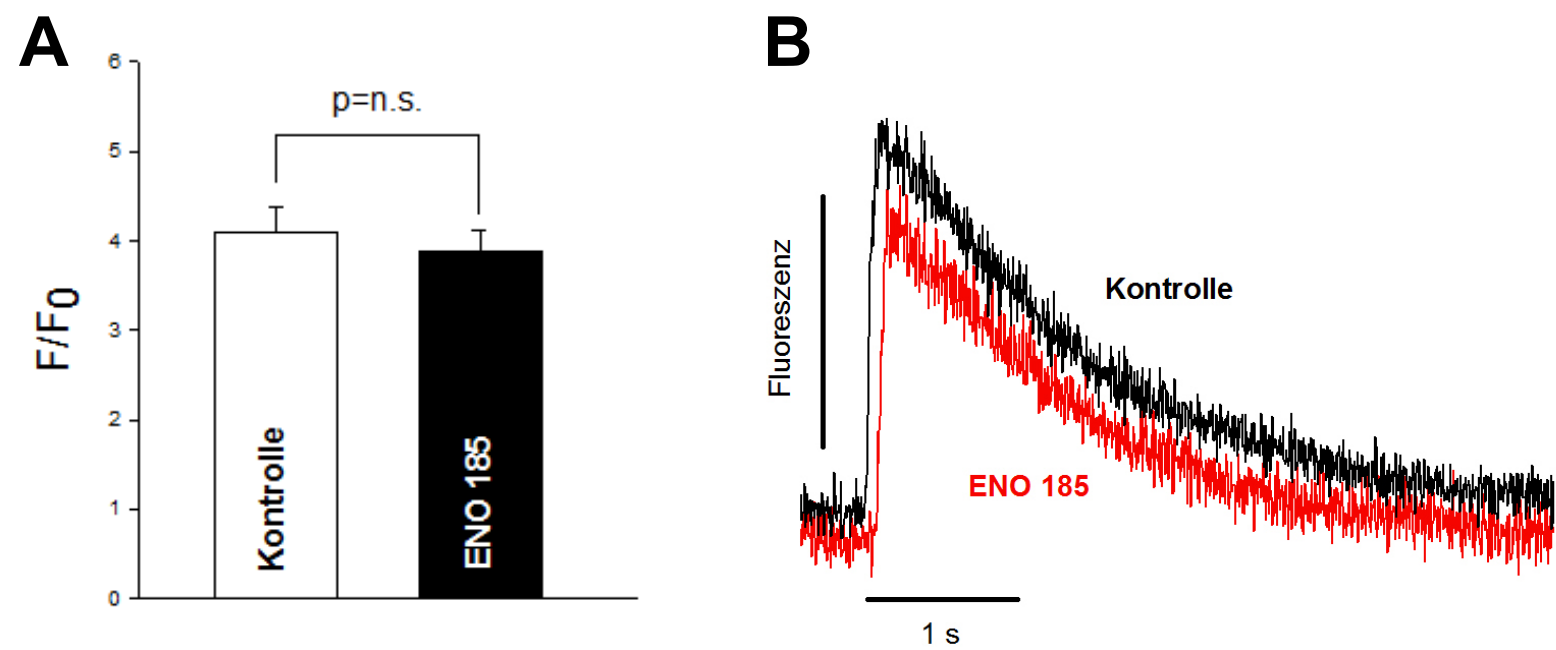

Abb 3.24 Auswirkungen von ENO185 auf den SR Ca ${ }^{2+}$-Gehalt von Ratten-Kardiomyozyten

A: Mittelwerte der koffeininduzierten $\mathrm{Ca}^{2+}$-Transienten-Amplitude $\mathrm{F} / \mathrm{F}_{0}$ von Kontrolle $(n=12)$ und ENO185 $(n=12) ; \quad B:$ Repräsentative Originalregistrierung der $\mathrm{Ca}^{2+}$-Transienten nach KoffeinApplikation; Signifikanzen: keine

\subsubsection{ENO209}

Die Koffein- induzierten $\mathrm{Ca}^{2+}$-Amplituden beider Gruppen unterscheiden sich kaum. Tendenziell ist die Amplitude durch ENO209 gegenüber der Kontrolle minimal vergrößert.
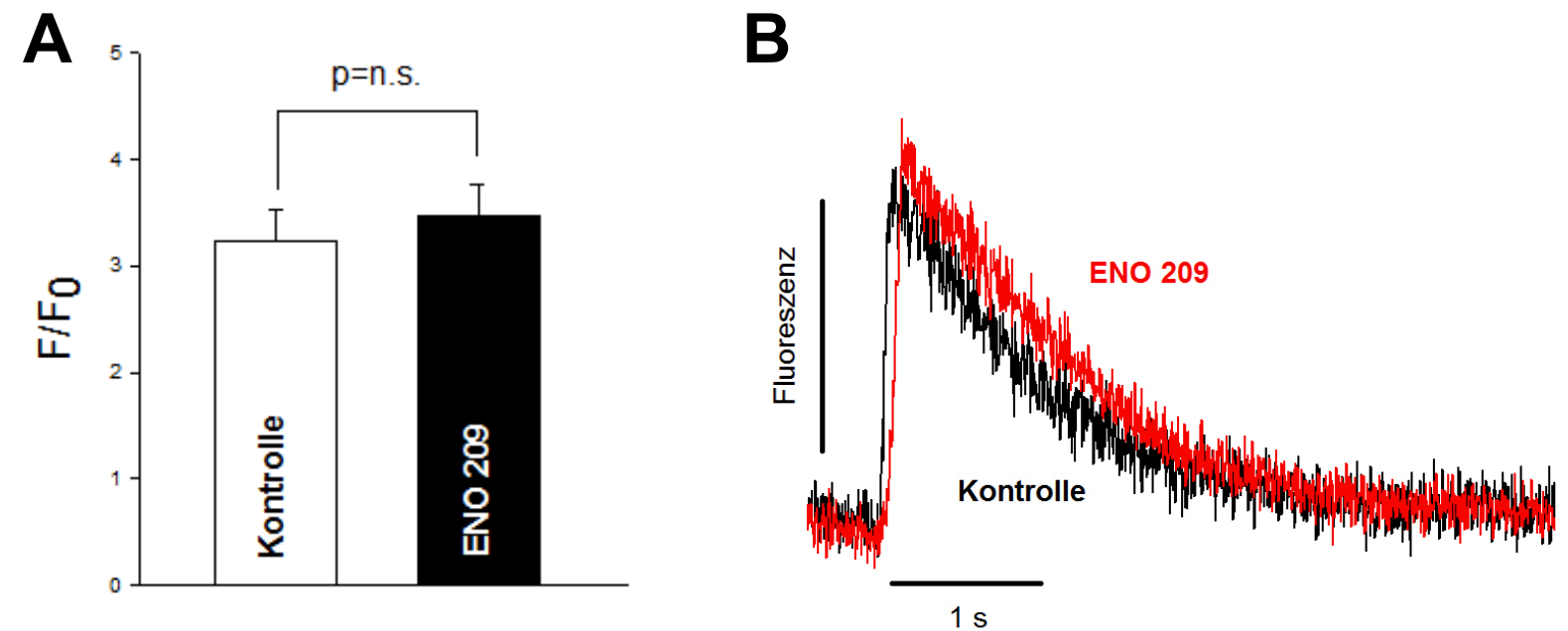

Abb 3.25 Auswirkungen von ENO209 auf den SR Ca ${ }^{2+}$-Gehalt von Ratten-Kardiomyozyten

A: Mittelwerte der koffeininduzierten $\mathrm{Ca}^{2+}$-Transienten-Amplitude $\mathrm{F} / \mathrm{F}_{0}$ von Kontrolle $(n=14)$ und ENO209 $(n=10) ; \quad B:$ Repräsentative Originalregistrierung der $\mathrm{Ca}^{2+}-$ Transienten nach KoffeinApplikation; Signifikanzen: keine 


\subsubsection{GPZ003362}

Die Koffein-induzierte $\mathrm{Ca}^{2+}$-Amplitude ist unter GPZ003362 tendenziell etwas größer als die der Kontrolle, jedoch nicht signifikant, wie aus Abb. 3.26 ersichtlich.
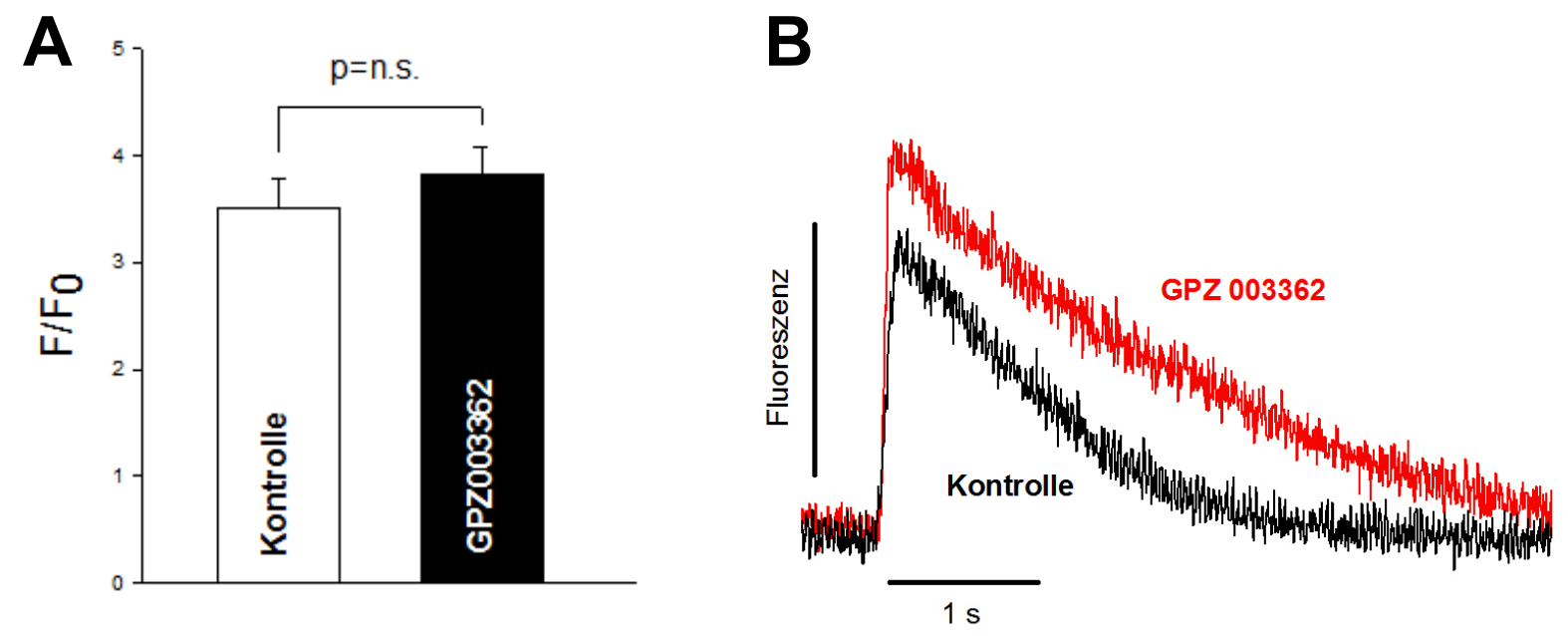

Abb 3.26 Auswirkungen von GPZ003362 auf den SR $\mathrm{Ca}^{2+}$-Gehalt von Ratten-Kardiomyozyten A: Mittelwerte der koffeininduzierten $\mathrm{Ca}^{2+}$-Transienten-Amplitude $\mathrm{F} / \mathrm{F}_{0}$ von Kontrolle $(n=10)$ und GPZ003362 ( $n=11)$; B: Repräsentative Originalregistrierung der $\mathrm{Ca}^{2+}$-Transienten nach KoffeinApplikation; Signifikanzen: keine

\subsection{Einfluss auf humane Muskelzellverbände}

Um die SERCA2a-Modulatoren auch hinsichtlich ihrer Wirkung auf menschliches Herzmuskelgewebe einerseits und auf Zellverbände andererseits zu untersuchen, wurden mit innen Muskelstreifenexperimente durchgeführt, und zwar in den gleichen Konzentrationen wie auch schon bei den Epifluoreszenz-Messungen: 0,1 $\mu \mathrm{M}, 1 \mu \mathrm{M}$ und 10 $\mu \mathrm{M}$. Zur Charakterisierung der Effekte wurden die entwickelte Kraft und die Zeit vom Kraftmaximum bis zu $50 \%$ der Relaxation $\left(\mathrm{RT}_{50}\right)$ herangezogen.

\subsubsection{ENL055}

Wie aus Abb. 3.27 ersichtlich, nimmt die entwickelte Kraft in Prozent der Ausgangskraft bei ENL055 im Verlauf zunehmend ab. Bei $10 \mu \mathrm{M}$ ist sie im Vergleich zu Kontrolle signifikant reduziert $(p=0,03)$. Auch die Relaxation ist bei $10 \mu \mathrm{M}$ im Vergleich zur Kontrolle verlangsamt, mit $p=0,06$ jedoch nicht auf Signifikanzniveau. 

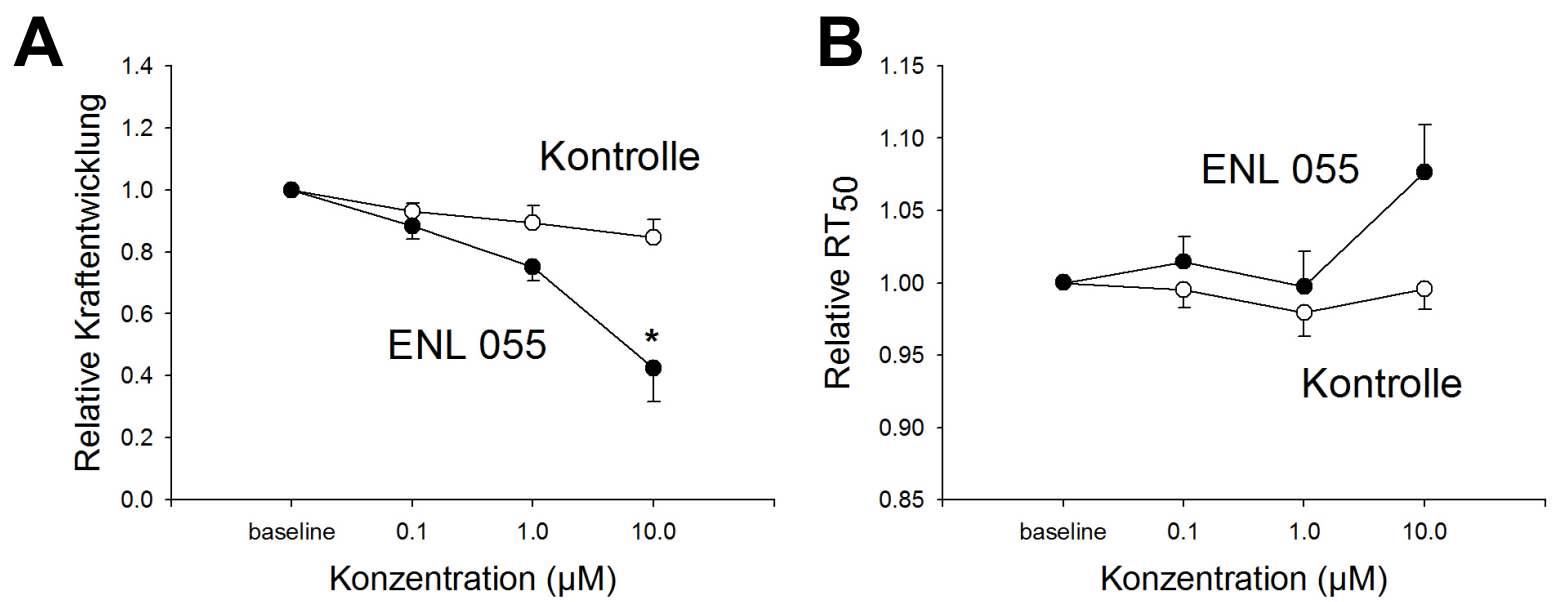

Abb. 3.27 Konzentrationsabhängige Änderung der relativen entwickelten Kraft und der Relaxationszeit im Muskelstreifenexperiment durch ENL055 ( $n=3)$ vs. Kontrolle $(n=3)$

A: Relative Kraft im Verhältnis zur Ausgangskraft; B: Relative Relaxationszeit im Verhältnis zum Ausgangswert; * Signifikanz mit $p=0,03$ zwischen ENL055 und Kontrolle

\subsubsection{ENO107}

Die entwickelte Kraft von ENO107 im Muskelstreifenexperiment zeigt im Vergleich zur Kontrolle keinen Unterschied. Auch bezüglich der Relaxationszeiten lassen sich keine signifikanten Unterschiede nachweisen.

A

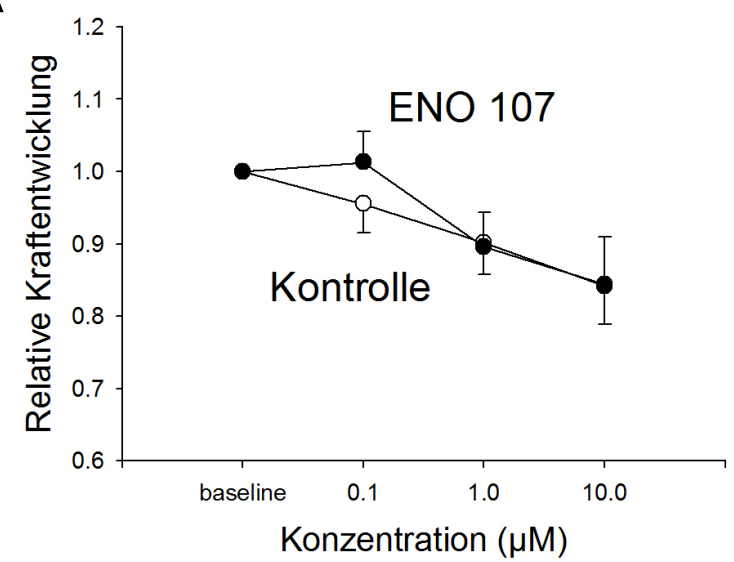

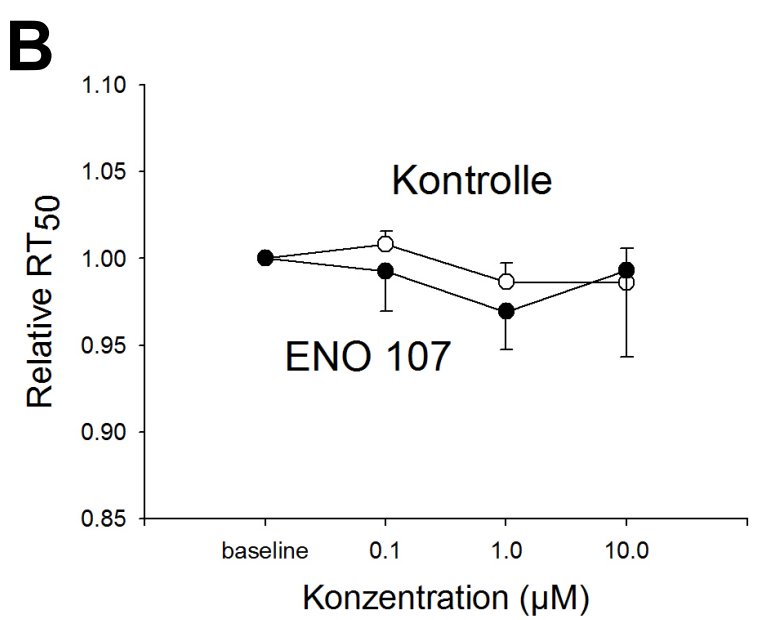

Abb. 3.28 Konzentrationsabhängige Änderung der relativen entwickelten Kraft und der Relaxationszeit im Muskelstreifenexperiment durch ENO107 ( $n=6)$ vs. Kontrolle $(n=6)$

A: Relative Kraft im Verhältnis zur Ausgangskraft; B: Relative Relaxationszeit im Verhältnis zum Ausgangswert; Signifikanzen: keine 


\subsubsection{ENO114}

Wie aus Abb. 3.29 ersichtlich, nimmt die entwickelte Kraft in Prozent der Ausgangskraft bei ENO114 im Verlauf zunehmend und im Vergleich zur Kontrolle stärker ab. Der statistische Vergleich von Kontrolle und ENO114 ergibt diesbezüglich jedoch keine Signifikanz.

Die Relaxationszeit unter ENO114 ist bei $0,1 \mu \mathrm{M}$ und $1 \mu \mathrm{M}$ im Vergleich zur Kontrolle deutlich verkürzt, bei 0,1 $\mu \mathrm{M}$ mit einer Signifikanz von $p=0,01$. Bei höchster Konzentration dagegen gleichen sich die Relaxationszeiten wieder an.
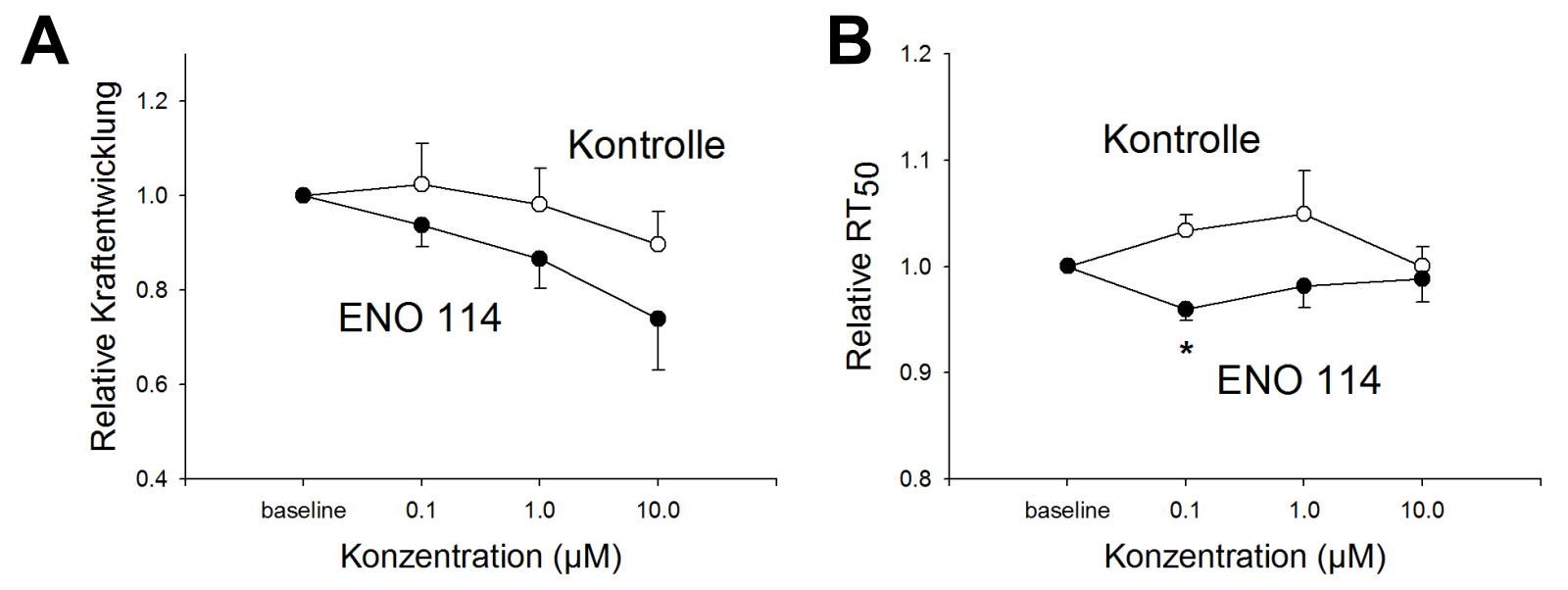

Abb. 3.29 Konzentrationsabhängige Änderung der relativen entwickelten Kraft und der Relaxationszeit im Muskelstreifenexperiment durch ENO114 $(n=4)$ vs. Kontrolle $(n=4)$

A: Relative Kraft im Verhältnis zur Ausgangskraft; B: Relative Relaxationszeit im Verhältnis zum Ausgangswert; Signifikanzen: keine

\subsubsection{ENO185}

Sowohl der Vergleich der Kraft als auch der Relaxationszeit zeigt keine signifikanten Unterschiede zwischen ENO185 und der Kontrolle.
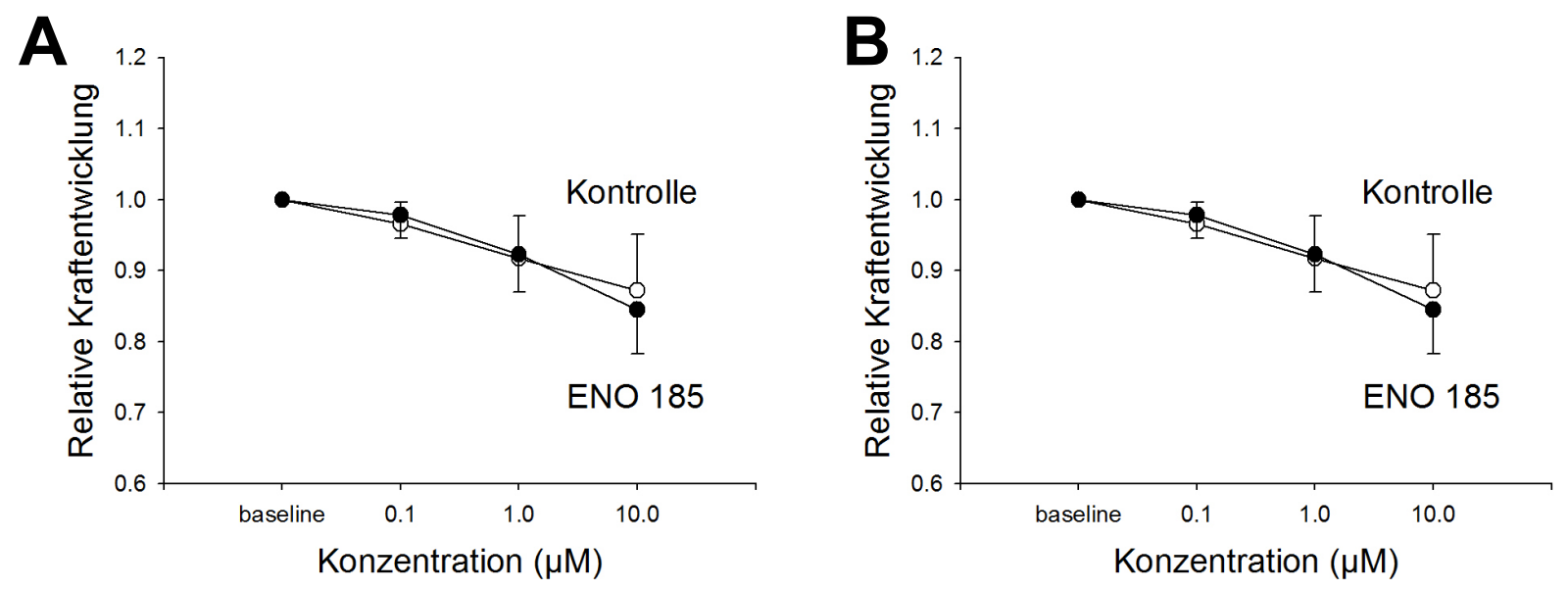

Abb. 3.30 Konzentrationsabhängige Änderung der relativen entwickelten Kraft und der Relaxationszeit im Muskelstreifenexperiment durch ENO185 ( $n=6)$ vs. Kontrolle $(n=4)$

A: Relative Kraft im Verhältnis zur Ausgangskraft; B: Relative Relaxationszeit im Verhältnis zum Ausgangswert; Signifikanzen: keine 


\subsubsection{ENO209}

Die entwickelte Kraft von ENO209 im Muskelstreifenexperiment zeigt im Vergleich zur Kontrolle keinen Unterschied. Tendenziell ist sie bei höchster Konzentration von $10 \mu \mathrm{M}$ minimal kleiner als die der Kontrolle. Auch die Relaxationszeit zeigt im Vergleich zur Kontrolle keine signifikanten Unterschiede, tendenziell ist sie bei $0,1 \mu \mathrm{M}$ und $10 \mu \mathrm{M}$ leicht verkürzt.

\section{A}

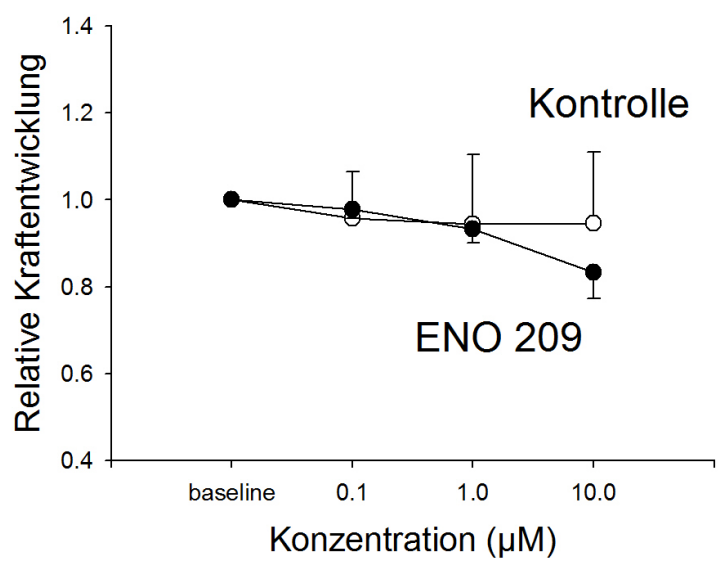

B

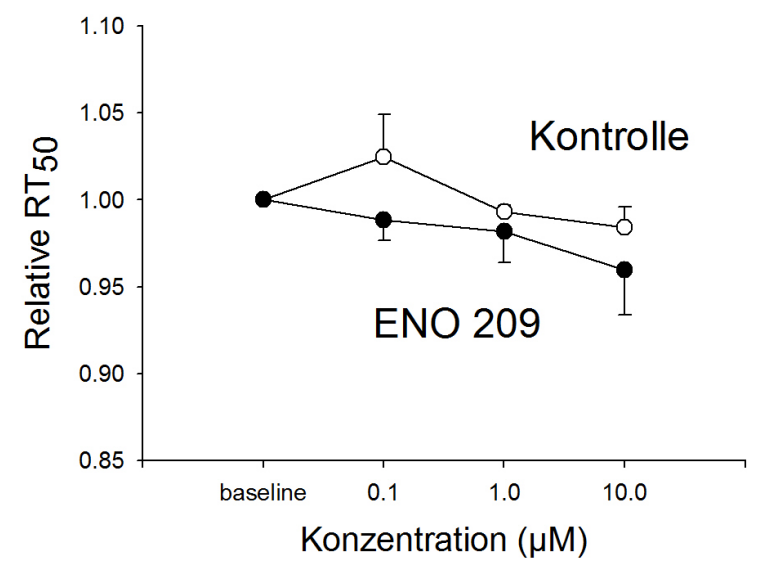

Abb. 3.31 Konzentrationsabhängige Änderung der relativen entwickelten Kraft und der Relaxationszeit im Muskelstreifenexperiment durch ENO209 ( $n=4)$ vs. Kontrolle $(n=3)$

A: Relative Kraft im Verhältnis zur Ausgangskraft; B: Relative Relaxationszeit im Verhältnis zum Ausgangswert; Signifikanzen: keine 


\subsubsection{GPZ003362}

In den Muskelstreifenexperimenten mit dem SERCA2a-Modulator GPZ003362 zeigte sich bei niedrigster Konzentration von 0,1 $\mu \mathrm{M}$ eine signifikante Zunahme der entwickelten Kraft mit $\mathrm{p}=0,05$, wie Abb. 3.32 zeigt. Während die Kraft in Prozent zur Ausgangskraft bei 0,1 $\mu \mathrm{M}$ unter GPZ003362 auf 101,1 \% $\pm 5,4 \%$ minimal ansteigt, fällt diese unter Kontrollösung auf $93,2 \pm 8,5 \%$ ab. Die Relaxation ist tendenziell bei allen Konzentrationen des SERCA2aModulators leicht verlängert, im statistischen Vergleich zur Kontrolle jedoch nicht signifikant.
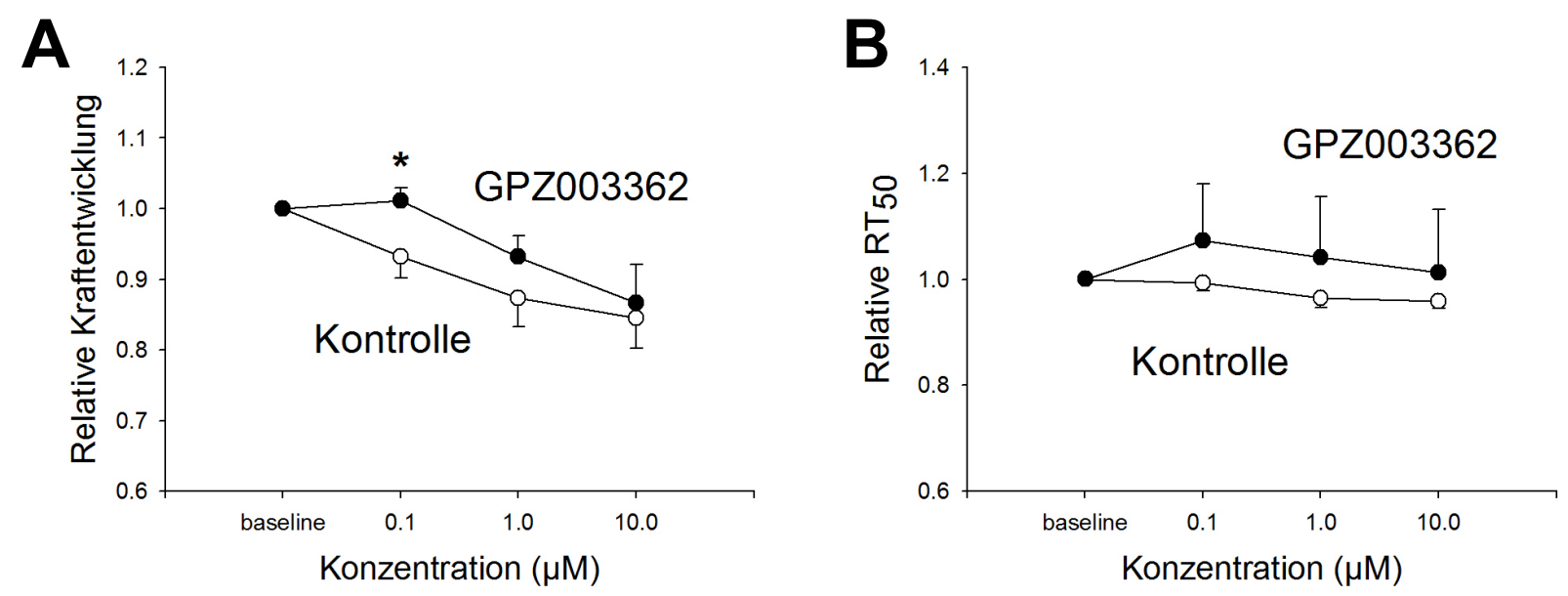

Abb. 3.32 Konzentrationsabhängige Änderung der relativen entwickelten Kraft und der Relaxationszeit im Muskelstreifenexperiment durch GPZ003362 $(n=8)$ vs. Kontrolle $(n=8)$

A: Relative Kraft im Verhältnis zur Ausgangskraft; B: Relative Relaxationszeit im Verhältnis zum Ausgangswert; * Signifikanz mit $p=0,05$ zwischen GPZ003362 und Kontrolle 


\section{Diskussion}

In der vorliegenden Arbeit wurde der Einfluss einer Auswahl von potentiellen SERCA2aModulatoren auf die Aktivität der Myokard-spezifischen sarkoplasmatischen $\mathrm{Ca}^{2+}$-ATPase untersucht. Der Schwerpunkt lag dabei auf einer qualitativen Untersuchung der Relaxation und der $\mathrm{Ca}^{2+}$-Extrusion aus dem Zytosol als direkte Parameter der SERCA2a-Funktion. Als indirekte Funktionsparameter der SERCA2a wurden die Zellkontraktilität, die $\mathrm{Ca}^{2+}{ }_{-}$ Transienten-Amplitude und der SR $\mathrm{Ca}^{2+}$-Gehalt gemessen.

Eine Steigerung der SERCA2a-Aktivität würde erwartungsgemäß zu einer beschleunigten $\mathrm{Ca}^{2+}$-Extrusion aus dem Zytosol und konsekutiv zu verkürzten Relaxationszeiten führen. Folglich könnte es sekundär zu einer stärkeren $\mathrm{Ca}^{2+}$-Beladung des SR und damit zu einer erhöhten SR $\mathrm{Ca}^{2+}$-Ausschüttung pro Exzitationszyklus mit daraus resultierender Steigerung von $\mathrm{Ca}^{2+}$-Transienten und Kontraktilität kommen. Derartige Veränderungen durch eine erhöhte SERCA2a-Aktivität konnten bereits durch mehrere Studien mittels Gentherapeutischer Überexpression der SERCA2a belegt werden. Ein adenoviraler Gentransfer der SERCA2a führte in Tiermodellen sowohl zu einer erhöhten Kontraktilität und verkürzten Relaxationszeit als auch zu einer erhöhten Kalziumamplitude und einem beschleunigten Kalziumabfall (Hajjar et al. 1997; Baker et al. 1998; Meyer und Dillmann 1998; Yao et al. 1998; Müller et al. 2003; Maier et al. 2005). Entsprechend konnten auch in HerzinsuffizienzModellen verbesserte Pumpfunktionen und erhöhte Relaxationsgeschwindigkeiten bestätigt werden, sowohl in Tiermodellen (Miyamoto et al. 2000; Müller et al. 2003; Byrne et al. 2008; Fu et al. 2008; Kawase et al. 2008; Mi et al. 2009; Mariani et al. 2011; Xin et al. 2011) als auch in Versuchen mit isolierten Myozyten aus humanen, terminal insuffizienten Herzen (Del Monte et al. 1999). Neben diesen Studien zu gesteigerter Kontraktilität durch Gentransfer wurde in den letzten Jahren auch ein neuer positiv inotroper Wirkstoff namens Istaroxime (PST2744) entwickelt, der einerseits seine Wirkung ähnlich den Digitalis-Präparaten über eine Hemmung der $\mathrm{Na}^{+} / \mathrm{K}^{+}$-ATPase entfaltet, aber zusätzlich auch die SERCA2a stimulieren soll (Micheletti et al. 2002; De Munari et al. 2003; Rocchetti et al. 2005; Mattera et al. 2007; Sabbah et al. 2007). In allen genannten Studien konnte erwartungsgemäß neben einer Verbesserung der systolischen Funktion und teilweise der diastolischen Funktion auch eine Beschleunigung der Relaxationszeit und/oder des Kalziumabfalls gezeigt werden.

Die im Rahmen dieser Arbeit untersuchten SERCA2a-Modulatoren wiesen bezüglich der genannten Parameter deutliche Unterschiede auf. Aufgrund des übergeordneten Ziels dieser Arbeit, eine neue Therapieoption für die Behandlung der chronischen Herzinsuffizienz, d. h. ein neues potentielles Inotropikum, zu finden, werden die SERCA2a-Modulatoren im Folgenden nach ihrem Einfluss auf die Kontraktilität gruppiert diskutiert. 


\subsection{Positiv inotrope SERCA2a-Modulatoren}

\subsubsection{ENO114}

Die Ergebnisse der vorliegenden Arbeit zeigen, dass ENO114 im fluoreszenzoptischen Versuch mit Kardiomyozyten aus Rattenherzen eine signifikant erhöhte Kontraktilität bei höchster untersuchter Konzentration von $10 \mu \mathrm{M}$ bewirkt. Interessanterweise kam es bei 3 der 8 gemessenen Zellen unter höchster Konzentration kurzzeitig zu Arrhythmien. Sowohl eine Beschleunigung der $\mathrm{Ca}^{2+}$-Extrusion (gemessen als Abfallsexponent $\tau$ ) als auch der Relaxationszeit konnten in der ersten Versuchsreihe mit Rattenherzzellen jedoch nicht nachgewiesen werden. Es zeigte sich lediglich ein im Trend erhöhter Koffein-induzierter $\mathrm{Ca}^{2+}$-Transient als Ausdruck für einen erhöhten Kalziumgehalt des SR.

Ein erhöhter SR $\mathrm{Ca}^{2+}$-Gehalt kann in diesem Fall die Ursache für die beschriebenen Arrhythmien der Ratten-Kardiomyozyten sein. Seit einigen Jahren ist bekannt, dass eine $\mathrm{Ca}^{2+}$-Überladung des SR ab einer bestimmten Schwelle $z u$ diastolischen Kalziumentladungen führen kann - messbar als sog. Kalzium-Sparks, die eine erhöhte Öffnungswahrscheinlichkeit der Ryanodinrezeptoren widerspiegeln. Spontane SRKalziumentladungen sind dabei wahrscheinlich die wichtigste Grundlage für die Entstehung arrhythmogener später Nachdepolarisationen. Infolge kurzzeitiger Erhöhung des Kalziumgehaltes im Zytosol kommt es zu einem vorübergehenden Kalzium-abhängigen Einstrom von $\mathrm{Na}^{+}$-Ionen über den $\mathrm{NCX}\left(\mathrm{I}_{\mathrm{NCX}}\right)$ in die Zelle, der folglich zur spontanen Membrandepolarisation führen kann (Satoh et al. 1997; Schlotthauer und Bers 2000; Pogwizd et al. 2001). Insofern können die spontan aufgetretenen Arrhythmien als ein Hinweis für eine $\mathrm{Ca}^{2+}$-Überladung des $\mathrm{SR}$ angesehen werden und somit indirekt darauf hinweisen, dass ENO114 die SERCA2a-Funktion tatsächlich stimuliert und konsekutiv zu einer erhöhten SR $\mathrm{Ca}^{2+}$-Beladung führt. Unterstützt wird diese Hypothese durch eine Studie, in der eine Gen-therapeutische Überexpression der SERCA2a am Modell der Ratte ebenfalls zu vermehrten Arrhythmien führte (Chen et al. 2004). Dem gegenüber stehen jedoch neueste widersprüchliche Ergebnisse, die eine Reduktion ventrikulärer Arrhythmien durch SERCA2a-Überexpression beschreiben (Lyon et al. 2011; Cutler et al. 2012). Allerdings scheinen letztere Ergebnisse aufgrund der Durchführung an Herzinsuffizienzmodellen - und nicht wie in dieser Arbeit an gesunden Rattenzellen - nur eingeschränkt vergleichbar.

Passend zum leicht erhöhten SR $\mathrm{Ca}^{2+}$-Gehalt im Einzelzellexperiment wird am Muskelstreifen aus herzinsuffizienten humanen Herzen die Relaxationszeit bei minimaler Konzentration von 0,1 $\mu \mathrm{M}$ signifikant verkürzt, was ebenfalls auf eine Steigerung der SERCA2a-Aktivität hinweisen könnte.

Im deutlichen Kontrast der positiv inotropen Wirkung im Einzelzellexperiment steht jedoch das Ergebnis einer unveränderten bzw. in der Tendenz verminderten Kraft mit steigender Konzentration im Muskelstreifenexperiment. 
Die divergierenden Ergebnisse einer erhöhten Kontraktilität der Rattenzellen einerseits und der unveränderten bzw. verminderten Kraft der humanen insuffizienten Muskelstreifen andererseits können vielfältiger Natur sein, lassen sich aber möglicherweise am ehesten aufgrund der Unterschiede zwischen gesunden versus insuffizienten Kardiomyozyten erklären:

Mehrere Studien konnten in den vergangenen Jahren zeigen, dass bei Herzinsuffizienz ein erhöhtes RyR-abhängiges diastolisches $\mathrm{SR} \mathrm{Ca}^{2+}$-Leck vorliegt, das neben einer veränderten SERCA2a- und NCX-Aktivität zu einer Reduktion des SR $\mathrm{Ca}^{2+}$-Gehaltes und somit zur kontraktilen Dysfunktion bei Herzinsuffizienz beiträgt (Shannon et al. 2003; Belevych et al. 2007). Es wird angenommen, dass solch ein erhöhtes diastolisches SR Ca ${ }^{2+}$-Leck durch eine vermehrte Phosphorylierung des RyR bedingt ist. Dieses entsteht infolge der bei Herzinsuffizienz gesteigerten $\beta$-adrenergen Stimulation (Marx et al. 2000) und erhöhten Expression und Aktivität der $\mathrm{Ca}^{2+}-/$ Calmodulin-abhängigen Proteinkinase II (CaMKII), eines Enzyms, das neben anderen Zielproteinen auch den RyR im herzinsuffizienten Myokard hyperphosphoryliert (Maier et al. 2003; Ai et al.2005; Curran et al. 2007; Sossalla et al. 2010). Auch für die in dieser Arbeit verwendeten terminal insuffizienten Muskelstreifen kann eine Hyperphosphorylierung des RyR und somit ein erhöhtes diastolisches SR Ca ${ }^{2+}$-Leck angenommen werden. Möglicherweise hat damit eine verstärkte $\mathrm{Ca}^{2+}$-Aufnahme ins SR im humanen terminal insuffizienten Myokard keinen wesentlichen Einfluss auf den SR $\mathrm{Ca}^{2+}$ Gehalt, da das $\mathrm{Ca}^{2+}$ im Sinne eines Kurzschlusses das SR in der Diastole über die undichten RyR wieder verlassen kann.

Zur Erläuterung der unveränderten bzw. tendenziell verminderten Kontraktilität am insuffizienten Myokard sind weiterhin die Unterschiede in der SERCA2a- und NCXExpression zu verdeutlichen: Während in Rattenzellen in der Diastole das im Zytosol befindliche Kalzium zu über 90\% über die SERCA2a sequestriert wird (Hove-Madsen und Bers 1993), tragen in terminal insuffizienten menschlichen Herzzellen SERCA2a und NCX fast gleichermaßen zur diastolischen Kalziumelimination bei (Studer et al. 1994, Flesch et al. 1996, Bers et al. 2002). Zum einen ist dieser Unterschied Spezies-bedingt, da am gesunden humanen Herzen während der Diastole etwa $70 \%$ des intrazellulären Kalziums in das SR befördert werden (Maier und Bers 2002). Zum anderen wird als zusätzlicher Faktor bei Herzinsuffizienz die SERCA2a deutlich schwächer (Mercadier et al. 1990; Hasenfuss et al. 1994; Studer et al. 1994; Meyer et al. 1995) und der NCX stärker exprimiert (Studer et al. 1994, Flesch et al. 1996, Bers et al. 2002) als im gesunden Herzen.

Tatsächlich konnten Mackiewicz und Lewartowski 2008 an Herzmuskelzellen von Meerschweinchen zeigen, dass der Effekt eines SR Ca ${ }^{2+}$-Lecks auf die MyozytenKontraktilität von der NCX-Aktivität abhängig ist. Bei erhöhter NCX-Aktivität wird das aus dem SR "leckende“ Kalzium vermehrt aus der Zelle transportiert. Dieser Netto-Verlust an 
Kalzium führt folglich zu einer verminderten Kontraktilität, da weniger Kalzium für die nächste Kontraktion zur Verfügung steht.

Zusammengefasst könnte der Effekt einer unveränderten bis verminderten Kontraktilität am humanen insuffizienten Myokard trotz potentiell erhöhter SERCA2a-Aktivität durch ENO114 auf ein erhöhtes SR $\mathrm{Ca}^{2+}$-Leck bei ebenfalls erhöhter NCX-Funktion zurückzuführen sein. Andersherum entsteht die positive Inotropie im Einzellzellexperiment mit gesunden Kardiomyozyten der Ratte vermutlich durch eine gesteigerte SERCA2a-Funktion ohne gleichzeitigen Netto-Ca ${ }^{2+}-$ Verlust.

Im Widerspruch zu dieser Theorie scheinen jedoch neueste Ergebnisse mittels Gentherapeutischer SERCA2a-Überexpression zu stehen: Sowohl Lyon et al. 2011 als auch Cutler et al. 2012 konnten zeigen, dass eine Überexpression der SERCA2a am Herzinsuffizienzmodell zu einem verminderten SR Ca ${ }^{2+}$-Leck führt. Möglicherweise ist die Ursache dieser gegenteiligen Ergebnisse bzw. Hypothesen in den unterschiedlichen Versuchsbedingungen und den Spezies-Unterschieden zu finden: Während in den beiden genannten Studien sowohl In vivo-Daten als auch Ex vivo-Einzelzell-Daten an einem Herzinsuffizienzmodell der Ratte bzw. des Meerschweinchens verwendet wurden, wurden im Rahmen dieser Arbeit Ex vivo-Ergebnisse anhand insuffizienter Muskelzellverbände von humanen Herzen erhoben. Zudem birgt die Verwendung einer Substanz-bedingten SERCA2a-Stimulation versus einer SERCA2a-Aktivitätssteigerung mittels Überexpression weitere Möglichkeiten unterschiedlicher Wirkungen bzw. Ergebnisse in sich.

Ferner kommt eine weitere Erklärung für die unterschiedlichen Ergebnisse in dieser Arbeit, $d$. h. positive Inotropie im Ratten-Modell und unveränderte Kontraktilität im humanem Herzinsuffizienzmodell, in Frage: Die Diskrepanz der Ergebnisse könnte durch die unterschiedlichen Versuchsmethoden - Einzelzellen versus Zellverbände - bedingt sein. Verlängerte Diffusionsstrecken sowie fibrosierte Areale im Muskelzellverband sind Beispiele für eine mögliche Ursache von veränderten Effekten der SERCA2a-Modulatoren am insuffizienten Myokard.

Aufgrund des nicht eindeutigen Einflusses von ENO114 auf den Kalzium-Haushalt muss außerdem eingeräumt werden, dass mögliche Off-Target-Effekte entweder zusätzlich oder unabhängig von der SERCA2a-Modulation zu der erhöhten Kontraktilität im Einzelzellexperiment der Ratte führen. Als möglicher Off-Target-Effekt von ENO114 ist eine Erhöhung der Kalziumsensitivität der Myofilamente denkbar. Auf diese Weise ließe sich die gesteigerte Kontraktilität ohne gleichzeitige Erhöhung der $\mathrm{Ca}^{2+}$-Transienten erklären, wie es vergleichsweise für die $\mathrm{Ca}^{2+}$-Sensitizer EMD 57033 und CGP 48506 sowie den MyosinAktivator Omecamtiv Mecarbil beschrieben worden ist (Herzig et al. 1996; Brixius et al. 2002; Endoh 2008; Teerlink 2009). Allerdings wäre dann im Muskelstreifenexperiment unter solch einem Wirkmechanismus ebenfalls eine positive Inotropie zu erwarten. 
Insgesamt bleibt die Wirkungsweise von ENO114 zunächst noch spekulativ. Tatsache bleibt jedoch, dass ENO114 im fluoreszenzoptischen Versuch mit Rattenzellen eine signifikant erhöhte Kontraktilität bewirkt und somit ein interessanter Wirkstoff für kommende Untersuchungen bleibt.

\subsubsection{GPZ003362}

Die vorliegenden Daten zeigen, dass der SERCA2a-Modulator GPZ003362 sowohl im Einzelzell- als auch im Muskelstreifenexperiment einen positiv inotropen Effekt aufweist. Dieser kann durch eine Steigerung der SERCA2a-Funktion bedingt sein, da GPZ003362 sowohl jeweils in der Tendenz zu einer Beschleunigung des zytosolischen Kalziumabfalls als auch zu einer Steigerung des Koffein-induzierte $\mathrm{Ca}^{2+}$-Transienten als Hinweis für einen erhöhten SR $\mathrm{Ca}^{2+}$-Gehalt führt. Paradoxerweise kann ein Einfluss auf die $\mathrm{Ca}^{2+}-$ TransientenAmplitude und die Relaxationszeiten in beiden Versuchsreihen nicht nachgewiesen werden.

Der Nachweis unveränderter Kalziumtransienten trotz erhöhter SERCA2a-Aktivität ist vergleichbar mit den Ergebnissen von Reilly et al. 2001 an einem Ratten-Modell, die zeigten, dass eine Überexpression der SERCA2a zwar zu einer Beschleunigung des Kalziumabfalls, nicht aber zu erhöhten Kalziumtransienten führen. Dem gegenüber stehen allerdings mehrheitlich Studien mit erhöhten Kalziumtransienten durch Gen-therapeutische SERCA2aÜberexpression (Hajjar et al. 1997; Baker et al. 1998; Yao et al. 1998; Müller et al. 2003).

Aufgrund des nicht eindeutigen Einflusses von GPZ003362 auf den $\mathrm{Ca}^{2+}$-Haushalt sind auch bei diesem SERCA2a-Modulator Off-Target-Effekte nicht auszuschließen. Ähnlich wie bei dem SERCA2a-Modulator ENO114 wäre eine erhöhte Kalziumsensitivierung der Myofilamente durch GPZ003362 denkbar, die unabhängig vom $\mathrm{Ca}^{2+}$-Haushalt zu einer erhöhten Kontraktilität sowohl im Einzelzellexperiment der Ratte als auch im Muskelstreifenexperiment führen könnte.

Ob GPZ003362 über eine Steigerung der SERCA2a-Funktion oder über mögliche OffTarget-Effekte zu der positiven Inotropie führt, muss in weiteren Untersuchungen überprüft werden.

\subsection{SERCA2a-Modulatoren ohne nachweisbaren Effekt auf die Kontraktilität}

Die Ergebnisse der vorliegenden Arbeit zeigen, dass die SERCA2a-Modulatoren ENF018, EN0166, ENO187, ENO207, GPZ000876, GPZ001441 und GPZ007738 im fluoreszenzoptischen Versuch mit Kardiomyozyten aus Rattenherzen weder einen Einfluss auf die Kontraktilität noch einen wesentlichen Effekt auf die SERCA2a-Aktivität aufweisen. 
Als Ursache dieser Ergebnisse kommen zum einen Stoff-bedingte Eigenschaften und zum anderen methodische Bedingungen in Betracht. Eine methodisch bedingte Ursache kann beispielsweise die äußere Zellmembran der Kardiomyozyten sein, da sie die Passage bzw. Diffusion der SERCA2a-Modulatoren zum SR verhindern könnte. Dieses potentielle Hindernis könnte experimentell durch eine Erweiterung der in dieser Arbeit verwandten Methode umgangen werden, indem eine Porenbildung in der äußeren Zellmembran geschaffen würde, wie z. B. durch den Gebrauch von $\beta$-escin. $\beta$-escin permeabilisiert selektiv die äußere Zellmembran, indem es mit Cholesterinmolekülen Komplexe bildet. So kommt es in der äußeren Zellmembran, die einen zehn Mal höheren Gehalt an Cholesterinmolekülen aufweist als die Membran des SR, zu einer selektiven Porenbildung (Thelestam und Möllby, 1979). Allerdings wäre eine solche Anwendung am Menschen nicht möglich und wurde deshalb im Rahmen dieser Arbeit nicht angewendet.

Ferner ist eine potentiell nicht hinreichende Löslichkeit der Stoffe in Normaltyrode als mögliche methodisch-bedingte Ursache der genannten Ergebnisse in Erwägung zu ziehen. Zwar wurde beim Arbeiten mit den Stoffen auf eine makroskopische Löslichkeit geachtet, diese wurde aber nicht im Speziellen getestet. Die Bestimmung der Löslichkeit hätte mithilfe von Leitfähigkeitsmessungen durch ein Konduktometer erfolgen können.

Eine weitere Ursache könnte in der Wahl der Versuchskonzentrationen von 0,1 $\mu \mathrm{M}, 1 \mu \mathrm{M}$ und $10 \mu \mathrm{M}$ bestehen. Bei der Planung der Experimente wurde ein für die Testung von Medikamenten gängiges Konzentrationsfenster gewählt, dennoch ist nicht auszuschließen, dass ein optimaler Konzentrationsbereich verfehlt wurde.

Ein Beispiel für eine Stoff-bedingte Ursache könnte sein, dass die genannten SERCA2aModulatoren zwar aufgrund der mutmaßlichen strukturbedingten Affinität an die SERCA2a binden, jedoch keine Änderung ihrer Aktivität bewirken. Eine Änderung der SERCA2aAktivität wäre beispielsweise potentiell bei einer Wechselwirkung des SERCA2a-Modulators nahe der Bindungsstelle des Phospholambans denkbar, da auf diese Weise die Interaktion zwischen SERCA2a und Phospholamban gestört würde. Zuletzt kommt auch die strukturbedingte Unfähigkeit der SERCA2a-Modulatoren, tatsächlich an die SERCA2a zu binden, als Ursache der Ergebnisse in Betracht.

Die SERCA2a-Modulatoren ENO107, ENO185 und ENO209 weisen in Zusammenschau der Ergebnisse ebenfalls keinen wesentlichen Effekt auf die Kontraktilität und SERCA2a-Aktivität auf. Da bei den genannten Stoffen im fluoreszenzoptischen Versuch mit Kardiomyozyten aus Rattenherzen zwar eine tendenzielle Zunahme der Kontraktilität dokumentiert werden konnte, bot dies Anlass, die genannten Modulatoren im Hinblick auf SR $\mathrm{Ca}^{2+}$-Gehalt und Auswirkung auf humane Muskelstreifen näher zu untersuchen. In Zusammenschau mit diesen Ergebnissen, die weder einen Einfluss auf die Kontraktilität der Muskelstreifen noch 
einen wesentlichen Effekt auf den SR $\mathrm{Ca}^{2+}$-Gehalt zeigen, ist jedoch am ehesten ebenfalls von einem nicht vorhandenen Effekt auf die SERCA2a-Aktivität auszugehen. Eine spekulative Ursache der erhöhten Kontraktilität im Einzelzellexperiment könnte ein Wirkmechanismus sein, der eine positive Inotropie unabhängig vom $\mathrm{Ca}^{2+}$-Haushalt verursacht. Hierzu würde z. B. eine erhöhte Sensitivität der Myofilamente für Kalzium zählen. In diesem Fall müsste die unbeeinflusste Kontraktilität im Muskelstreifenexperiment damit begründet werden, dass die SERCA2a-Modulatoren ENO107, ENO185 und ENO209 beispielsweise aufgrund längerer Diffusionsstrecken ihre Wirkung am insuffizienten Muskelzellverband nicht entfalten können. Da die Ergebnisse bezüglich der Kontraktilität im Einzelzellexperiment nicht signifikant sind und die Streubreiten insbesondere bei den SERCA2a-Modulatoren ENO185 und ENO107 sehr groß ausfallen, sind methodischexperimentelle Ursachen für die vermeintlich positive Inotropie jedoch am wahrscheinlichsten.

Separat zu diskutieren sind außerdem die Ergebnisse des SERCA2a-Modulatoren ENF018: Dieser zeigt im Einzelzellexperiment mit Rattenzellen einen signifikant reduzierten $\mathrm{Ca}^{2+}$ Transienten bei höchster untersuchter Konzentration von $10 \mu \mathrm{M}$. Verminderte $\mathrm{Ca}^{2+}-$ Transienten würden erwartungsgemäß - sei es beispielsweise durch eine Hemmung der SERCA2a-Aktivität oder durch einen anderen Wirkmechanismus - mit einer verminderten Kontraktilität einhergehen. Paradoxer Weise bleiben jedoch sowohl die Kontraktilität als auch die Relaxationszeit und der Kalziumabfallsexponent $\tau$ durch ENF018 unbeeinflusst.

Eine Interpretation der Ergebnisse ist allein basierend auf den hier durchgeführten funktionellen Untersuchungen nicht möglich. Aufgrund der Vielfältigkeit und Widersprüchlichkeit der Messergebnisse liegt die Vermutung nahe, dass Off-Target-Effekte - entweder separat oder zusätzlich zur SERCA2a-Modulation - vorliegen, die mittels der durchgeführten funktionellen Experimente nicht getestet wurden.

\subsection{Negativ inotrope SERCA2a-Modulatoren}

Die Ergebnisse der vorliegenden Arbeit zeigen, dass die SERCA2a-Modulatoren ENG020, ENH036, ENL055, ENL056 und GPZ006800 die Kontraktilität von Kardiomyozyten dosisabhängig reduzieren.

Da sich die SERCA2a-Modulatoren durch eine strukturbedingte Affinität zur SERCA2a auszeichnen, ist am ehesten von einer Inihibition der SERCA2a als Ursache der Reduktion der myokardialen Kontraktilität auszugehen. Erwartungsgemäß würde eine Hemmung der SERCA2a-Aktivität sowohl zu einer verlangsamten Relaxationszeit und $\mathrm{Ca}^{2+}$-Elimination führen als auch zu einer verminderten Kontraktilität und einem verminderten $\mathrm{Ca}^{2+}$ Transienten. Derartige Parameter-Veränderungen durch eine Hemmung der SERCA2a- 
Aktivität konnten mehrere Arbeitsgruppen belegen, die in Versuchen an isolierten Herzmuskelzellen der Ratte Thapsigargin - einen bekannten Inhibitor der SERCA2a verwendeten (Davia et al. 1997; Li et al. 2005; Bode et al. 2011).

Während der SERCA2a-Modulator ENH036 vergleichbare Effekte wie Thapsigargin aufweist und somit von einer Hemmung der SERCA2a-Aktivität durch ENH036 ausgegangen werden kann, weisen die übrigen oben genannten SERCA2a-Modulatoren uneinheitliche Effekte bezüglich der genannten Parameter auf: Die Ergebnisse zeigen sowohl verminderte (ENG020), unveränderte (ENL056, ENL055) als auch tendenziell erhöhte (GPZ006800) $\mathrm{Ca}^{2+}$-Transienten trotz des gemeinsamen negativ inotropen Effektes. Allen Stoffen gemeinsam ist dagegen eine Verlangsamung der Kalziumelimination, die am ehesten auf eine Hemmung der SERCA2a hinweisen kann.

Aufgrund der uneinheitlichen und nicht signifikanten Ergebnisse kommen weitere Wirkmechanismen als Ursache der negativen Inotropie in Frage:

Reduzierte Kontraktilität bei unveränderten $\mathrm{Ca}^{2+}$-Transienten und Relaxationsparametern wie im Falle des SERCA2a-Modulators ENL056 könnte beispielsweise durch eine Hemmung der Aktin-Myosin-Interaktion hervorgerufen sein - ähnlich dem Wirkstoff Blebbistatin (Fedorov et al. 2007) - wobei diese detaillierte Untersuchung über den Gegenstand der vorliegenden Arbeit hinausgeht und deshalb nicht durchgeführt wurde.

Negative Inotropie einhergehend mit erhöhten $\mathrm{Ca}^{2+}$-Transienten wie bei dem SERCA2aModulator GPZ006800 erscheint paradox und möglicherweise nur durch eine Kombination unterschiedlicher Effekte erklärbar. Spekulativ wäre beispielsweise eine Kombination aus SERCA2a-Stimulation und Hemmung der Aktin-Myosin-Interaktion denkbar, wobei letzterer Effekt in Bezug auf die Kontraktilität überwiegen müsste. Aufgrund der insignifikanten Ergebnisse von GPZ003362 sind methodisch-experimentelle Ursachen für die vermeintlich erhöhten Kalziumtransienten jedoch am wahrscheinlichsten.

Eine weitere zu diskutierende Konstellation ergibt sich bei dem SERCA2a-Modulator ENL055: Während sich im Einzelexperiment mit Rattenzellen eine unveränderte bis tendenziell erhöhte Kontraktilität bei unveränderten $\mathrm{Ca}^{2+}$-Transienten zeigt, führt ENL055 am terminal insuffizienten humanen Herzen zu einer signifikant reduzierten Kraft bei verlangsamter Relaxation. Die Ursache für diese Diskrepanz zwischen deutlich negativer Inotropie im Muskelstreifenexperiment einerseits und dem nicht nachweisbaren Effekt auf Kontraktilität bzw. der tendenziellen Zunahme der Kontraktilität im Einzelzellexperiment andererseits ist möglicherweise der Umstand, dass die verwendeten humanen Herzen im Muskelstreifenexperiment bereits terminal insuffizient waren. Denkbar wäre, dass die gesunden Rattenzellen mit putativ normaler SERCA2a-Funktion den durch ENL055 hervorgerufenen und im humanen insuffizienten Myokard demaskierten SERCA2ainhibierenden Effekt kompensieren können. Untersuchungen an einem genetisch 
modifiziertem Mausmodell, bei dem das SERCA2a-kodierende Gen Atp2a2 exzidiert wurde und somit ein funktioneller SERCA2a-Knockout vorlag, konnten interessanterweise zeigen, dass ein kompletter Verlust der SERCA2a-Aktivität lediglich zu einer moderaten kardialen Dysfunktion ohne Zeichen einer Herzinsuffizienz führte. Die Ergebnisse zeigten, dass zum einen ein erhöhter Kalziumeinstrom über die L-Typ $\mathrm{Ca}^{2+}-$ Kanäle und ein verminderter $\mathrm{Ca}^{2+}$ Ausstrom über den NCX und zum anderen eine erhöhte myofilamentäre Ansprechbarkeit auf Kalzium die Herzfunktion anfänglich erhalten kann (Andersson et al. 2009). Zu ähnlichen Ergebnissen waren vorher auch Brittsan et al. 2003 und Zaoh et al. 2006 gekommen, in deren Studien die SERCA2a-Aktivität mittels Gen-therapeutisch erzeugter, dauerhaft inhibierenden Formen von Phospholamban reduziert wurde. Durch ähnliche Mechanismen könnte auch die unveränderte bzw. sogar leicht gesteigerte Kontraktilität im Einzelexperiment mit den gesunden Rattenzellen erklärt werden. Eventuell wird der SERCA2a-inhibierende Effekt durch ENL055 in gesunden Rattenzellen durch erhöhte Ansprechbarkeit der Myofilamente auf Kalzium und durch einen erhöhten SR-unabhängigen Kalziumfluss kompensiert, wohingegen dieser Kompensationsmechanismus in den terminal insuffizienten Muskelstreifen womöglich nicht mehr funktioniert. Insgesamt wurden diese Effekte in der vorliegenden Arbeit jedoch nicht detailliert untersucht und bleiben deshalb spekulativ. Diese Theorie einschränkend muss außerdem erwähnt werden, dass derartige Kompensationsmechanismen wahrscheinlich erst nach einem gewissen Zeitraum eintreten. In den genannten Studien fanden die Experimente erst nach Ablauf mehrerer Wochen nach den jeweiligen Gen-Veränderungen statt.

Weiterhin könnte die Diskrepanz der Ergebnisse jedoch auch durch die unterschiedlichen Versuchsmethoden - mit Einzelzellen einerseits und Zellverbänden andererseits - bedingt sein. Beispielsweise können eine verlängerte Diffusionsstrecke sowie fibrosierte Areale im Muskelzellverband zu veränderten Effekten der SERCA2a-Modulatoren führen.

\subsection{Klinischer Ausblick}

Aufgrund der ungünstigen Effekte bisheriger Inotropika (siehe Kapitel 1.6) herrscht seit langem das Bestreben, Stoffgruppen zu finden, die vor allem langfristig die Kontraktionskraft des Herzens verbessern und dabei keine negativen Langzeiteffekte aufweisen.

Eine Steigerung der SERCA2a-Aktivität bietet diverse Vorteile gegenüber anderen Inotropika: Zum einen wird nicht nur die systolische, sondern auch die diastolische Funktion des Herzens verbessert. Außerdem wird die Energiebilanz positiv beeinflusst, so dass der Sauerstoffverbrauch des Herzens sinkt (del Monte et al. 2001; Sakata et al. 2007). Ferner führt eine Erhöhung der SERCA2a-Aktivität zu einer Verkürzung des Aktionpotentials, die eine Kalziumüberladung der Kardiomyozyten und somit Arrhythmien möglicherweise verhindern kann (Terracciano et al. 2002). Neben einer verbesserten linksventrikulären 
Funktion konnten $\mathrm{Fu}$ et al. 2012 in einem Herzinsuffizienz-Modell mit Hunden auch reduzierte inflammatorische und Stress-assoziierte Proteine im Serum nachweisen.

Der bisherige Versuch, die SERCA2a-Aktivität mittels Gentransfer zu steigern, hat jedoch den Nachteil, dass es aufgrund des adenoviralen Gentransfers zu immunologischen Nebenwirkungen am Menschen kommen kann (Yang et al. 1994; Di Paolo et al. 2009).

Neuere Verfahren mittels humanem Parvovirus weisen zwar eine geringere immunologische Antwort auf, haben jedoch den Nachteil, dass die Geneinschleusung derzeit noch invasiv erfolgen muss (Jessup et al. 2011).

Aufgrund der theoretisch positiven Beeinflussung der Herzinsuffizienz durch eine Steigerung der SERCA2a-Aktivität wurde daher im Rahmen dieser Arbeit nach neuen Wirkstoffen gesucht, die diese speziell stimulieren. Mit dem SERCA2a-Modulator GPZ003362 konnte tatsächlich ein neuer Stoff gefunden werden, der sowohl an isolierten Kardiomyozyten der Ratte als auch am humanen, insuffizienten Myokard positiv inotrop wirkt. Ferner ist auch der SERCA2a-Modulator ENO114 aufgrund seines eindeutig positiv inotropen Effektes an Rattenzellen ein weiterhin interessanter Wirkstoff. Bislang bleibt jedoch noch spekulativ, ob diese potentiellen neuen Inotropika ihre Wirkung tatsächlich über eine Steigerung der SERCA2a-Aktivität entfalten. Weitere Studien mit diesen möglicherweise bedeutungsvollen Wirkstoffen erscheinen daher sinnvoll. 


\section{Zusammenfassung}

Die verminderte Expression der sarkoplasmatischen $\mathrm{Ca}^{2+}$-ATPase (SERCA2a) ist ein bedeutender Mechanismus in der Pathogenese der Herzinsuffizienz. In den vergangenen Jahren rückte daher die Stimulation der SERCA2a als neuer therapeutischer Ansatz immer mehr in den Vordergrund.

In der vorliegenden Arbeit wurde der Effekt von siebzehn neu entwickelten SERCA2aModulatoren auf die Kontraktilität und den $\mathrm{Ca}^{2+}$-Haushalt von isolierten Kardiomyozyten der Ratte im Einzellzellexperiment untersucht. Zur Einschätzung der SERCA2a-Aktivität wurden mittels Epifluoreszenzverfahren die $\mathrm{Ca}^{2+}$-Transientenamplitude, die Relaxationszeit, die Geschwindigkeit der Kalziumelimination aus dem Zytosol und die Koffein-induzierte $\mathrm{Ca}^{2+}$ Transientenamplitude als Maß für den SR- $\mathrm{Ca}^{2+}$-Gehalt gemessen.

Insgesamt ließen sich die Wirkstoffe bezüglich ihrer inotropen Eigenschaften in drei Gruppen einteilen: Es konnte gezeigt werden, dass fünf der insgesamt siebzehn SERCA2aModulatoren die Kontraktilität im Einzelzellexperiment dosisabhängig reduzieren. Der Einfluss auf den $\mathrm{Ca}^{2+}$-Haushalt war bei diesen Wirkstoffen uneinheitlich. Weitere zehn Wirkstoffe wiesen keinen wesentlichen Effekt auf die Kontraktilität der Kardiomyozyten auf. Letztendlich konnten zwei SERCA2a-Modulatoren identifiziert werden, die die Kontraktilität von isolierten Kardiomyozyten der Ratte dosisabhängig erhöhen. Als Hinweis auf eine gesteigerte SERCA2a-Aktivität zeigte der SERCA2a-Modulator GPZ003362 sowohl eine Beschleunigung des intrazellulären Kalziumabfalls als auch eine Erhöhung des SR $\mathrm{Ca}^{2+}$ Gehaltes. Ein Einfluss auf die $\mathrm{Ca}^{2+}-$ Transienten und auf die Relaxationszeiten waren jedoch nicht nachweisbar. Zur weiteren Klärung der klinischen Relevanz wurden die potentiellen Inotropika auch hinsichtlich ihres Effekts auf die Kontraktionskraft von humanen terminal insuffizienten ventrikulären Muskelstreifen untersucht. GPZ003362 wies hier ebenfalls einen positiv inotropen Effekt auf. Aufgrund der uneinheitlichen Einflüsse auf den $\mathrm{Ca}^{2+}$-Haushalt bleibt allerdings unklar, ob der SERCA2a-Modulator GPZ003362 seine Wirkung tatsächlich über eine Steigerung der SERCA2a-Aktivität entfaltet oder ob ein anderer Wirkmechanismus vorliegt. Der SERCA2a-Modulator ENO114 wies im Einzelzellexperiment ebenfalls einen positiv inotropen Effekt auf. Im Muskelstreifenexperiment mit terminal insuffizientem Myokard konnte eine dosisabhängige Beschleunigung der Relaxation gezeigt werden, die auf eine gesteigerte SERCA2a-Aktivität hinweisen könnte. Ein wesentlicher Effekt auf die Kontraktiltät der Muskelstreifen konnte jedoch nicht nachgewiesen werden.

Angesichts der weiterhin schlechten Prognose und der limitierten Therapiemöglichkeiten der Herzinsuffizienz könnten die SERCA2a-Modulatoren GPZ003362 und ENO114 eine neue Therapieoption darstellen. Weiterführende Arbeiten sind notwendig, um den Wirkmechanismus dieser Stoffe aufzuklären und ihre Relevanz für die Therapie der Herzinsuffizienz einzuschätzen. 


\section{Literaturverzeichnis}

Ahlquist RP (1976): Present state of alpha- and beta-adrenergic drugs I. The adrenergic receptor. Am Heart J $\underline{92}, 661-664$

Ahmed A, Rich MW, Fleg JL, Zile MR, Young JB, Kitzman DW, Love TE, Aronow WS, Adams KF Jr, Gheorghiade M (2006): Effects of digoxin on morbidity and mortality in diastolic heart failure: the ancillary digitalis investigation group trial. Circulation 114, 397-403

Ai X, Curran JW, Shannon TR, Bers DM, Pogwizd SM (2005): $\mathrm{Ca}^{2+} /$ calmodulin-dependent protein kinase modulates cardiac ryanodine receptor phosphorylation and sarcoplasmic reticulum $\mathrm{Ca}^{2+}$ leak in heart failure. Circ Res $\underline{97}, 1314-1322$

Allen DG, Kurihara S (1982): The effects of muscle length on intracellular calcium transients in mammalian cardiac muscle. J Physiol $\underline{327}, 79-94$

Allen DG, Kentish JC (1985): The cellular basis of the length-tension relation in cardiac muscle. J Mol Cell Cardiol $\underline{17}$, 821-840

Alpert NR, Gordon MS (1962): Myofibrillar adenosine triphosphatase activity in congestive heart failure. Am J Physiol 202, 940-946

Andersson KB, Birkeland JA, Finsen AV, Louch WE, Sjaastad I, Wang Y, Chen J, Molkentin JD, Chien KR, Sejersted OM (2009): Moderate heart dysfunction in mice with inducible cardiomyocyte-specific excision of the Serca2 gene. J Mol Cell Cardiol $\underline{47}, 180-187$

Baartscheer A, Schumacher CA, Belterman CN, Coronel R, Fiolet JW (2003): SR calcium handling and calcium after-transients in a rabbit model of heart failure. Cardiovasc Res $\underline{58}$, 99-108

Baker DL, Hashimoto K, Grupp IL, Ji Y, Reed T, Loukianov E, Grupp G, Bhagwhat A, Hoit B, Walsh R (1998): Targeted overexpression of the sarcoplasmic reticulum $\mathrm{Ca}^{2+}$-ATPase increases cardiac contractility in transgenic mouse hearts. Circ Res $\underline{83}, 1205-1214$

Belevych A, Kubalova Z, Terentyev D, Hamlin RL, Carnes CA, Györke S (2007): Enhanced ryanodine receptor-mediated calcium leak determines reduced sarcoplasmic reticulum calcium content in chronic canine heart failure. Biophys $\mathrm{J} \underline{93}, 4083-4092$ 
Bendersky R, Chatterjee K, Parmley WW, Brundage BH, Ports TA (1981): Dobutamine in chronic ischemic heart failure: alterations in left ventricular function and coronary hemodynamics. Am J Cardiol $\underline{48}, 554-558$

Bers DM: Excitation-Contraction Coupling and Cardiac Contractile Force. 2. Auflage; Kluwer Academic Publishers, Amsterdam 2001

Bers DM (2002): Cardiac excitation-contraction coupling. Nature $\underline{415}, 198-205$

Bers DM, Pogwizd SM, Schlotthauer K (2002): Upregulated $\mathrm{Na} / \mathrm{Ca}$ exchange is involved in both contractile dysfunction and arrhythmogenesis in heart failure. Basic Res Cardiol $\underline{97}, 36-$ 42

Beuckelmann DJ, Erdmann E (1992): $\mathrm{Ca}^{2+}$-currents and intracellular $\left[\mathrm{Ca}^{2+}\right]$ i-transients in single ventricular myocytes isolated from terminally failing human myocardium. Basic Res Cardiol $\underline{87}, 235-243$

Beuckelmann DJ, Näbauer M, Erdmann E (1993): Alterations of $\mathrm{K}^{+}$currents in isolated human ventricular myocytes from patients with terminal heart failure. Circ Res $\underline{73}$, 379-385

Beuckelmann DJ, Näbauer M, Krüger C, Erdmann E (1995): Altered diastolic $\left[\mathrm{Ca}^{2+}\right]$ i handling in human ventricular myocytes from patients with terminal heart failure. Am Heart J $\underline{129}$, 684689

Birkeland JA, Sejersted OM, Taraldsen T, Sjaastad I (2005): EC-coupling in normal and failing hearts. Scand Cardiovasc J $\underline{39}, 13-23$

Bode EF, Briston SJ, Overend CL, O'Neill SC, Trafford AW, Eisner DA (2011): Changes of SERCA activity have only modest effects on sarcoplasmic reticulum $\mathrm{Ca}^{2+}$ content in rat ventricular myocytes. J Physiol $\underline{589}, 4723-4729$

Bowditch H (1871): Über die Eigentümlichkeiten der Reizbarkeit, welche die Muskelfasern des Herzens zeigen. Arb Physiol Inst Lpz $\underline{6}, 139-176$

Bristow MR, Ginsburg R, Minobe W, Cubicciotti RS, Sageman WS, Lurie K, Billingham ME, Harrison DC, Stinson EB (1982): Decreased catecholamine sensitivity and beta-adrenergicreceptor density in failing human hearts. N Engl J Med 307, 205-211 
Brittsan AG, Ginsburg KS, Chu G, Yatani A, Wolska BM, Schmidt AG, Asahi M, MacLennan DH, Bers DM, Kranias EG (2003): Chronic SR Ca ${ }^{2+}$-ATPase inhibition causes adaptive changes in cellular $\mathrm{Ca}^{2+}$ transport. Circ Res $\underline{92}, 769-776$

Brixius K, Reicke S, Reuter H, Schwinger RH (2002): Effects of the $\mathrm{Ca}^{2+}$ sensitizers EMD 57033 and CGP 48506 on myocardial contractility and $\mathrm{Ca}^{2+}$ transients in human ventricular and atrial myocardium. Z Kardiol 91, 312-318

Brodde OE (1991): Beta 1- and beta 2-adrenoceptors in the human heart: properties, function, and alterations in chronic heart failure Pharmacol Rev. $\underline{43}, 203-242$

Brodde OE, Broede A, Daul A, Kunde K, Michel MC (1992): Receptor systems in the nonfailing human heart. Basic Res Cardiol $\underline{87}, 1-14$

Bui AL, Horwich TB, Fonarow GC (2011): Epidemiology and risk profile of heart failure. Nat. Rev. Cardiol $\underline{8}, 30-41$

Burger AJ, Horton DP, LeJemtel T, Ghali JK, Torre G, Dennish G, Koren M, Dinerman J, Silver M, Cheng ML (2002): Effect of nesiritide (B-type natriuretic peptide) and dobutamine on ventricular arrhythmias in the treatment of patients with acutely decompensated congestive heart failure: the PRECEDENT study. Am Heart J $\underline{144}, 1102-1108$

Byrne MJ, Power JM, Preovolos A, Mariani JA, Hajjar RJ, Kaye DM (2008): Recirculating cardiac delivery of AAV2/1SERCA2a improves myocardial function in an experimental model of heart failure in large animals. Gene Ther $\underline{5}, 1550-1557$

Campbell KP, MacLennan DH, Jorgensen AO, Mintzer MC (1983): Purification and characterization of calsequestrin from canine cardiac sarcoplasmic reticulum and identification of the 53,000 dalton glycoprotein. J Biol Chem 258, 1197-204.

Chang HY, Klein RM, Kunos G (1982): Selective desensitization of cardiac beta adrenoceptors by prolonged in vivo infusion of catecholamines in rats. J Pharmacol Exp Ther $\underline{221}, 784-789$

Chatterjee K (2005): Neurohormonal activation in congestive heart failure and the role of vasopressin. Am J Cardiol 95, 8-13 
Chen Y, Escoubet B, Prunier F, Amour J, Simonides WS, Vivien B, Lenoir C, Heimburger M, Choqueux C, Gellen B (2004): Constitutive cardiac overexpression of sarcoplasmic/endoplasmic reticulum $\mathrm{Ca}^{2+}$-ATPase delays myocardial failure after myocardial infarction in rats at a cost of increased acute arrhythmias. Circulation $\underline{109}, 1898-1903$

Cohen CJ, Fozzard HA, Sheu SS (1982): Increase in intracellular sodium ion activity during stimulation in mammalian cardiac muscle. Circ Res $\underline{50}, 651-662$

Colucci WS, Leatherman GF, Ludmer PL, Gauthier DF (1987): Beta-adrenergic inotropic responsiveness of patients with heart failure: studies with intracoronary dobutamine infusion. Circ Res $\underline{61}, 82-86$

Colyer J (1998): Phosphorylation states of phospholamban. Ann N Y Acad Sci $\underline{853}$, 79-91

Communal C, Singh K, Sawyer DB, Colucci WS (1999): Opposing effects of beta(1)- and beta(2)-adrenergic receptors on cardiac myocyte apoptosis : role of a pertussis toxinsensitive $\mathrm{G}$ protein. Circulation $\underline{100}, 2210-2212$

Cuffe MS, Califf RM, Adams KF Jr, Benza R, Bourge R, Colucci WS, Massie BM, O'Connor CM, Pina I, Quigg R (2002): Short-term intravenous milrinone for acute exacerbation of chronic heart failure: a randomized controlled trial. JAMA 287, 1541-1547

Curran J, Hinton MJ, Ríos E, Bers DM, Shannon TR (2007): Beta-adrenergic enhancement of sarcoplasmic reticulum calcium leak in cardiac myocytes is mediated by calcium/calmodulin-dependent protein kinase. Circ Res 100, 391-398

Cutler MJ, Wan X, Plummer BN, Liu H, Deschenes I, Laurita KR, Hajjar RJ, Rosenbaum DS (2012): Targeted sarcoplasmic reticulum $\mathrm{Ca}^{2+}$ ATPase 2a gene delivery to restore electrical stability in the failing heart. Circulation $\underline{126}, 2095-2104$

Dash R, Frank KF, Carr AN, Moravec CS, Kranias EG (2001): Gender influences on sarcoplasmic reticulum $\mathrm{Ca}^{2+}$-handling in failing human myocardium. J Mol Cell Cardiol $\underline{33}$, $1345-1353$

Davia K, Davies CH, Harding SE (1997): Effects of inhibition of sarcoplasmic reticulum calcium uptake on contraction in myocytes isolated from failing human ventricle. Cardiovasc Res $\underline{33}, 88-97$ 
De Munari S, Cerri A, Gobbini M, Almirante N, Banfi L, Carzana G, Ferrari P, Marazzi G, Micheletti R, Schiavone A (2003): Structure-based design and synthesis of novel potent $\mathrm{Na}^{+}, \mathrm{K}^{+}$-ATPase inhibitors derived from a 5alpha,14alpha-androstane scaffold as positive inotropic compounds. J Med Chem 느, 3644-3654

del Monte F, Harding SE, Schmidt U, Matsui T, Kang ZB, Dec GW, Gwathmey JK, Rosenzweig A, Hajjar RJ (1999): Restoration of contractile function in isolated cardiomyocytes from failing human hearts by gene transfer of SERCA2a. Circulation $\underline{100}$, 2308-2311

del Monte F, Williams E, Lebeche D, Schmidt U, Rosenzweig A, Gwathmey JK, Lewandowski ED, Hajjar RJ (2001): Improvement in survival and cardiac metabolism after gene transfer of sarcoplasmic reticulum $\mathrm{Ca}^{2+}$-ATPase in a rat model of heart failure. Circulation $\underline{104}$, 1424-1429

del Monte F, Lebeche D, Guerrero JL, Tsuji T, Doye AA, Gwathmey JK, Hajjar RJ (2004): Abrogation of ventricular arrhythmias in a model of ischemia and reperfusion by targeting myocardial calcium cycling. Proc Natl Acad Sci U S A 101, 5622-5627

Di Paolo NC, Miao EA, Iwakura Y, Murali-Krishna K, Aderem A, Flavell RA, Papayannopoulou T, Shayakhmetov DM (2009): Virus binding to a plasma membrane receptor triggers interleukin-1 alpha-mediated proinflammatory macrophage response in vivo. Immunity $\underline{31}, 110-121$

Drop LJ (1985): lonized calcium, the heart, and hemodynamic function. Anesth Analg $\underline{64}$, $432-51$

Ebashi S, Masaki T, Tsukui R (1974): Cardiac contractile proteins. Adv Cardiol 12, 59-69

Endoh M (1991): Physiological and pathophysiological modulation of calcium signaling in myocardial cells. Jpn Circ J $\underline{55}, 1108-1117$

Endoh M (2008): Cardiac $\mathrm{Ca}^{2+}$ signaling and $\mathrm{Ca}^{2+}$ sensitizers. Circ J $\underline{72}, 1915-1925$

Ezzaher A, el Houda Bouanani N, Crozatier B (1992): Force-frequency relations and response to ryanodine in failing rabbit hearts. Am J Physiol 263, 1710-1715 
Fabiato A, Fabiato F (1973): Activation of skinned cardiac cells. Subcellular effects of cardioactive drugs. Eur J Cardiol 1 , 143-155

Fedorov VV, Lozinsky IT, Sosunov EA, Anyukhovsky EP, Rosen MR, Balke CW, Efimov IR (2007): Application of blebbistatin as an excitation-contraction uncoupler for electrophysiologic study of rat and rabbit hearts. Heart Rhythm $\underline{4}, 619-626$

Ferrans VJ, Maron BJ, Jones M, Thiedemann KU (1976): Ultrastructural aspects of contractile proteins in cardiac hypertrophy and failure. Recent Adv Stud Cardiac Struct Metab 12, $129-140$

Fisch C, Knoebel SB (1985): Digitalis cardiotoxicity. J Am Coll Cardiol $\underline{5}$, 91-98

Flesch M, Schwinger RH, Schiffer F, Frank K, Südkamp M, Kuhn-Regnier F, Arnold G, Böhm $M$ (1996): Evidence for functional relevance of an enhanced expression of the $\mathrm{Na}^{+}-\mathrm{Ca}^{2+}$ exchanger in failing human myocardium. Circulation $\underline{94}, 992-1002$

Frank O (1895): Zur Dynamik des Herzmuskels. Z Biol 32, 370-477

Fu ZQ, Li XY, Liu XH, Sun S, Liu T, Mi YF, Zhou SA, Ye WH, Wang QS (2008): Overexpression of sarcoplasmic reticulum calcium ATPase induced hemodynamic and proteomic changes in a dog model of heart failure. Zhonghua Xin Xue Guan Bing Za Zhi $\underline{36}$, 260-265

Fu ZQ, Li XY, Lu XC, Mi YF, Liu T, Ye WH (2012): Ameliorated stress related proteins are associated with improved cardiac function by sarcoplasmic reticulum calcium ATPase gene transfer in heart failure. J Geriatr Cardiol $\underline{9}$, 269-277

Go AS, Mozaffarian D, Roger VL, Benjamin EJ, Berry JD, Borden WB, Bravata DM, Dai S, Ford ES, Fox CS (2013): Executive Summary: Heart Disease and Stroke Statistics -2013 Update: A Report From the American Heart Association. Circulation 127, 143-152

Gordon AM, Huxley AF, Julian FJ (1966): The variation in isometric tension with sarcomere length in vertebrate muscle fibres. J Physiol $\underline{184}, 170-192$ 
Greenberg B, Butler J, Felker GM, Ponikowski P, Voors AA, Pogoda JM, Provost R, Guerrero J, Hajjar RJ, Zsebo KM (2016): Prevalence of AAV1 neutralizing antibodies and consequences for a clinical trial of gene transfer for advanced heart failure. Gene Ther $\underline{23}$, 313-319

Grossman W, Jones D, McLaurin LP (1975): Wall stress and patterns of hypertrophy in the human left ventricle. J Clin Invest $\underline{56}, 56-64$

Grynkiewicz G, Poenie M, Tsien R (1985): A new generation of $\mathrm{Ca}^{2+}$ indicators with greatly improved fluorescence properties. J Biol Chem $\underline{260}, 3440-3450$

Gwathmey JK, Copelas L, MacKinnon R, Schoen FJ, Feldman MD, Grossman W, Morgan JP (1987): Abnormal intracellular calcium handling in myocardium from patients with endstage heart failure. Circ Res $\underline{61}, 70-6$

Haikala H, Kaivola J, Nissinen E, Wall P, Levijoki J, Lindén IB (1995): Cardiac troponin C as a target protein for a novel calcium sensitizing drug, levosimendan. J Mol Cell Cardiol $\underline{27}$, 1859-1866

Hajjar RJ, Kang JX, Gwathmey JK, Rosenzweig A (1997): Physiological effects of adenoviral gene transfer of sarcoplasmic reticulum calcium ATPase in isolated rat myocytes. Circulation $\underline{95}, 423-429$

Hasenfuss G, Pieske B (2002): Calcium cycling in congestive heart failure. J Mol Cell Cardiol $\underline{34}, 951-969$

Hasenfuss G, Mulieri LA, Holubarsch C, Pieske B, Just H, Alpert NR (1992): Energetics of calcium cycling in nonfailing and failing human myocardium. Basic Res Cardiol $\underline{87}$, 81-92

Hasenfuss G, Reinecke H, Studer R, Meyer M, Pieske B, Holtz J, Holubarsch C, Posival H, Just H, Drexler H (1994): Relation between myocardial function and expression of sarcoplasmic reticulum $\mathrm{Ca}^{2+}$-ATPase in failing and nonfailing human myocardium. Circ Res $\underline{75}, 434-442$

Hasenfuss G, Schillinger W, Lehnart SE, Preuss M, Pieske B, Maier LS, Prestle J, Minami K, Just $\mathrm{H}$ (1999): Relationship between $\mathrm{Na}^{+}-\mathrm{Ca}^{2+}$-exchanger protein levels and diastolic function of failing human myocardium. Circulation 99, 641-648 
Hauptman PJ, Kelly RA (1999): Digitalis. Circulation 99, 1265-1270

Herzig JW, Chiesi M, Depersin H, Grüninger S, Hasenfuss G, Kubalek R, Leutert T, Pieske B, Pioch K, Wenk P (1996): $\mathrm{Ca}^{2+}$ sensitization in idiopathic dilated human myocardium. Differential in vitro effects of (+)-(5-methyl-6-phenyl)-1,3,5,6-tetrahydro-3,6-methano-1,5benzodiazocine-2,4-dione, a novel purely $\mathrm{Ca}^{2+}$ sensitizing agent, and (+)-5-(1-(3,4dimethoxybenzoyl)-1,2,3,4-tetrahydroquinolin-6-yl)-6-methyl-3, 6-dihydro-2H-1,3,4-thiadiazin$2-o n e$ on skinned fibres and isolated ventricular strips. Arzneimittelforschung $\underline{46}, 586-593$

Hobai IA, O'Rourke B (2001): Decreased sarcoplasmic reticulum calcium content is responsible for defective excitation-contraction coupling in canine heart failure. Circulation $\underline{103}, 1577-1584$

Holubarsch C, Hasenfuss G, Schmidt-Schweda S, Knorr A, Pieske B, Ruf T, Fasol R, Just H (1993): Angiotensin I and II exert inotropic effects in atrial but not in ventricular human myocardium. An in vitro study under physiological experimental conditions. Circulation $\underline{88}$, 1228-1237

Holubarsch C, Ruf T, Goldstein DJ, Ashton RC, Nickl W, Pieske B, Pioch K, Lüdemann J, Wiesner S, Hasenfuss G (1996): Existence of the Frank-Starling mechanism in the failing human heart. Investigations on the organ, tissue, and sarcomere levels. Circulation 94, 683689

Hoppe UC, Böhm M, Dietz R, Hanrath P, Kroemer HK, Osterspey A, Schmaltz AA, Erdmann E (2005): Leitlinien zur Therapie der chronischen Herzinsuffizienz. Z Kardiol 94, 488-509

Hove-Madsen L, Bers DM (1993): Sarcoplasmic reticulum $\mathrm{Ca}^{2+}$ uptake and thapsigargin sensitivity in permeabilized rabbit and rat ventricular myocytes. Circ Res $\underline{73}, 820-828$

Hulme JT, Orchard CH (1998): Effect of acidosis on $\mathrm{Ca}^{2+}$ uptake and release by sarcoplasmic reticulum of intact rat ventricular myocytes. Am J Physiol 275, 977-987

Huxley HE (1969): The mechanism of muscular contraction. Science $\underline{164}, 1356$

Ibrahim M, Gorelik J, Yacoub MH, Terracciano CM (2011): The structure and function of cardiac t-tubules in health and disease. Proc Biol Sci 278, 2714-2723 
Inesi G (1985): Mechanism of calcium transport. Annu Rev Physiol $\underline{47}, 573-601$

James P, Inui M, Tada M, Chiesi M, Carafoli E (1989): Nature and site of phospholamban regulation of the $\mathrm{Ca}^{2+}$ pump of sarcoplasmic reticulum. Nature $\underline{342}, 90-92$

Jessup M, Greenberg B, Mancini D, Cappola T, Pauly DF, Jaski B, Yaroshinsky A, Zsebo KM, Dittrich H, Hajjar RJ (2011): Calcium Upregulation by Percutaneous Administration of Gene Therapy in Cardiac Disease (CUPID): a phase 2 trial of intracoronary gene therapy of sarcoplasmic reticulum $\mathrm{Ca}^{2+}$-ATPase in patients with advanced heart failure. Circulation $\underline{124}$, 304-313

Johnson I, Spence MTZ: Molecular Probes Handbook - A Guide to Fluorescent Probes and Labeling Technologies. 11. Auflage; Life Technologies Corporation, Carlsbad 2010

Junqueira LC, Carneiro J: Histologie. 6. Auflage; Springer-Verlag, Berlin/ Heidelberg 2005

Kawase Y, Ly HQ, Prunier F, Lebeche D, Shi Y, Jin H, Hadri L, Yoneyama R, Hoshino K, Takewa $Y$ (2008): Reversal of cardiac dysfunction after long-term expression of SERCA2a by gene transfer in a pre-clinical model of heart failure. J Am Coll Cardiol $\underline{51}, 1112-1119$

Kim HW, Steenaart NA, Ferguson DG, Kranias EG (1990): Functional reconstitution of the cardiac sarcoplasmic reticulum $\mathrm{Ca}^{2+}$-ATPase with phospholamban in phospholipid vesicles. $\mathrm{J}$ Biol Chem 265, 1702-1709

Kohl C, Schmitz W, Scholz H, Scholz J, Tóth M, Döring V, Kalmár P (1989): Evidence for alpha 1-adrenoceptor-mediated increase of inositol trisphosphate in the human heart. $\mathrm{J}$ Cardiovasc Pharmacol $\underline{13}$, 324-327

Kohlhaas M: Die Bedeutung der subzellulären CaMKIIס-Überexpression auf den intrazellulären $\mathrm{Ca}^{2+}$-Stoffwechsel in Herzmuskelzellen. Biol. Diss. Göttingen 2006

Komamura K, Shannon RP, Ihara T, Shen YT, Mirsky I, Bishop SP, Vatner SF (1993): Exhaustion of Frank-Starling mechanism in conscious dogs with heart failure. Am J Physiol $\underline{265}, 1119-1131$

Koss KL, Grupp IL, Kranias EG (1997): The relative phospholamban and SERCA2 ratio: a critical determinant of myocardial contractility. Basic Res Cardiol 92, 17-24 
Kranias EG, Di Salvo J (1986): A phospholamban protein phosphatase activity associated with cardiac sarcoplasmic reticulum. J Biol Chem 261, 10029-10032

Lakowicz JR: Principles of Fluorescence Spectroscopy. 3. Auflage; Springer Verlag, New York 2006

Langendorff O (1895): Untersuchungen am überlebenden Säugetierherzen. Pflügers Arch 61, 291-332

Leblanc N, Hume JR (1990): Sodium current-induced release of calcium from cardiac sarcoplasmic reticulum. Science $\underline{248}, 372-376$

Levy D, Kenchaiah S, Larson MG, Benjamin EJ, Kupka MJ, Ho KK, Murabito JM, Vasan RS (2002): Long-term trends in the incidence of and survival with heart failure. $\mathrm{N}$ Engl $\mathrm{J}$ Med $\underline{347}, 1397-1402$

Li GR, Lau CP, Ducharme A, Tardif JC, Nattel S (2002): Transmural action potential and ionic current remodeling in ventricles of failing canine hearts. Am J Physiol Heart Circ Physiol $\underline{283}, 1031-1041$

Li SY, Golden KL, Jiang Y, Wang GJ, Privratsky JR, Zhang X, Eason AR, Culver B, Ren J (2005): Inhibition of sarco(endo)plasmic reticulum $\mathrm{Ca}^{2+}$-ATPase differentially regulates contractile function in cardiac myocytes from normotensive and spontaneously hypertensive rats: role of $\mathrm{Ca}^{2+}$ regulatory proteins. Cell Biochem Biophys $\underline{42}, 1-12$

Lindner M, Erdmann E, Beuckelmann DJ (1998): Calcium content of the sarcoplasmic reticulum in isolated ventricular myocytes from patients with terminal heart failure. $\mathrm{J}$ Mol Cell Cardiol $\underline{30}, 743-749$

Loewenstein WR (1981): Junctional intercellular communication: the cell-to-cell membrane channel. Physiol Rev $\underline{61}$, 829-913

Lompré AM, Anger M, Levitsky D (1994): Sarco(endo)plasmic reticulum calcium pumps in the cardiovascular system: function and gene expression. J Mol Cell Cardiol $\underline{26}, 1109-1121$ 
Lyon AR, Bannister ML, Collins T, Pearce E, Sepehripour AH, Dubb SS, Garcia E, O'Gara P, Liang L, Kohlbrenner E (2011): SERCA2a gene transfer decreases sarcoplasmic reticulum calcium leak and reduces ventricular arrhythmias in a model of chronic heart failure. Circ Arrhythm Electrophysiol $\underline{4}, 362-372$

Mackiewicz U, Lewartowski B (2008): The effect of sarcoplasmic reticulum $\mathrm{Ca}^{2+}$ leak on contractile activity of guinea pig heart myocytes depends in activity of sarcoplasmic reticulum $\mathrm{Ca}^{2+}$-ATPase and $\mathrm{Na}^{+} / \mathrm{Ca}^{2+}$ exchanger. J Physiol Pharmacol $\underline{59}, 287-300$

MacLennan DH (1990): Molecular tools to elucidate problems in excitation-contraction coupling. Biophys J $\underline{58}, 1355-1365$

Mager G, Klocke RK, Kux A, Höpp HW, Hilger HH (1991): Phosphodiesterase III inhibition or adrenoreceptor stimulation: milrinone as an alternative to dobutamine in the treatment of severe heart failure. Am Heart J 121, 1974-1983

Maier LS, Bers DM (2002): Calcium, calmodulin, and calcium-calmodulin kinase II: heartbeat to heartbeat and beyond. J Mol Cell Cardiol $\underline{34}, 919-939$

Maier LS, Bers DM, Pieske B (2000): Differences in $\mathrm{Ca}^{2+}$-handling and sarcoplasmic reticulum $\mathrm{Ca}^{2+}$-content in isolated rat and rabbit myocardium. J Mol Cell Cardiol $\underline{32}, 2249$ 2258

Maier LS, Zhang T, Chen L, DeSantiago J, Brown JH, Bers DM (2003): Transgenic CaMKIldeltaC overexpression uniquely alters cardiac myocyte $\mathrm{Ca}^{2+}$ handling: reduced $\mathrm{SR}$ $\mathrm{Ca}^{2+}$ load and activated SR Ca ${ }^{2+}$ release. Circ Res $\underline{92}$, 904-911

Maier LS, Wahl-Schott C, Horn W, Weichert S, Pagel C, Wagner S, Dybkova N, Müller OJ, Näbauer M, Franz WM (2005): Increased SR Ca ${ }^{2+}$ cycling contributes to improved contractile performance in SERCA2a-overexpressing transgenic rats. Cardiovasc Res $\underline{67}, 636-646$

Mariani JA, Smolic A, Preovolos A, Byrne MJ, Power JM, Kaye DM (2011): Augmentation of left ventricular mechanics by recirculation-mediated AAV2/1-SERCA2a gene delivery in experimental heart failure. Eur J Heart Fail $\underline{13}$, 247-253

Marx SO, Reiken S, Hisamatsu Y, Jayaraman T, Burkhoff D, Rosemblit N, Marks AR (2000): PKA phosphorylation dissociates FKBP12.6 from the calcium release channel (ryanodine receptor): defective regulation in failing hearts. Cell 101, 365-376 
Mattera GG, Lo Giudice P, Loi FM, Vanoli E, Gagnol JP, Borsini F, Carminati P (2007): Istaroxime: a new luso-inotropic agent for heart failure. Am J Cardiol 99, 33-40

McMurray J (1996): Concise Guide to the Management of Heart Failure - World health Organization/Council on Geriatric Cardiology Task Force on Heart Failure Education. Am J Geriatr Cardiol $\underline{5}, 13-30$

McMurray JJ, Stewart S (2000): Epidemiology, aetiology, and prognosis of heart failure. Heart $\underline{83}, 596-602$

Mercadier JJ, Lompré AM, Duc P, Boheler KR, Fraysse JB, Wisnewsky C, Allen PD, Komajda M, Schwartz K (1990): Altered sarcoplasmic reticulum $\mathrm{Ca}^{2+}$-ATPase gene expression in the human ventricle during end-stage heart failure. J Clin Invest $\underline{85}, 305-309$

Meyer M, Dillmann WH (1998): Sarcoplasmic reticulum $\mathrm{Ca}^{2+}$-ATPase overexpression by adenovirus mediated gene transfer and in transgenic mice. Cardiovasc Res $\underline{37}$, 360-366

Meyer M, Schillinger W, Pieske B, Holubarsch C, Heilmann C, Posival H, Kuwajima G, Mikoshiba K, Just H, Hasenfuss G (1995): Alterations of sarcoplasmic reticulum proteins in failing human dilated cardiomyopathy. Circulation $\underline{92}, 778-784$

Mi YF, Li XY, Tang LJ, Lu XC, Fu ZQ, Ye WH (2009): Improvement in cardiac function after sarcoplasmic reticulum $\mathrm{Ca}^{2+}$-ATPase gene transfer in a beagle heart failure model. Chin Med $\mathrm{J}($ Engl) $\underline{122}, 1423-1428$

Micheletti R, Mattera GG, Rocchetti M, Schiavone A, Loi MF, Zaza A, Gagnol RJ, De Munari $S$, Melloni P, Carminati $P$ (2002): Pharmacological profile of the novel inotropic agent $(E, Z)-$ 3-((2-aminoethoxy)imino)androstane-6,17-dione hydrochloride (PST2744). J Pharmacol Exp Ther $\underline{303}, 592-600$

Minta A, Kao JP, Tsien RY (1989): Fluorescent indicators for cytosolic calcium based on rhodamine and fluorescein chromophores. J Biol Chem $\underline{264}$, 8171-8178

Miyamoto MI, del Monte F, Schmidt U, DiSalvo TS, Kang ZB, Matsui T, Guerrero JL, Gwathmey JK, Rosenzweig A, Hajjar RJ (2000): Adenoviral gene transfer of SERCA2a improves left-ventricular function in aortic-banded rats in transition to heart failure. Proc Natl Acad Sci U S A $\underline{97}, 793-798$ 
Moiseyev VS, Põder P, Andrejevs N, Ruda MY, Golikov AP, Lazebnik LB, Kobalava ZD, Lehtonen LA, Laine T, Nieminen MS (2002): Safety and efficacy of a novel calcium sensitizer, levosimendan, in patients with left ventricular failure due to an acute myocardial infarction. A randomized, placebo-controlled, double-blind study (RUSSLAN). Eur Heart J $\underline{23}$, $1422-1432$

Möllmann H, Schmidt-Schweda S, Nef H, Möllmann S, Burstin JV, Klose S, Elsässer A, Holubarsch CJ (2007): Contractile effects of angiotensin and endothelin in failing and nonfailing human hearts. Int J Cardiol $\underline{114}, 34-40$

Morgan JP, Erny RE, Allen PD, Grossman W, Gwathmey JK (1990): Abnormal intracellular calcium handling, a major cause of systolic and diastolic dysfunction in ventricular myocardium from patients with heart failure. Circulation $\underline{81}, 21-32$

Mulieri LA, Hasenfuss G, Ittleman F, Blanchard EM, Alpert NR (1989): Protection of human left ventricular myocardium from cutting injury with 2,3-butanedione monoxime. Circ Res $\underline{65}$, 1441-1449

Mulieri LA, Hasenfuss G, Leavitt B, Allen PD, Alpert NR (1992): Altered myocardial forcefrequency relation in human heart failure. Circulation $\underline{85}, 1743-1750$

Müller OJ, Lange M, Rattunde H, Lorenzen HP, Müller M, Frey N, Bittner C, Simonides W, Katus HA, Franz WM (2003): Transgenic rat hearts overexpressing SERCA2a show improved contractility under baseline conditions and pressure overload. Cardiovasc Res $\underline{59}$, 380-389

Nawrath $\mathrm{H}$ (1989): Adrenoceptor-mediated changes of excitation and contraction in isolated heart muscle preparations. J Cardiovasc Pharmacol 14, 1-10

Nieminen MS, Altenberger J, Ben-Gal T, Böhmer A, Comin-Colet J, Dickstein K, Edes I, Fedele F, Fonseca C, García-González MJ (2014): Repetitive use of levosimendan for treatment of chronic advanced heart failure: clinical evidence, practical considerations, and perspectives: an expert panel consensus. Int J Cardiol 174, 360-367 
Nikolaidis LA, Trumble D, Hentosz T, Doverspike A, Huerbin R, Mathier MA, Shen YT, Shannon RP (2004): Catecholamines restore myocardial contractility in dilated cardiomyopathy at the expense of increased coronary blood flow and myocardial oxygen consumption (MvO2 cost of catecholamines in heart failure). Eur J Heart Fail $\underline{6}$, 409-419

Olivetti G, Melissari M, Balbi T, Quaini F, Cigola E, Sonnenblick EH, Anversa P (1994): Myocyte cellular hypertrophy is responsible for ventricular remodelling in the hypertrophied heart of middle aged individuals in the absence of cardiac failure. Cardiovasc Res $\underline{28}, 1199$ 1208

Packer M (1992): The neurohormonal hypothesis: a theory to explain the mechanism of disease progression in heart failure. J Am Coll Cardiol 20, 248-254

Periasamy M, Kalyanasundaram A (2007): SERCA pump isoforms: their role in calcium transport and disease. Muscle Nerve $\underline{35}, 430-442$

Pieske B, Kretschmann B, Meyer M, Holubarsch C, Weirich J, Posival H, Minami K, Just H, Hasenfuss G (1995): Alterations in intracellular calcium handling associated with the inverse force-frequency relation in human dilated cardiomyopathy. Circulation $\underline{92}, 1169-1178$

Pieske B, Beyermann B, Breu V, Löffler BM, Schlotthauer K, Maier LS, Schmidt-Schweda S, Just $H$, Hasenfuss G (1999 a): Functional effects of endothelin and regulation of endothelin receptors in isolated human nonfailing and failing myocardium. Circulation $\underline{99}, 1802-1809$

Pieske B, Maier LS, Bers DM, Hasenfuss G (1999 b): $\mathrm{Ca}^{2+}$ handling and sarcoplasmic reticulum $\mathrm{Ca}^{2+}$ content in isolated failing and nonfailing human myocardium. Circ Res $\underline{85}$, 3846

Pieske B, Maier LS, Piacentino V 3rd, Weisser J, Hasenfuss G, Houser S (2002): Rate dependence of $\left[\mathrm{Na}^{+}\right] \mathrm{i}$ and contractility in nonfailing and failing human myocardium. Circulation $\underline{106}$, 447-453

Piot C, Lemaire S, Albat B, Seguin J, Nargeot J, Richard S (1996): High frequency-induced upregulation of human cardiac calcium currents. Circulation $\underline{93}, 120-128$ 
Pogwizd SM, Schlotthauer K, Li L, Yuan W, Bers DM (2001): Arrhythmogenesis and contractile dysfunction in heart failure: Roles of sodium-calcium exchange, inward rectifier potassium current, and residual beta-adrenergic responsiveness. Circ Res $\underline{88}, 1159-1167$

Potter JD, Gergely J (1974): Troponin, tropomyosin, and actin interactions in the $\mathrm{Ca}^{2+}$ regulation of muscle contraction. Biochemistry $\underline{13}, 2697-2703$

Prunier F, Kawase Y, Gianni D, Scapin C, Danik SB, Ellinor PT, Hajjar RJ, Del Monte F (2008): Prevention of ventricular arrhythmias with sarcoplasmic reticulum $\mathrm{Ca}^{2+}$ ATPase pump overexpression in a porcine model of ischemia reperfusion. Circulation $\underline{118}, 614-624$

Rayment I, Holden HM, Whittaker M, Yohn CB, Lorenz M, Holmes KC, Milligan RA (1993): Structure of actin-myosin complex and its implications for muscle contraction. Science $\underline{261}$, 58-65

Reilly AM, Petrou S, Panchal RG, Williams DA (2001): Restoration of calcium handling properties of adult cardiac myocytes from hypertrophied hearts. Cell Calcium $\underline{30}, 59-66$

Rocchetti M, Besana A, Mostacciuolo G, Micheletti R, Ferrari P, Sarkozi S, Szegedi C, Jona I, Zaza A (2005): Modulation of sarcoplasmic reticulum function by $\mathrm{Na}^{+} / \mathrm{K}^{+}$pump inhibitors with different toxicity: digoxin and PST2744 [(E,Z)-3-((2-aminoethoxy)imino)androstane-6,17dione hydrochloride]. J Pharmacol Exp Ther $\underline{313}$, 207-215

Rokita AG: Der Einfluss der konditionalen Überexpression der neuronalen StickstoffmonoxidSynthase (nNOS) im Herzen auf die Kontraktilität und den Kalzium-Stoffwechsel von ventrikulären Herzmuskelzellen. Med. Diss. Göttingen 2008

Sabbah HN, Imai M, Cowart D, Amato A, Carminati P, Gheorghiade M (2007): Hemodynamic properties of a new-generation positive luso-inotropic agent for the acute treatment of advanced heart failure. Am J Cardiol $\underline{99}$, 41-46

Sakata S, Lebeche D, Sakata N, Sakata Y, Chemaly ER, Liang LF, Tsuji T, Takewa Y, del Monte F, Peluso R (2007): Restoration of mechanical and energetic function in failing aorticbanded rat hearts by gene transfer of calcium cycling proteins. J Mol Cell Cardiol $\underline{42}, 852-$ 861 
Sande JB, Sjaastad I, Hoen IB, Bøkenes J, Tønnessen T, Holt E, Lunde PK, Christensen G (2002): Reduced level of serine(16) phosphorylated phospholamban in the failing rat myocardium: a major contributor to reduced SERCA2 activity. Cardiovasc Res $\underline{53}, 382-391$

Satoh H, Blatter LA, Bers DM (1997): Effects of $\left[\mathrm{Ca}^{2+}\right]$ i, SR Ca ${ }^{2+}$ load, and rest on $\mathrm{Ca}^{2+}$ spark frequency in ventricular myocytes. Am J Physiol 272, 657-668

Schatzmann HJ (1989): The calcium pump of the surface membrane and of the sarcoplasmic reticulum. Annu Rev Physiol $\underline{51}$, 473-485

Schlotthauer K, Bers DM (2000): Sarcoplasmic reticulum $\mathrm{Ca}^{2+}$ release causes myocyte depolarization. Underlying mechanism and threshold for triggered action potentials. Circ Res $\underline{87}, 774-780$

Schmidt U, Hajjar RJ, Kim CS, Lebeche D, Doye AA, Gwathmey JK (1999): Human heart failure: cAMP stimulation of $\mathrm{SR} \mathrm{Ca}^{2+}$-ATPase activity and phosphorylation level of phospholamban. Am J Physiol 277, 474-480

Schwinger RH, Böhm M, Koch A, Schmidt U, Morano I, Eissner HJ, Uberfuhr P, Reichart B, Erdmann $E$ (1994): The failing human heart is unable to use the Frank-Starling mechanism. Circ Res $\underline{74}$, 959-969

Schwinger RH, Münch G, Bölck B, Karczewski P, Krause EG, Erdmann E (1999): Reduced $\mathrm{Ca}^{2+}$-sensitivity of SERCA2a in failing human myocardium due to reduced serin-16 phospholamban phosphorylation. J Mol Cell Cardiol 31, 479-491

Shannon TR, Pogwizd SM, Bers DM (2003): Elevated sarcoplasmic reticulum $\mathrm{Ca}^{2+}$ leak in intact ventricular myocytes from rabbits in heart failure. Circ Res $\underline{93}, 592-594$

Shiels HA, White E (2008): The Frank-Starling mechanism in vertebrate cardiac myocytes. J Exp Biol 211, 2005-2013

Shull GE (2000): Gene knockout studies of $\mathrm{Ca}^{2+}$-transporting ATPases. Eur J Biochem 267, $5284-5290$ 
Slawsky MT, Colucci WS, Gottlieb SS, Greenberg BH, Haeusslein E, Hare J, Hutchins S, Leier CV, LeJemtel TH, Loh E (2000): Acute hemodynamic and clinical effects of levosimendan in patients with severe heart failure. Study Investigators. Circulation $\underline{102}$, 2222-2227

Soltysinska E, Thiele S, Olesen SP, Osadchii OE (2011): Chronic sympathetic activation promotes downregulation of $\beta$-adrenoceptor-mediated effects in the guinea pig heart independently of structural remodeling and systolic dysfunction. Pflugers Arch $\underline{462}, 529-543$

Sossalla S, Fluschnik N, Schotola H, Ort KR, Neef S, Schulte T, Wittköpper K, Renner A, Schmitto JD, Gummert J (2010): Inhibition of elevated $\mathrm{Ca}^{2+} /$ calmodulin-dependent protein kinase II improves contractility in human failing myocardium. Circ Res $\underline{107}, 1150-1161$

Starling EH: The linacre Lecture on the Law of the Heart. Longmans, Green and Co., London 1918

Stüdeli R, Jung S, Mohacsi P, Perruchoud S, Castiglioni P, Wenaweser P, Heimbeck G, Feller M, Hullin R (2006): Diastolic dysfunction in human cardiac allografts is related with reduced SERCA2a gene expression. Am J Transplant $\underline{6}, 775-782$

Studer R, Reinecke H, Bilger J, Eschenhagen T, Böhm M, Hasenfuss G, Just H, Holtz J, Drexler $\mathrm{H}$ (1994): Gene expression of the cardiac $\mathrm{Na}^{+}-\mathrm{Ca}^{2+}$ exchanger in end-stage human heart failure. Circ Res $\underline{75}$, 443-453

Tada M, Katz AM (1982): Phosphorylation of the sarcoplasmic reticulum and sarcolemma. Annu Rev Physiol 44, 401-423

Tada M, Yamamoto T, Tonomura Y (1978): Molecular mechanism of active calcium transport by sarcoplasmic reticulum. Physiol Rev $\underline{58}, 1-79$

Takahashi M, Sasayama S, Kawai C, Kotoura H (1980): Contractile performance of the hypertrophied ventricle in patients with systemic hypertension. Circulation $\underline{62}, 116-126$

Teerlink JR (2009): A novel approach to improve cardiac performance: cardiac myosin activators. Heart Fail Rev $\underline{14}$, 289-298 
Terracciano CM, Hajjar RJ, Harding SE (2002): Overexpression of SERCA2a accelerates repolarisation in rabbit ventricular myocytes. Cell Calcium 31, 299-305

Thelestam M, Möllby R (1979): Classification of microbial, plant and animal cytolysins based on their membrane-damaging effects of human fibroblasts. Biochim Biophys Acta $\underline{57}, 156-$ 169

Toyofuku T, Kurzydlowski K, Tada M, MacLennan DH (1993): Identification of regions in the $\mathrm{Ca}^{2+}$-ATPase of sarcoplasmatic reticulum that affect functional association with phospholamban. J Biol Chem $\underline{268}, 2809-2815$

Vahl CF, Timek T, Bonz A, Kochsiek N, Fuchs H, Schäffer L, Rosenberg M, Dillmann R, Hagl $S$ (1997): Myocardial length-force relationship in end stage dilated cardiomyopathy and normal human myocardium: analysis of intact and skinned left ventricular trabeculae obtained during 11 heart transplantations. Basic Res Cardiol 92, 261-270

Vaughan-Jones RD, Spitzer KW, Swietach P (2009): Intracellular pH regulation in heart. J Mol Cell Cardiol $\underline{46}, 318-331$

Wankerl M, Schwartz K (1995): Calcium transport proteins in the nonfailing and failing heart: gene expression and function. J Mol Med (Berl) $\underline{73}, 487-496$

Wegener AD, Simmerman HK, Lindemann JP, Jones LR (1989): Phospholamban phosphorylation in intact ventricles. Phosphorylation of serine 16 and threonine 17 in response to beta-adrenergic stimulation. J Biol Chem 264, 11468-11474

Weinbrenner S, Langer T, Scherer M, Störk S, Ertl G, Muth Ch, Hoppe UC, Kopp I, Ollenschläger G (2012): The German National Disease Management Guideline "Chronic Heart Failure. Dtsch Med Wochenschr 137, 219-227

Xin W, Lu XC, Li XY, Niu K, Cai JM (2011): Effects of sarcoplasmic reticulum Ca ${ }^{2+}$-ATPase gene transfer in a minipig model of chronic ischemic heart failure. Zhonghua Xin Xue Guan Bing Za Zhi 39, 336-342

Yang Y, Nunes FA, Berencsi K, Furth EE, Gönczöl E, Wilson JM (1994): Cellular immunity to viral antigens limits E1-deleted adenoviruses for gene therapy. Proc Natl Acad Sci U S A $\underline{91}$, 4407-4411 
Yao A, Su Z, Dillmann WH, Barry WH (1998): Sarcoplasmic reticulum function in murine ventricular myocytes overexpressing SR $\mathrm{Ca}^{2+}$-ATPase. J Mol Cell Cardiol $\underline{30}$, 2711-2718

Zhao W, Yuan Q, Qian J, Waggoner JR, Pathak A, Chu G, Mitton B, Sun X, Jin J, Braz JC (2006): The presence of Lys27 instead of Asn27 in human phospholamban promotes sarcoplasmic reticulum $\mathrm{Ca}^{2+}$-ATPase superinhibition and cardiac remodeling. Circulation $\underline{113}, 995-1004$

Zsebo K, Yaroshinsky A, Rudy JJ, Wagner K, Greenberg B, Jessup M, Hajjar RJ. (2014): Long-Term Effects of AAV1/SERCA2a Gene Transfer in Patients With Severe Heart Failure: Analysis of Recurrent Cardiovascular Events and Mortality. Circ Res 114, 101-108 


\section{Danksagung}

In erster Linie möchte ich mich bei meinem Doktorvater Prof. Dr. Lars Maier für das Überlassen dieses spannenden Dissertationsthemas und das Nahebringen des wissenschaftlichen Arbeitens in einer mehr als freundlichen Arbeitsatmosphäre bedanken.

Besonderer Dank gilt meinem Betreuer Dr. Adam Rokita, der mich nicht nur in die Methodik der Epifluoreszenzmikroskopie einarbeitete und mir Hilfe bei der Interpretation der Ergebnisse gab, sondern mir zu jedem Zeitpunkt mit Rat und Tat zur Seite stand. Ohne seine hervorragende Betreuung und zugleich motivierende Unterstützung wäre die vorliegende Dissertation nicht durchführbar gewesen. Ich danke außerdem Dr. Karl Toischer für die Einarbeitung in die Muskelstreifenexperimente und für die Unterstützung bei der Interpretation der Ergebnisse.

Des Weiteren möchte ich allen Mitgliedern der Arbeitsgruppe unter Prof. Dr. Lars Maier für ihre ständige Ansprechbarkeit bei Fragen und Problemen, das stets freundliche Arbeitsklima und die technische Unterstützung danken.

Ganz herzlich möchte ich mich bei Gudrun Müller bedanken, die mir die isolierten Kardiomyozyten zur Verfügung stellte. 